Supporting Information

\title{
Cobalt-Catalyzed One-Step Access to Pyroquilon and C-7 Alkenylation of Indoline with Activated Alkenes Using Weakly Coordinating Functional Group
}

\author{
Shyam Kumar Banjare, Pragati Biswal and Ponneri Chandrababu Ravikumar* \\ School of Chemical Sciences, National Institute of Science Education and Research (NISER) Bhubaneswar, HBNI, Jatani, \\ Odisha 752050, India \\ E-mail:pcr@niser.ac.in
}

\begin{tabular}{|l|l|c|}
\hline No. & \multicolumn{1}{|c|}{ Content } & Page no. \\
\hline 1. & Optimization studies of C(7)-H Alkenylation & S2 \\
\hline 2. & Mechanistic Investigation & S3 \\
\hline 3. & Copies of product $\left({ }^{1} \mathrm{H}\right.$ NMR and ${ }^{13} \mathrm{C}$ NMR $)$ & S5 \\
\hline 4. & X-ray crystallography data & S37 \\
\hline
\end{tabular}




\section{Optimization studies}

Table S1. Optimization of C(7)-H Alkenylation of indoline with methyl acrylates ${ }^{\mathrm{a}}$

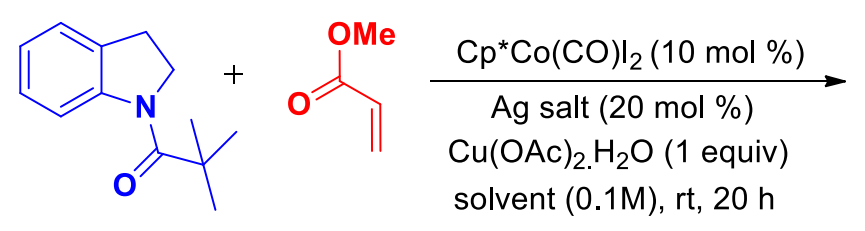

\begin{tabular}{|c|c|c|c|}
\hline entry & solvent & Ag salt & yield $(\%)^{b}$ \\
\hline 1 & toluene & $\mathrm{AgSbF}_{6}$ & 0 \\
\hline 2 & THF & $\mathrm{AgSbF}_{6}$ & 42 \\
\hline 3 & 1,4-dioxane & $\mathrm{AgSbF}_{6}$ & 15 \\
\hline 4 & $\mathrm{MeOH}$ & $\mathrm{AgSbF}_{6}$ & 0 \\
\hline 5 & ${ }^{\mathrm{t} A m y l}$ alcohol & $\mathrm{AgSbF}_{6}$ & 0 \\
\hline 6 & $\mathrm{DCM}$ & $\mathrm{AgSbF}_{6}$ & 21 \\
\hline 7 & DCE & $\mathrm{AgSbF}_{6}$ & 54 \\
\hline 8 & 1,2-DCB & $\mathrm{AgSbF}_{6}$ & 22 \\
\hline 9 & TFE & $\mathrm{AgSbF}_{6}$ & 34 \\
\hline 10 & TFT & $\mathrm{AgSbF}_{6}$ & 0 \\
\hline 11 & HFIP & $\mathrm{AgSbF}_{6}, 50^{\circ} \mathrm{C}$ & 72 \\
\hline 12 & DCE+HFIP (1:1) & $\mathrm{AgSbF}_{6}$ & 27 \\
\hline 13 & HFIP & $\mathrm{AgSbF}_{6}$ & 84 \\
\hline 14 & HFIP & $\mathrm{AgNTf}_{2}$ & 76 \\
\hline 15 & HFIP & $\mathrm{AgSbF}_{6}$, without $\mathrm{Cu}(\mathrm{OAc})_{2} \mathrm{H}_{2} \mathrm{O}$ & 11 \\
\hline 16 & HFIP & without $\mathrm{AgSbF}_{6}$ & 57 \\
\hline
\end{tabular}

${ }^{a}$ Reaction conditions: 1a $(0.1 \mathrm{mmol}), \mathbf{2 a}$ (4 equiv), $\mathrm{CoCp}^{*}(\mathrm{CO}) \mathrm{I}_{2}(10 \mathrm{~mol} \%)$, Ag salt (20 mol \%), $\mathrm{Cu}(\mathrm{OAc})_{2} \cdot \mathrm{H}_{2} \mathrm{O}$ (1 equiv), solvent $(0.1 \mathrm{M}), \mathrm{rt}, 20 \mathrm{~h}$. ${ }^{\mathrm{b}}$ Isolated yields. 


\section{Mechanistic Investigation:}

\section{$H / D$ exchange studies}

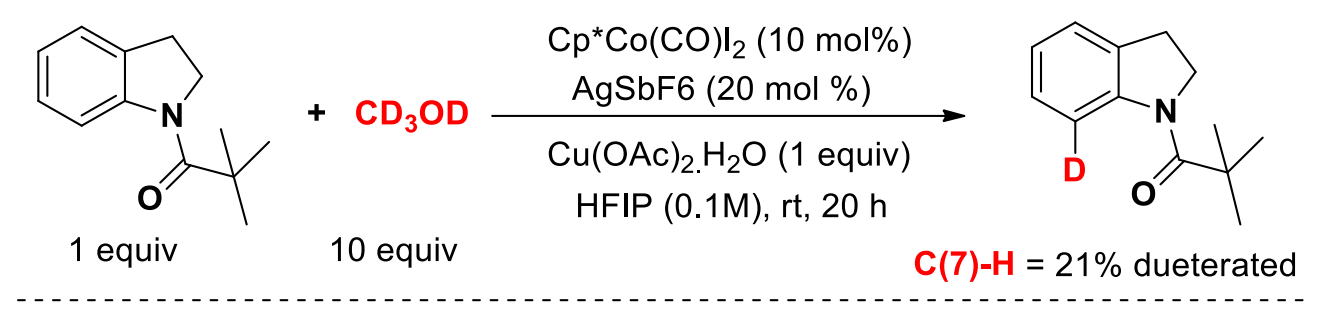

The reaction of $\mathrm{N}$-pivaloyl indoline with $\mathrm{CD}_{3} \mathrm{OD}$ to give 7-deuterated $\mathrm{N}$-pivaloyl indoline: To a predried sealed tube under $\mathrm{N}_{2}$, the mixture of $\mathrm{N}$-pivaloyl indoline 1 (0.1 mmol), $\mathrm{CD}_{3} \mathrm{OD}$ (10 equiv), $\left[\mathrm{Cp}^{*} \mathrm{Co}(\mathrm{CO}) \mathrm{I}_{2}\right](10 \mathrm{~mol} \%), \mathrm{AgSbF}_{6}(20 \mathrm{~mol} \%), \mathrm{Cu}(\mathrm{OAc})_{2} \cdot \mathrm{H}_{2} \mathrm{O}$ (1 equiv) and $\mathrm{HFIP}(1 \mathrm{~mL})$ were added and sealed. The reaction mixture was stirred vigorously at room temperature for $20 \mathrm{~h}$. After $20 \mathrm{~h}$ (completion of reaction as monitored by TLC analysis), the reaction mixture was cooled to room temperature and diluted with dichloromethane and passed through a short celite pad. The solvent was evaporated under reduced pressure and the crude mixture was purified by column chromatography using EtOAc/hexane mixture on silica gel to give the pure product. The percentage of deuteration was calculated from 1H-NMR analysis.

7-deuterated $N$-pivaloyl indoline: The crude reaction mixture was purified by column chromatography using silica gel (100-200 mesh) giving a white solid (19.6 mg, 98\% yield) $\mathbf{R}_{f}: 0.40$ (10\% EtOAc/hexane)

${ }^{1} \mathrm{H}$ NMR (CDCl3, $\left.400 \mathrm{MHz}\right): \delta 8.19(\mathrm{~d}, J=8.0 \mathrm{~Hz}, 1 \mathrm{H}), 7.18-7.14(\mathrm{~m}, 2 \mathrm{H}), 6.98(\mathrm{t}, J=7.6 \mathrm{~Hz}, 1 \mathrm{H})$, $4.22(\mathrm{t}, J=8.0 \mathrm{~Hz}, 2 \mathrm{H}), 3.13(\mathrm{t}, J=8.0 \mathrm{~Hz}, 2 \mathrm{H}), 1.37(\mathrm{~s}, 9 \mathrm{H})$. 


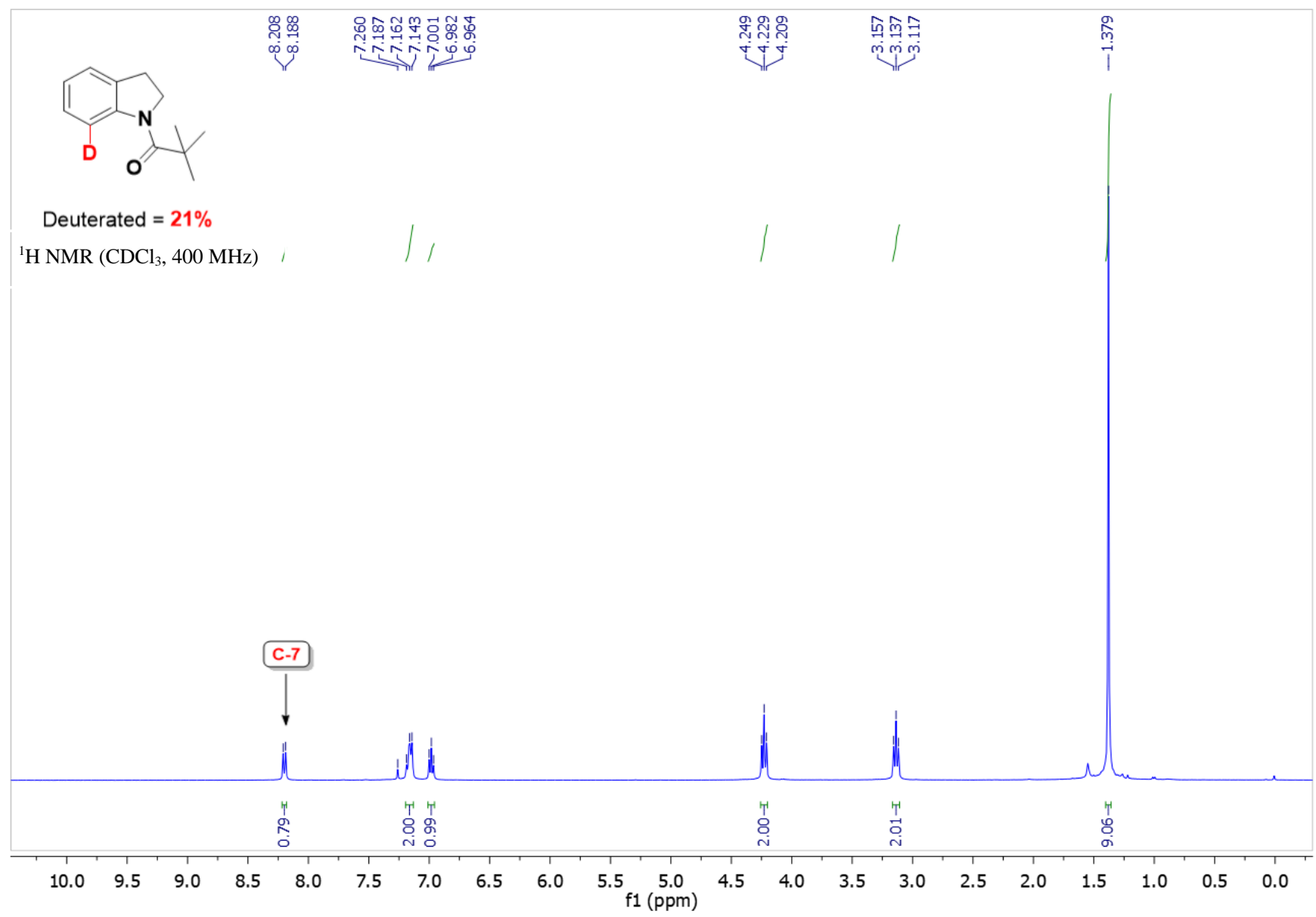


3. Copies of product ${ }^{1} \mathbf{H}$ NMR and ${ }^{13}$ C NMR: 5,6-Dihydro-1H-pyrrolo[3,2,1-ij]quinolin-4(2H)-one (3aa):

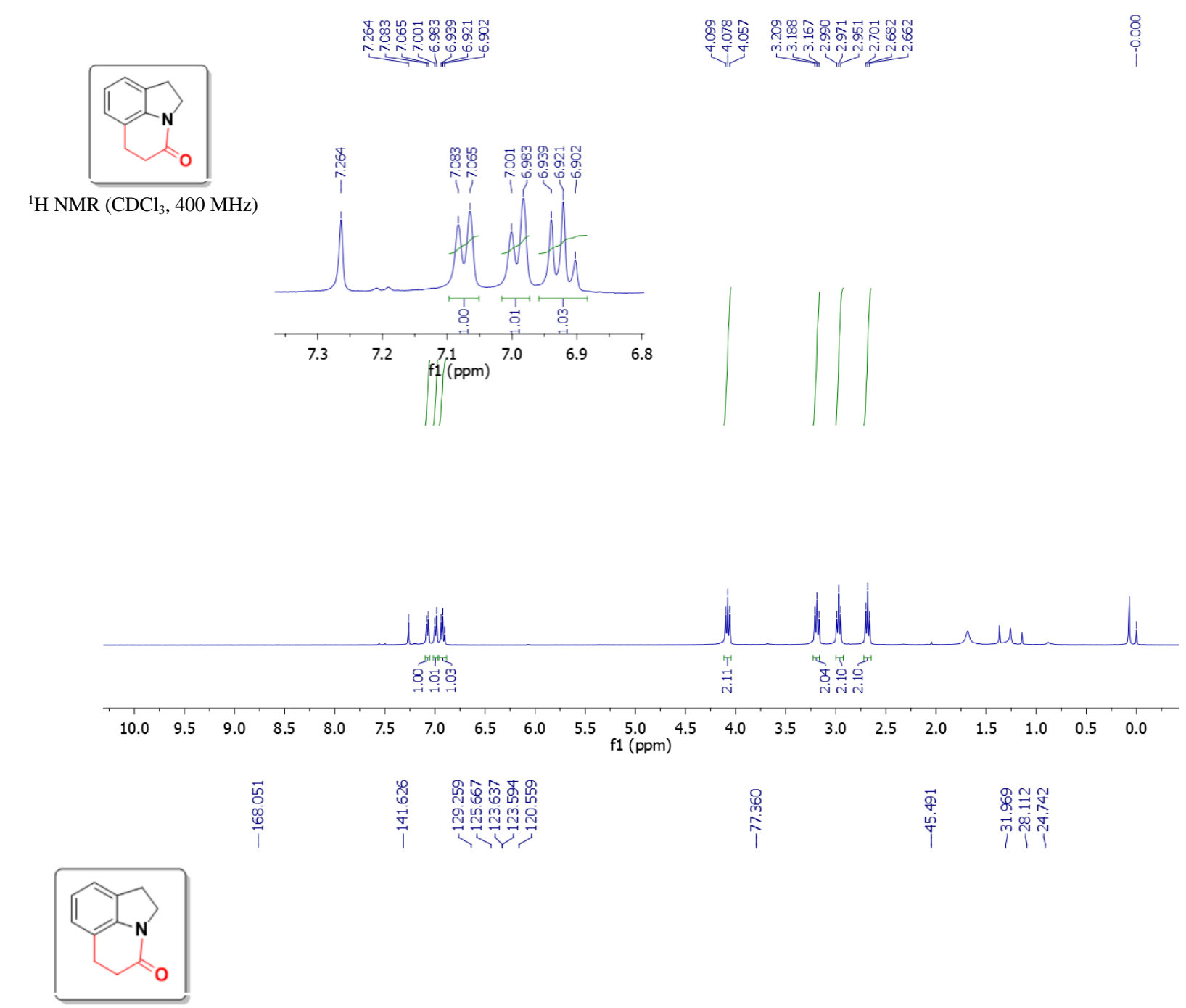

${ }^{13} \mathrm{C} \mathrm{NMR}\left(\mathrm{CDCl}_{3}, 100 \mathrm{MHz}\right)$

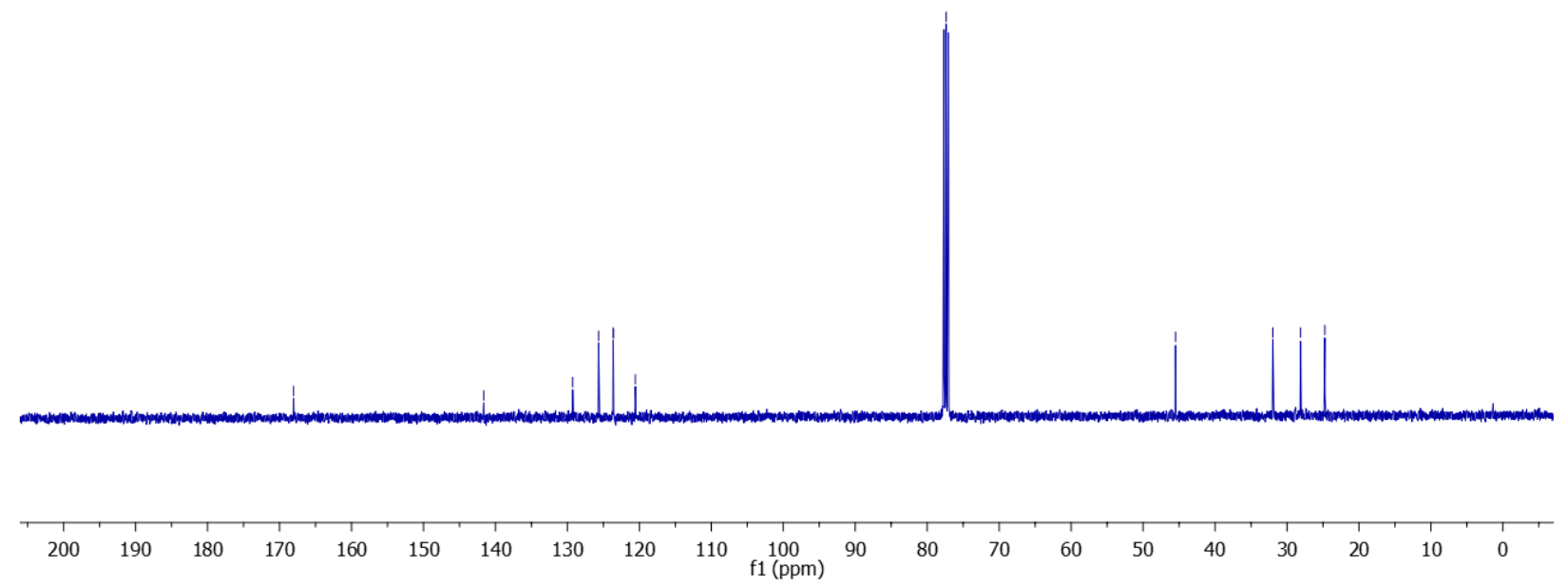


2-Methyl-5,6-dihydro-1H-pyrrolo[3,2,1-ij]quinolin-4(2H)-one (3ba):

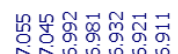

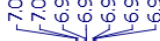

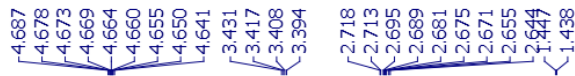

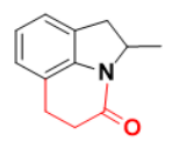

${ }^{1} \mathrm{H} \mathrm{NMR}\left(\mathrm{CDCl}_{3}, 700 \mathrm{MHz}\right)$

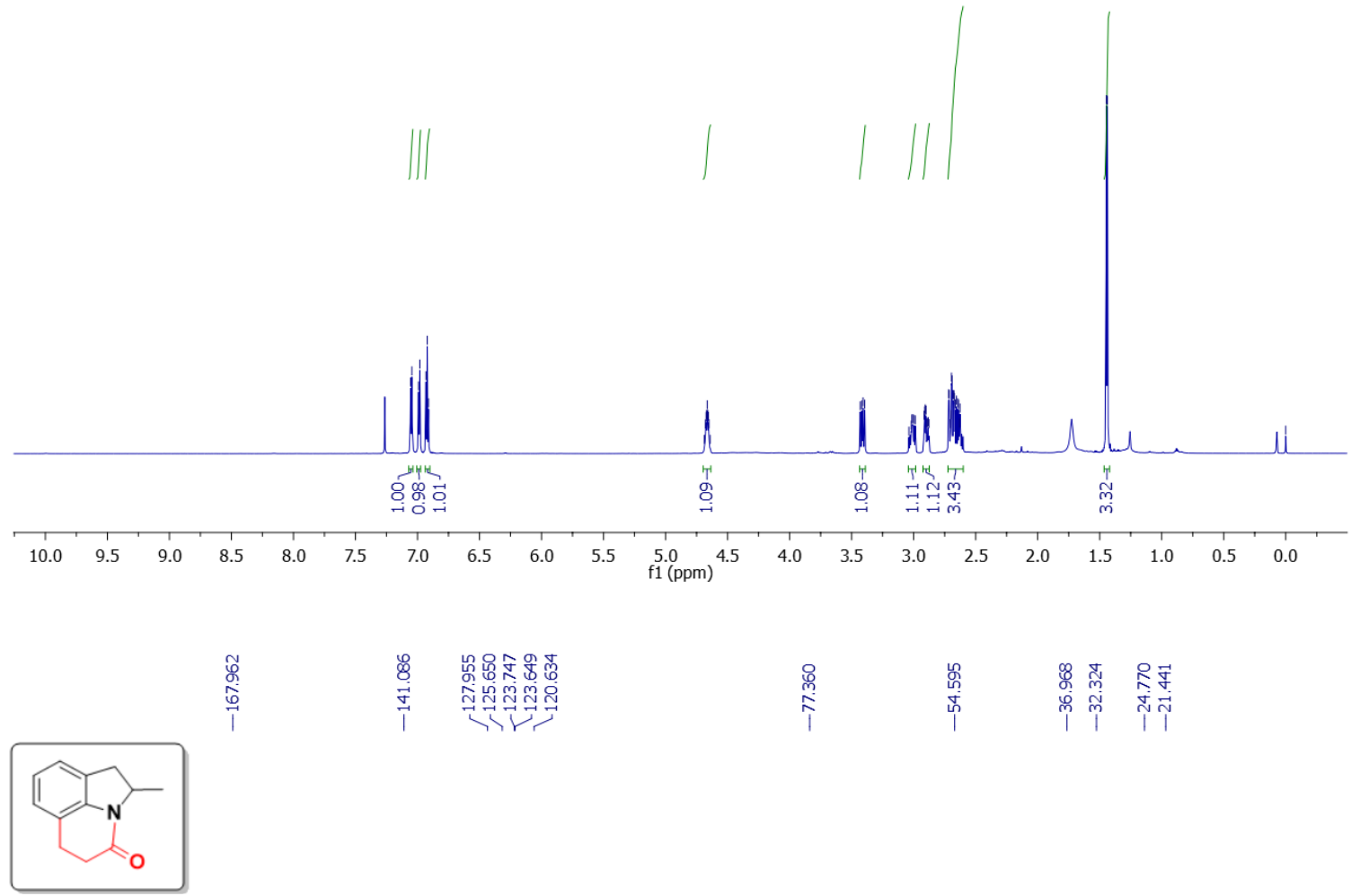

${ }^{13} \mathrm{C} \mathrm{NMR}\left(\mathrm{CDCl}_{3}, 175 \mathrm{MHz}\right)$

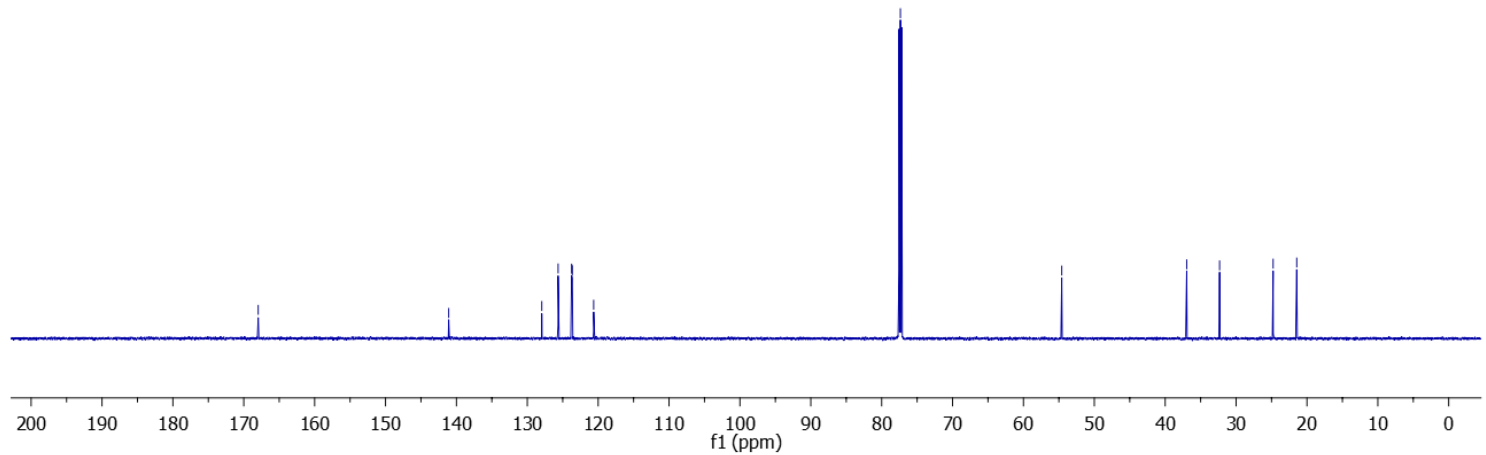




\section{1,2-Dimethyl-5,6-dihydro-1H-pyrrolo[3,2,1-ij]quinolin-4(2H)-one (3ca):}

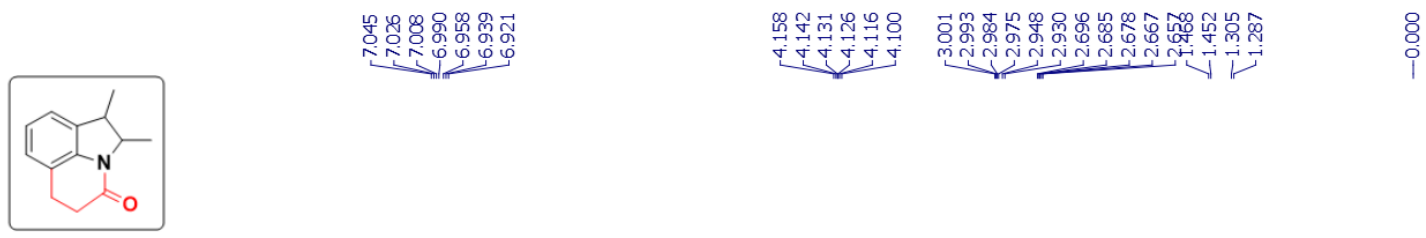

${ }^{1} \mathrm{H} \mathrm{NMR}\left(\mathrm{CDCl}_{3}, 400 \mathrm{MHz}\right)$

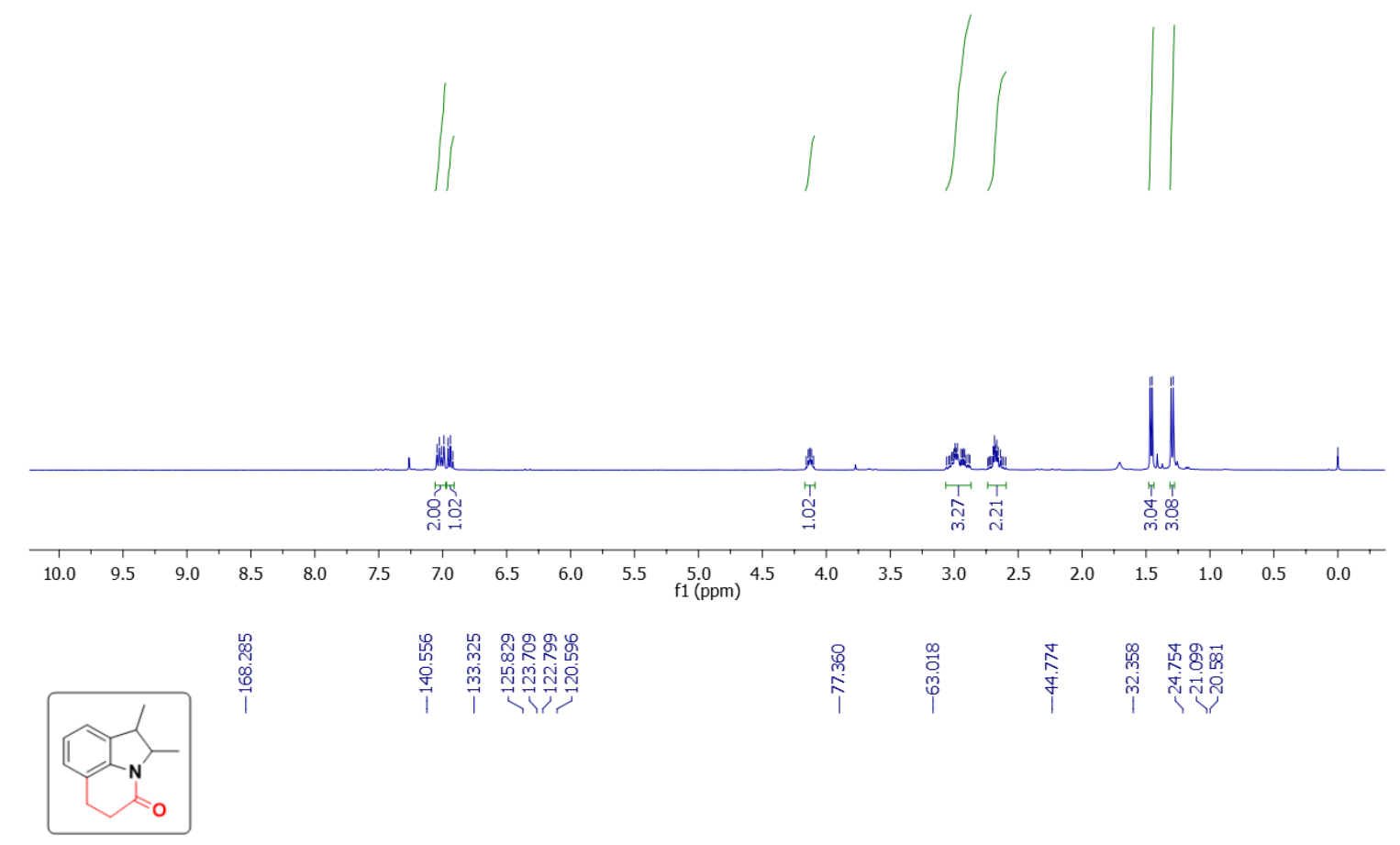

${ }^{13} \mathrm{C} \mathrm{NMR}\left(\mathrm{CDCl}_{3}, 100 \mathrm{MHz}\right)$

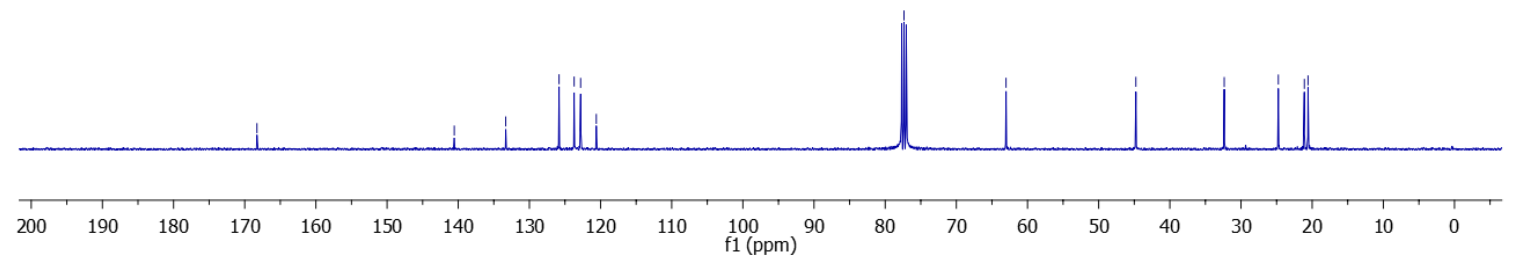


(E)-Methyl 3-(9-pivaloyl-2,3,4,4a,9,9a-hexahydro-1H-carbazol-8-yl)acrylate (4da):

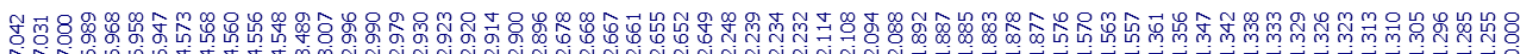

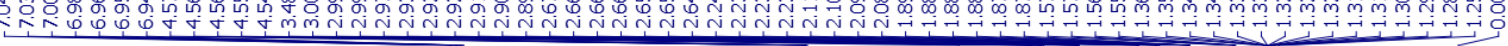

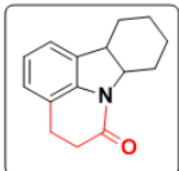

${ }^{1} \mathrm{H} \mathrm{NMR}\left(\mathrm{CDCl}_{3}, 700 \mathrm{MHz}\right)$

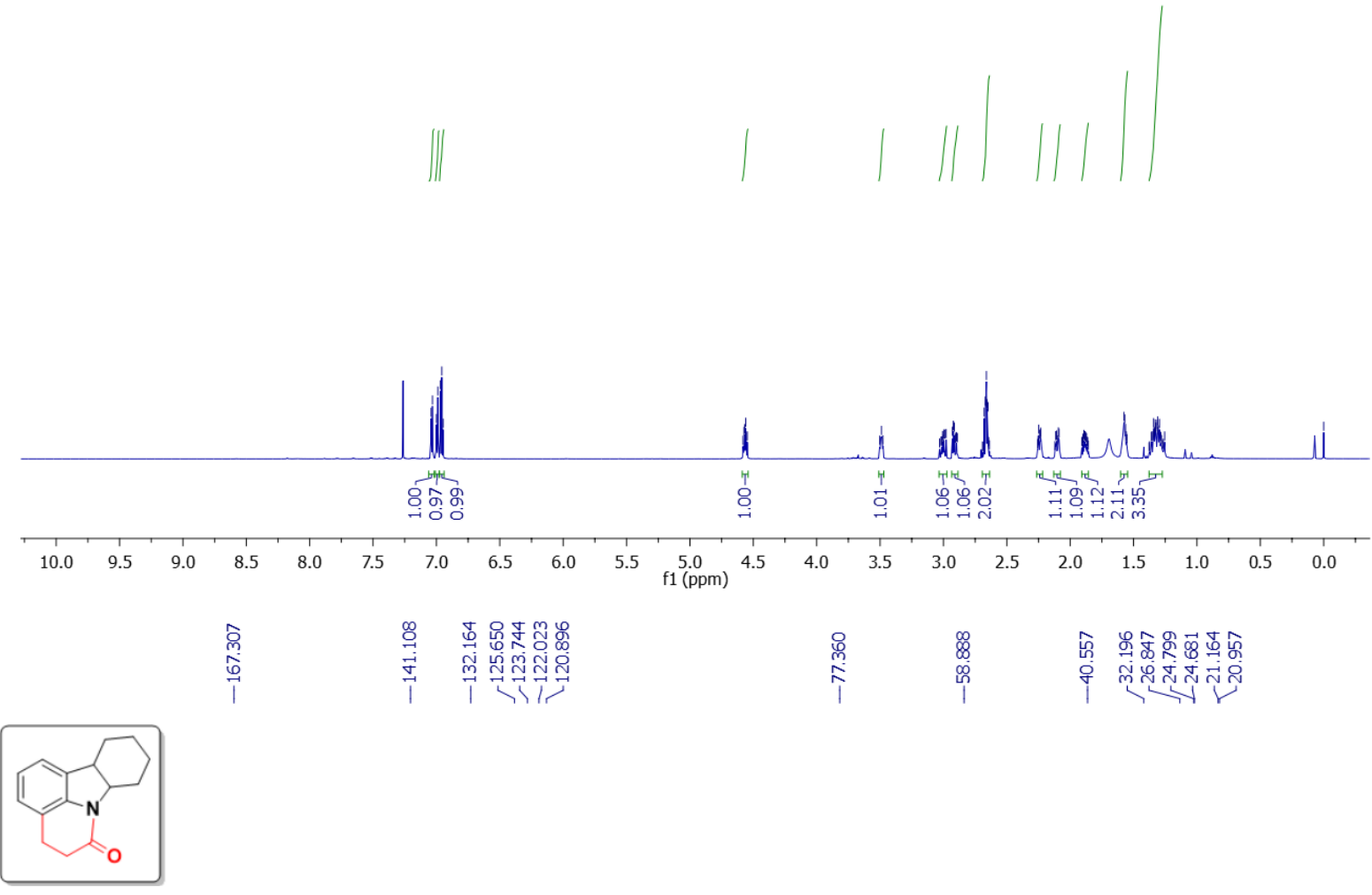

${ }^{13} \mathrm{C} \mathrm{NMR}\left(\mathrm{CDCl}_{3}, 175 \mathrm{MHz}\right)$

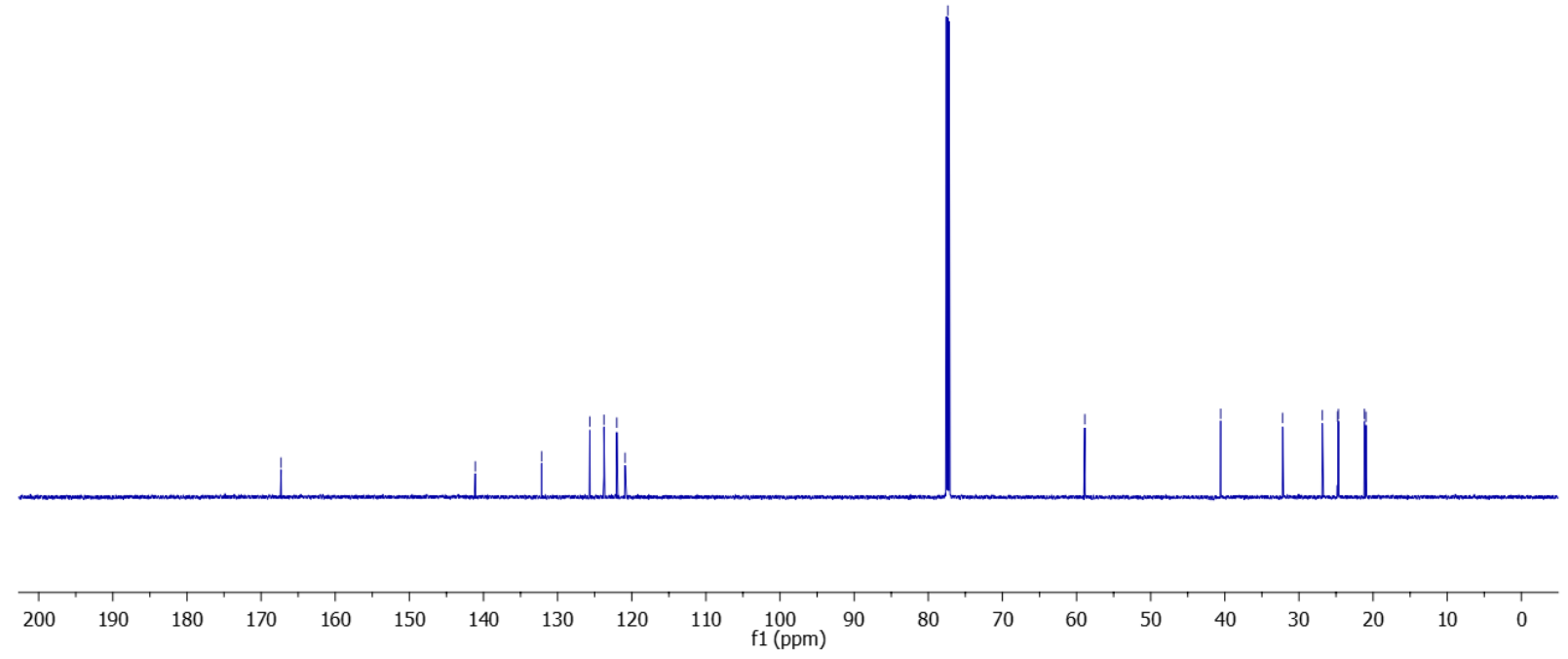




\section{8-Methoxy-5,6-dihydro-1H-pyrrolo[3,2,1-ij]quinolin-4(2H)-one (3ea):}

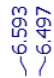

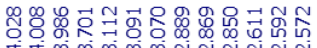

ن

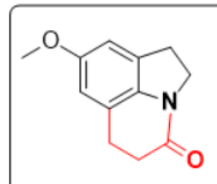

${ }^{1} \mathrm{H} \mathrm{NMR}\left(\mathrm{CDCl}_{3}, 400 \mathrm{MHz}\right)$

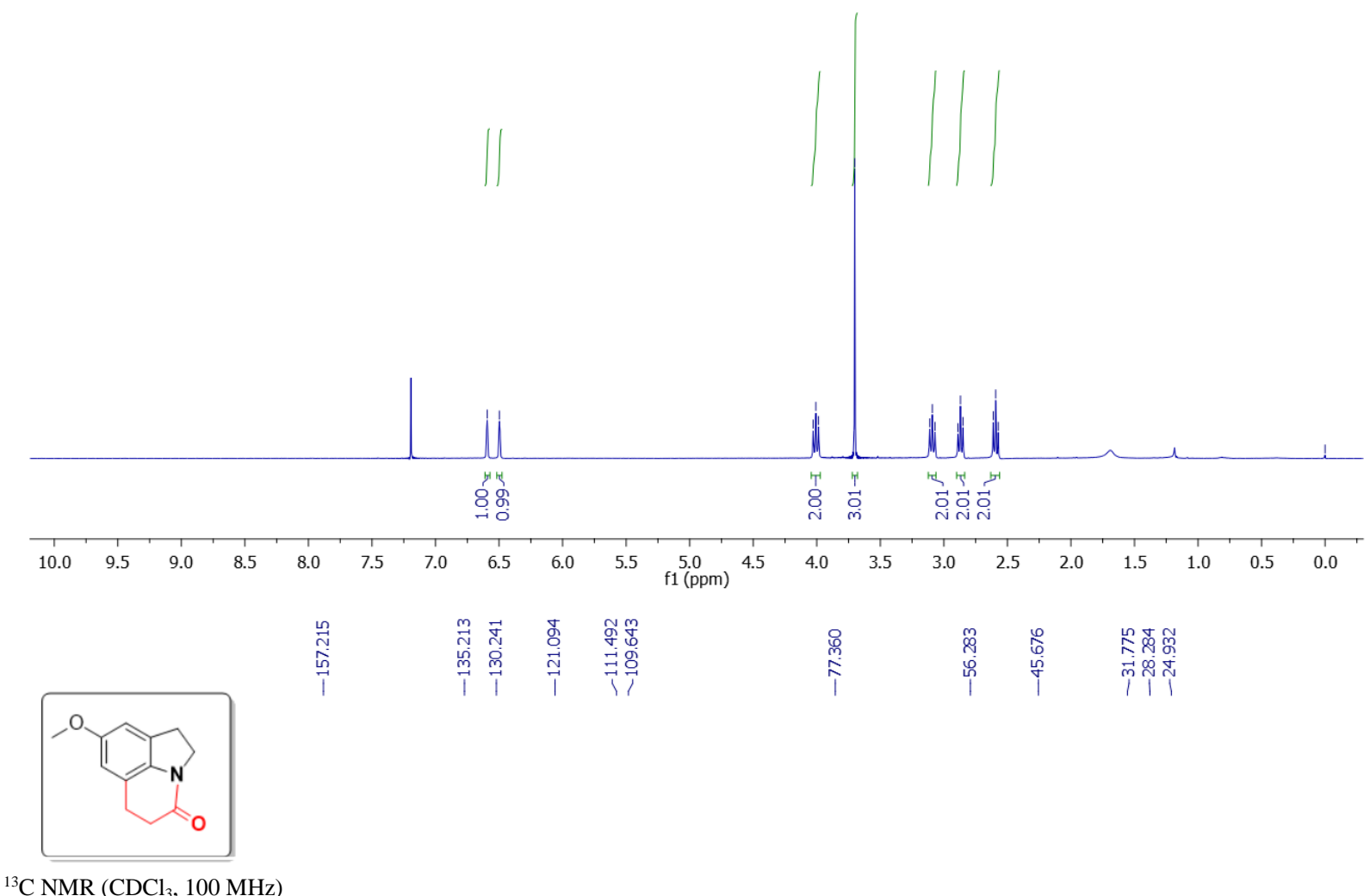

${ }^{13} \mathrm{C} \mathrm{NMR}\left(\mathrm{CDCl}_{3}, 100 \mathrm{MHz}\right)$

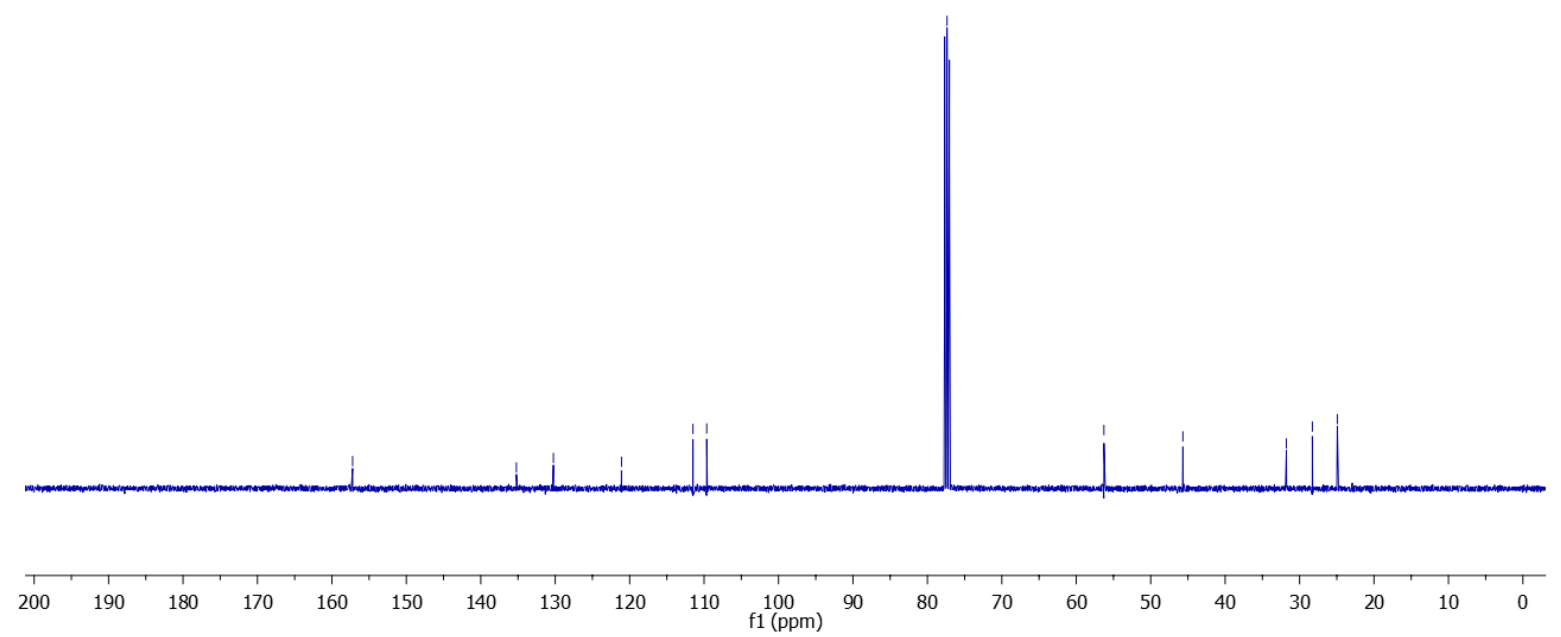


(E)-Methyl 3-(6-methoxy-1-pivaloylindolin-7-yl)acrylate (4fa):

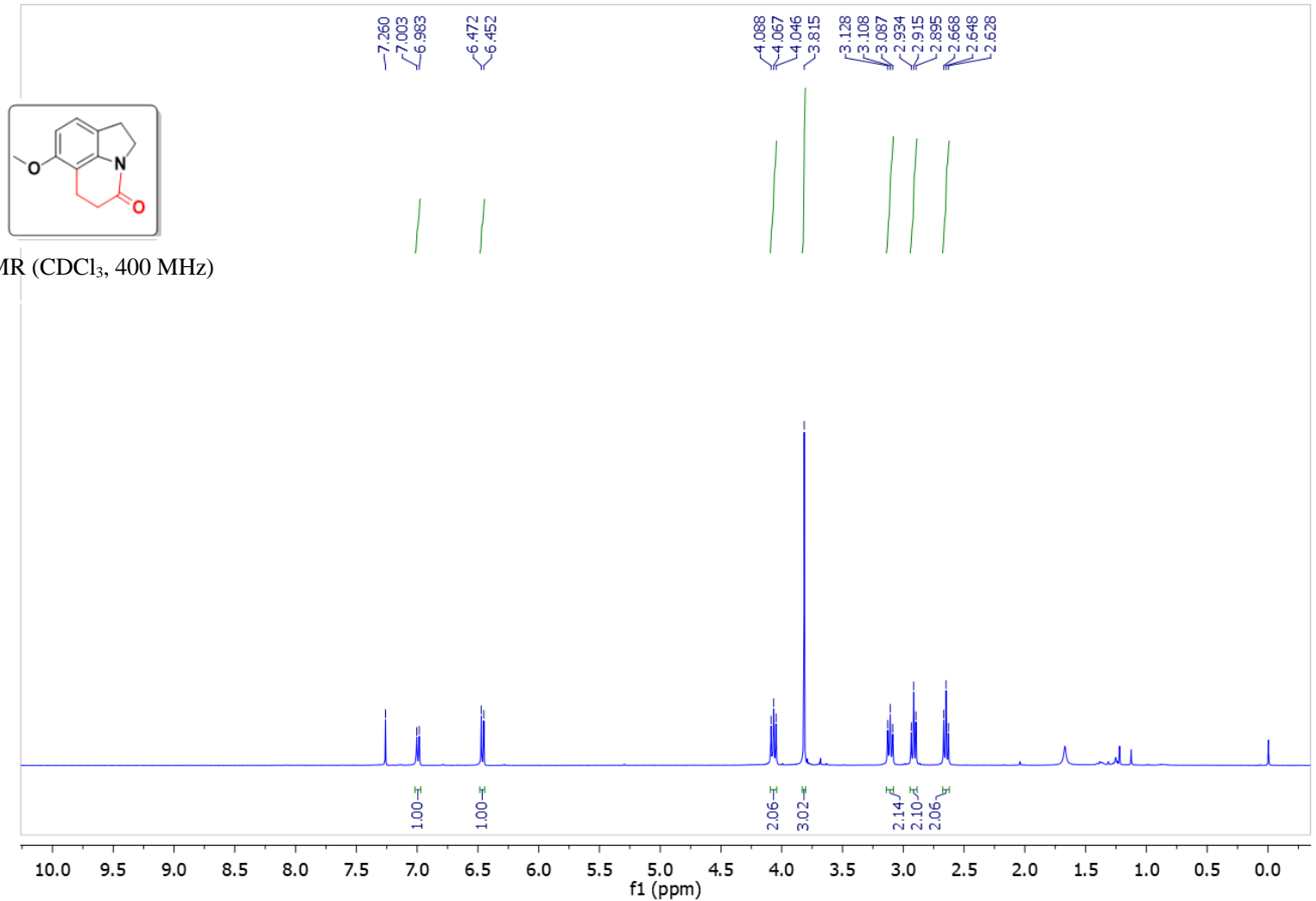

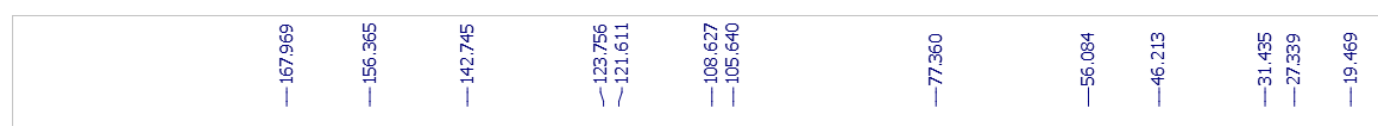

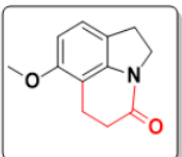

$\left.{ }^{13} \mathrm{C} \mathrm{NMR} \mathrm{(CDCl}, 100 \mathrm{MHz}\right)$

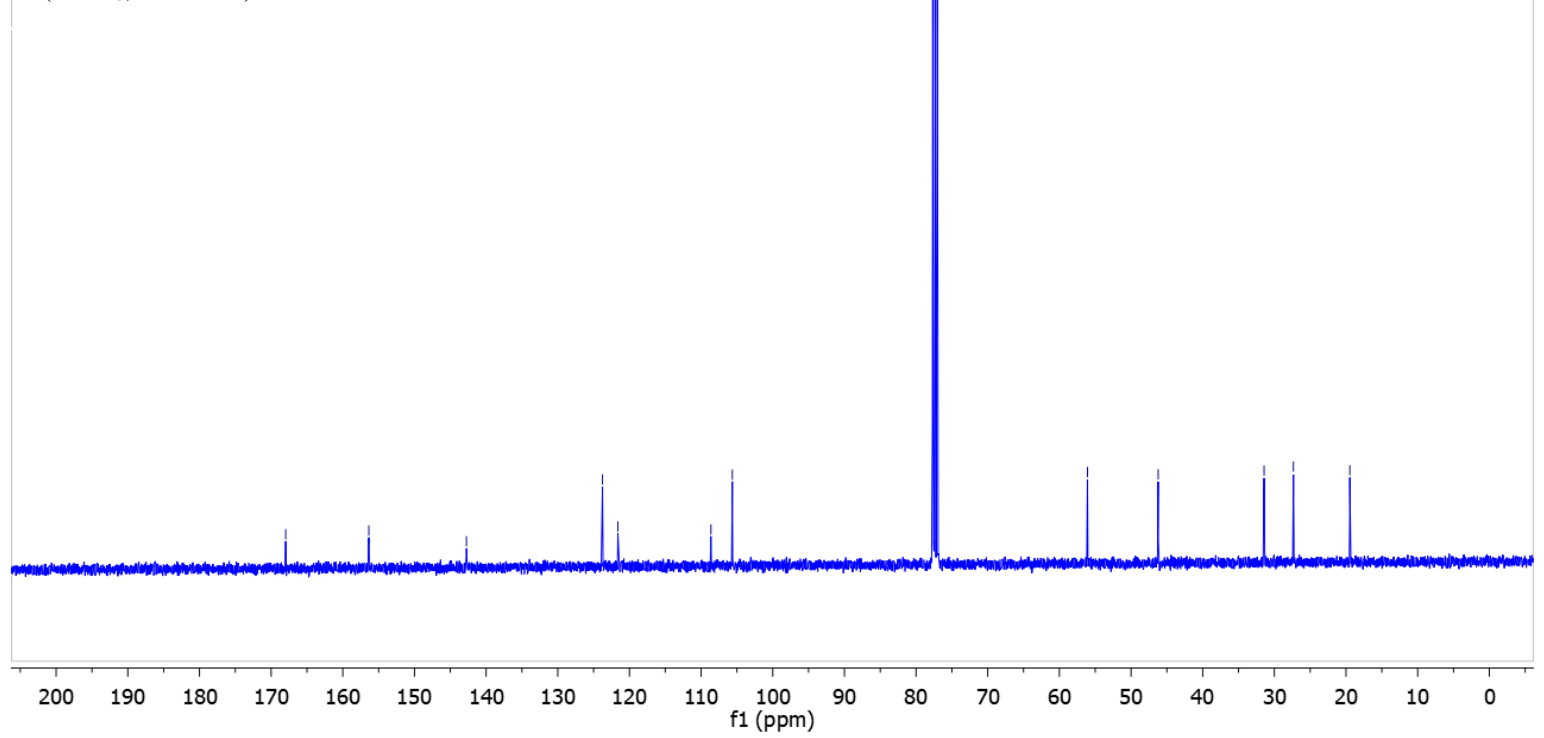


9-Bromo-5,6-dihydro-1H-pyrrolo[3,2,1-ij]quinolin-4(2H)-one (3ga):

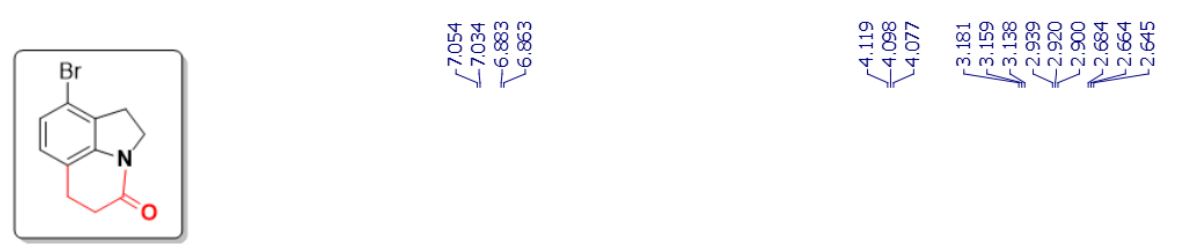

${ }^{1} \mathrm{H} \mathrm{NMR}\left(\mathrm{CDCl}_{3}, 400 \mathrm{MHz}\right)$

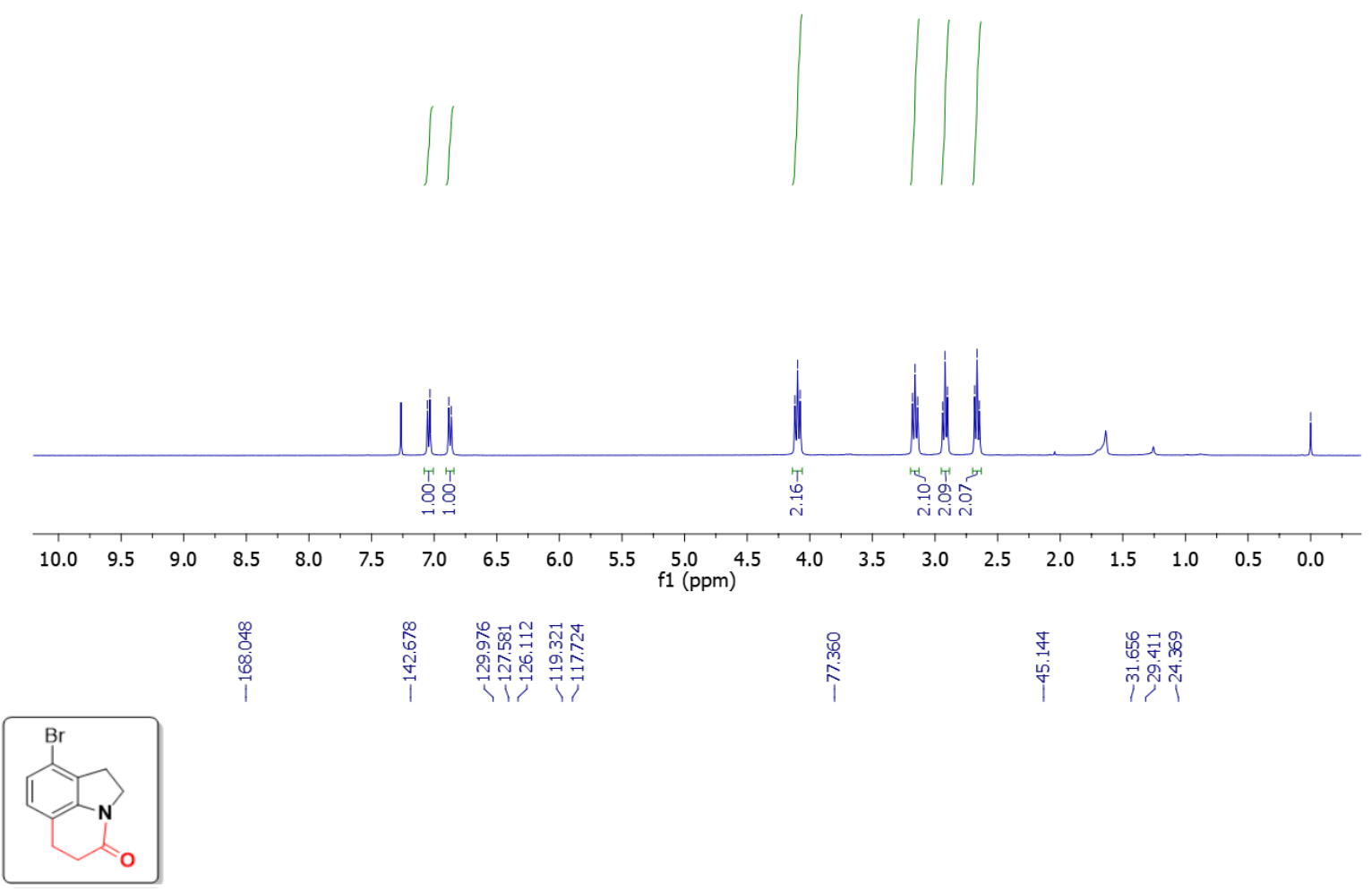

${ }^{13} \mathrm{C} \mathrm{NMR}\left(\mathrm{CDCl}_{3}, 100 \mathrm{MHz}\right)$

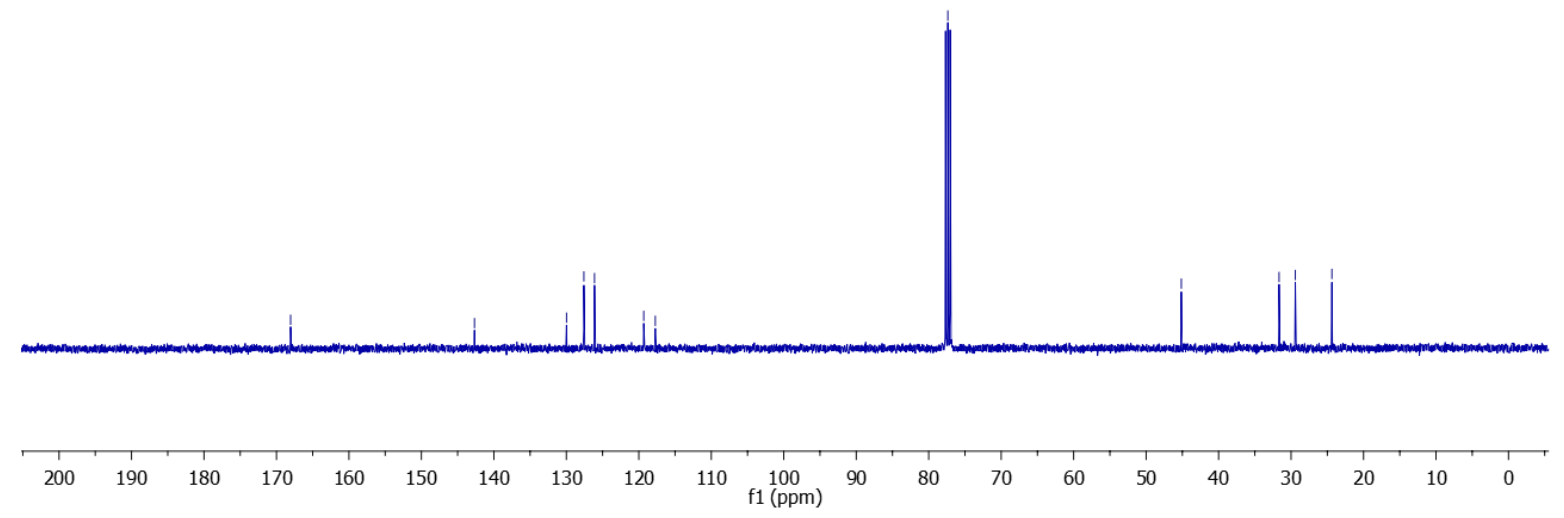

S11 I 
8-Bromo-5,6-dihydro-1H-pyrrolo[3,2,1-ij]quinolin-4(2H)-one (3ha):

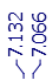

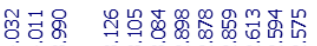

+ण

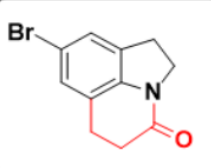

${ }^{1} \mathrm{H} \mathrm{NMR}\left(\mathrm{CDCl}_{3}, 400 \mathrm{MHz}\right)$

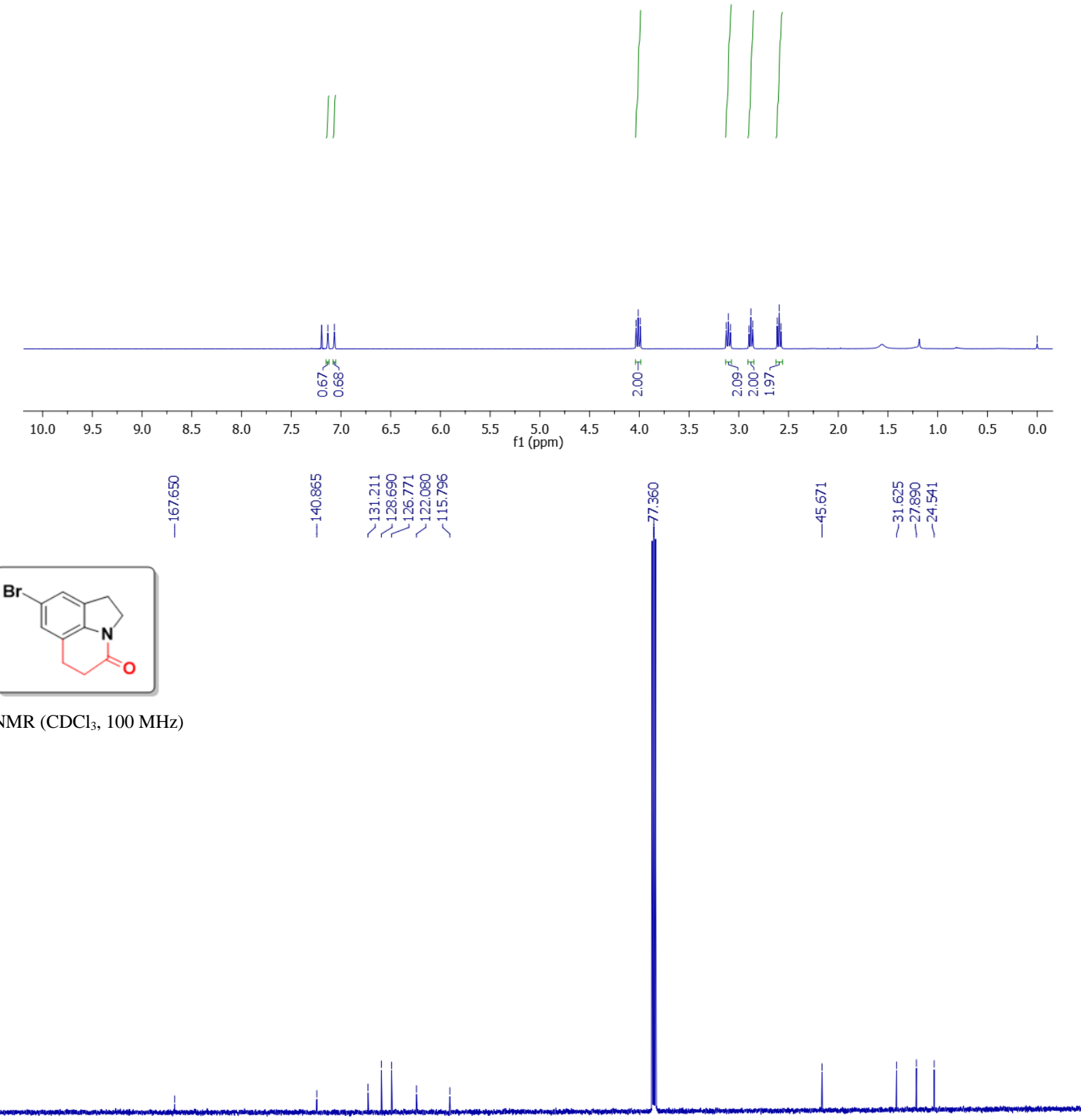

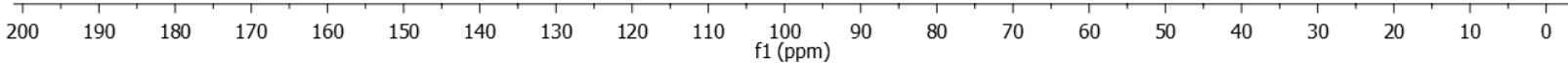

S12 I 
8-Fluoro-5,6-dihydro-1H-pyrrolo[3,2,1-ij]quinolin-4(2H)-one (3ia):
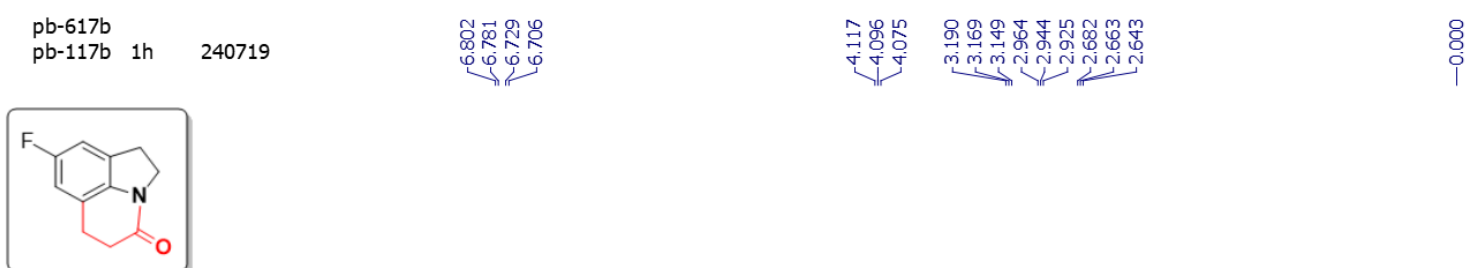

${ }^{1} \mathrm{H} \mathrm{NMR}\left(\mathrm{CDCl}_{3}, 700 \mathrm{MHz}\right)$

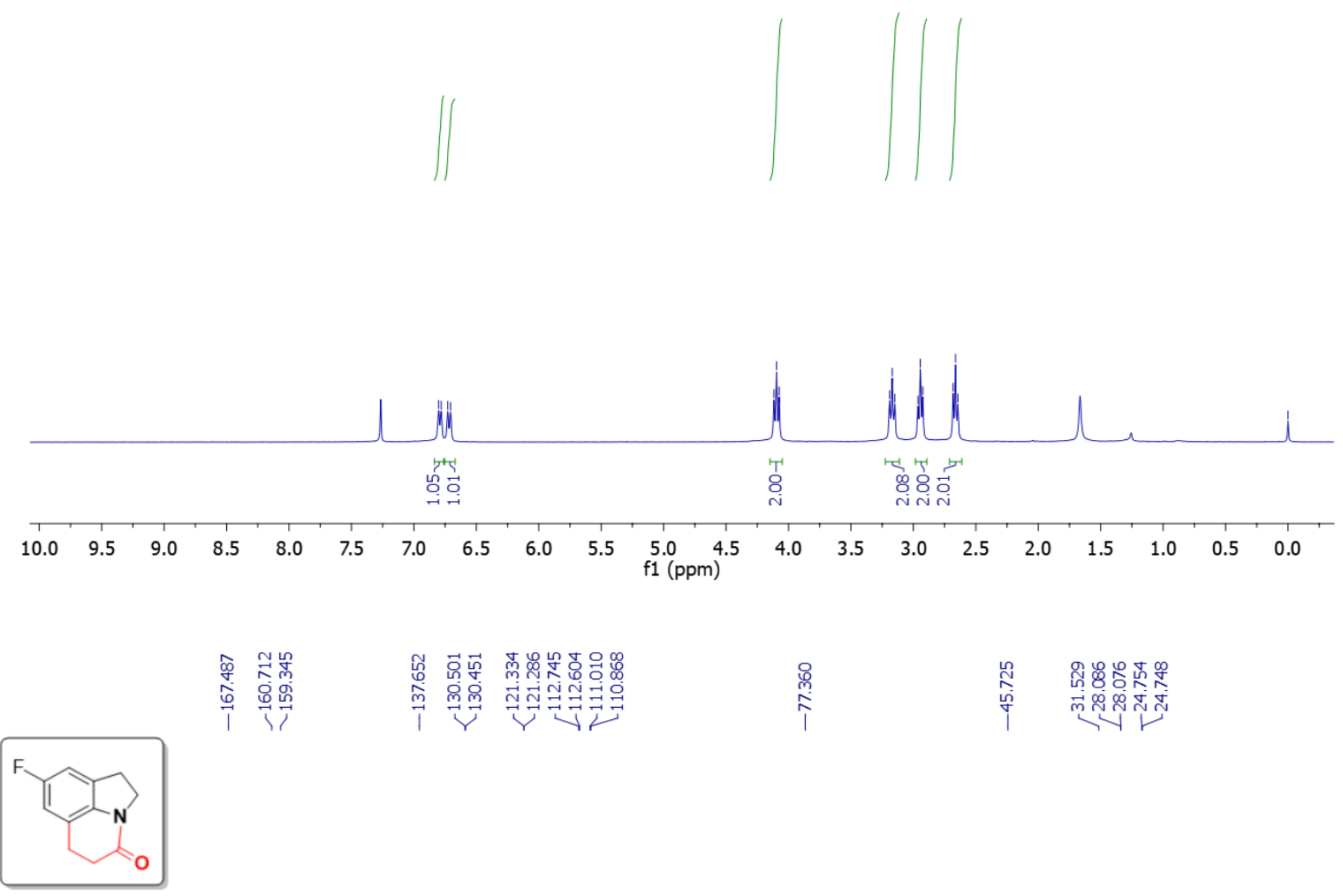

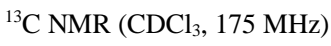

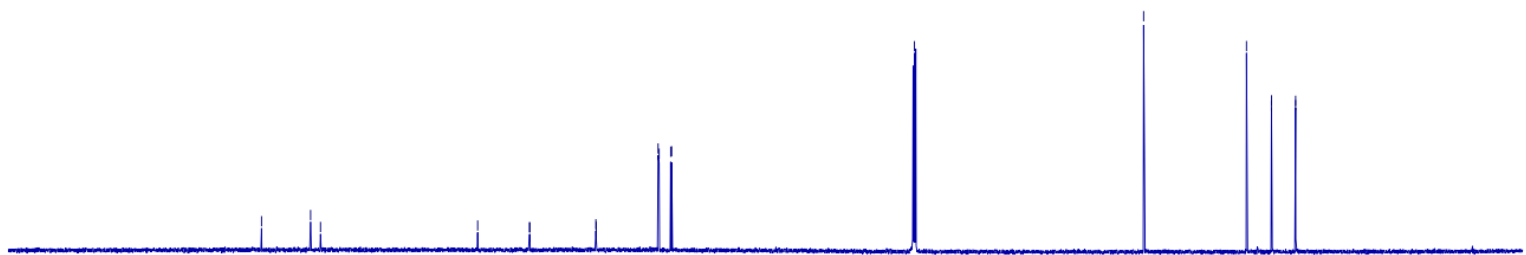

S13 |

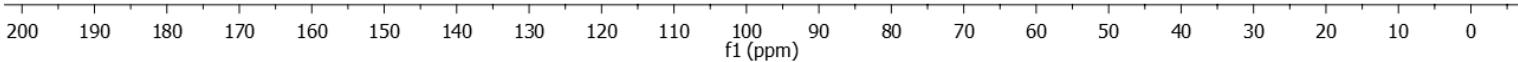


8-chloro-5,6-dihydro-1H-pyrrolo[3,2,1-ij]quinolin-4(2H)-one(3iia):
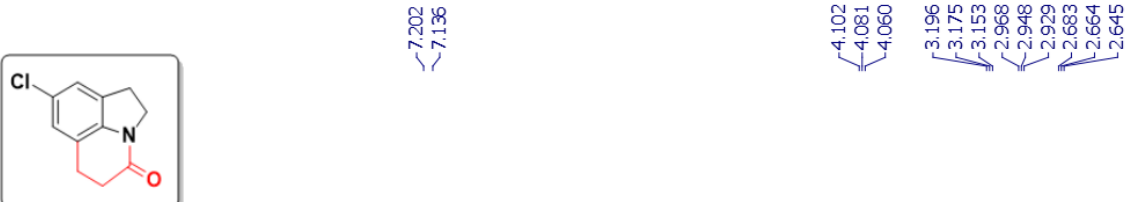

${ }^{13} \mathrm{C} \mathrm{NMR}\left(\mathrm{CDCl}_{3}, 400 \mathrm{MHz}\right)$

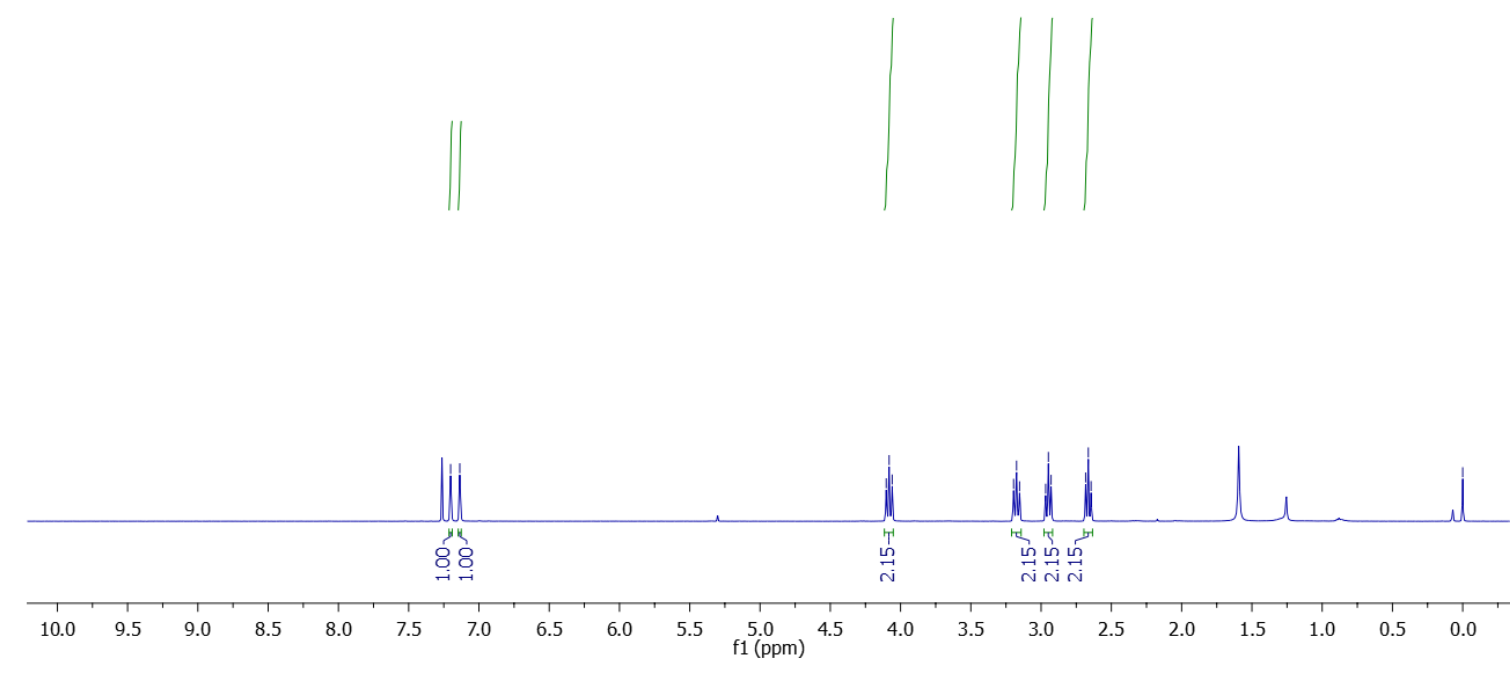

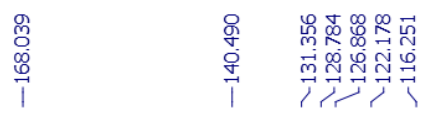

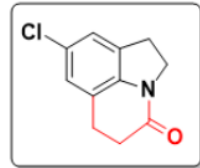

${ }^{13} \mathrm{C} \mathrm{NMR}\left(\mathrm{CDCl}_{3}, 100 \mathrm{MHz}\right)$
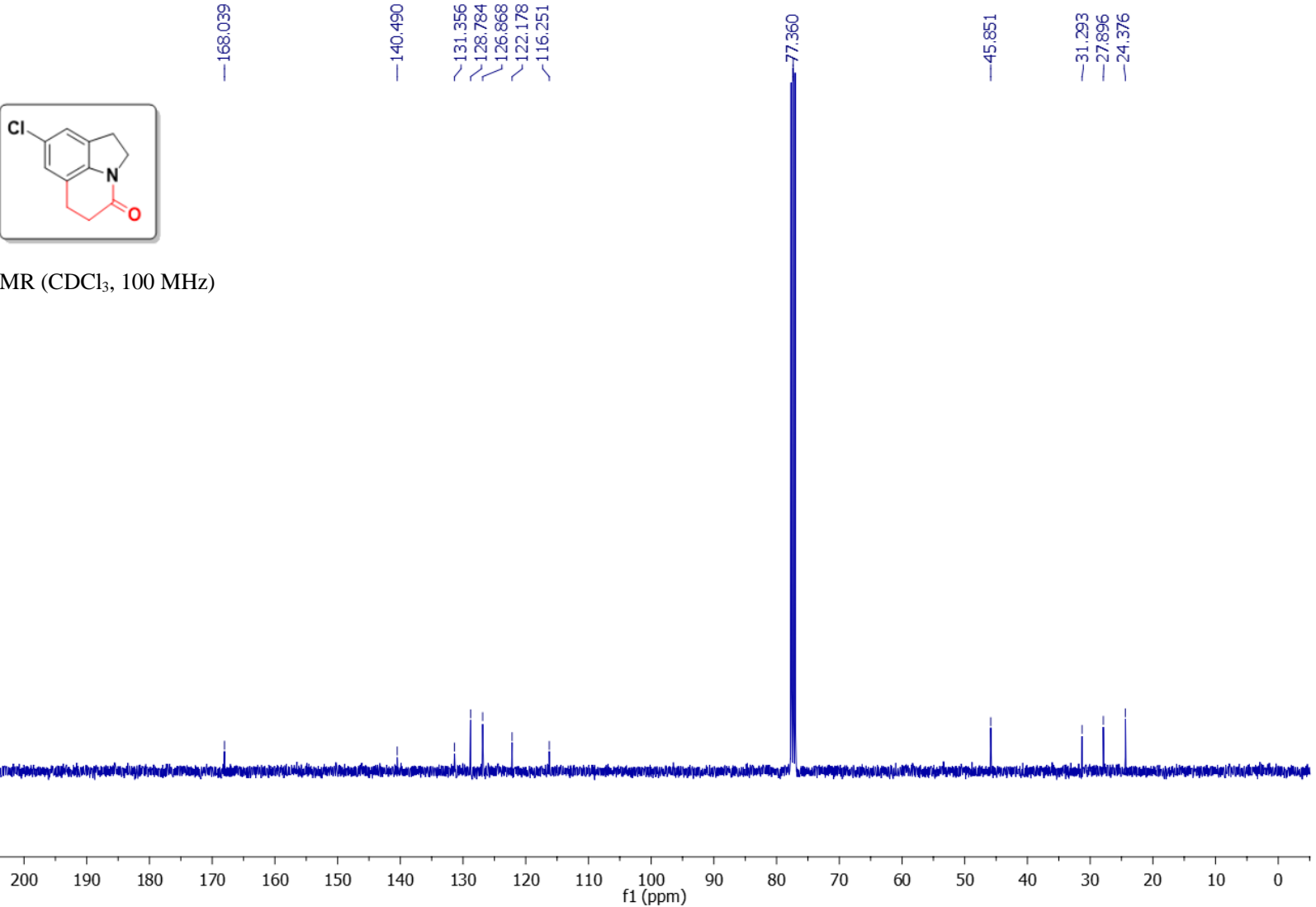
(E)-Methyl 3-(1-pivaloylindolin-7-yl)acrylate (4aa):
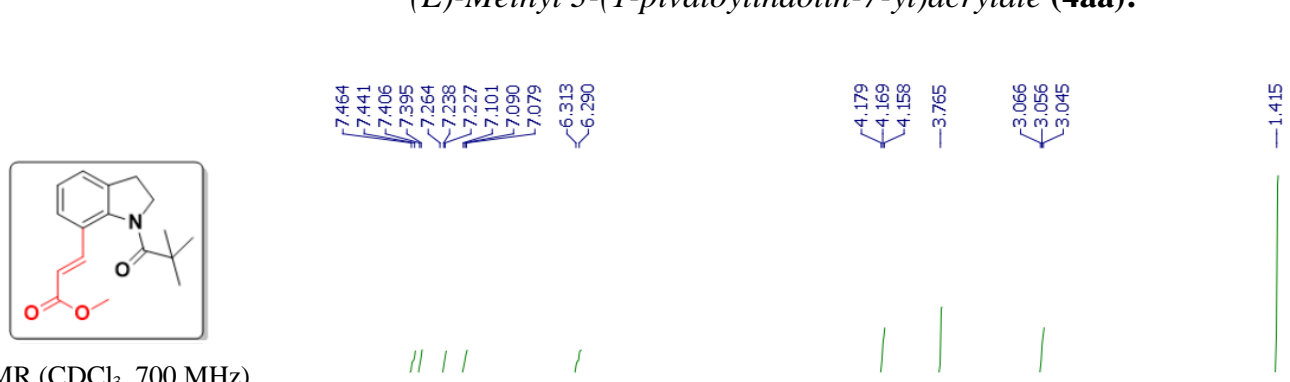

${ }^{1} \mathrm{H} \mathrm{NMR}\left(\mathrm{CDCl}_{3}, 700 \mathrm{MHz}\right)$
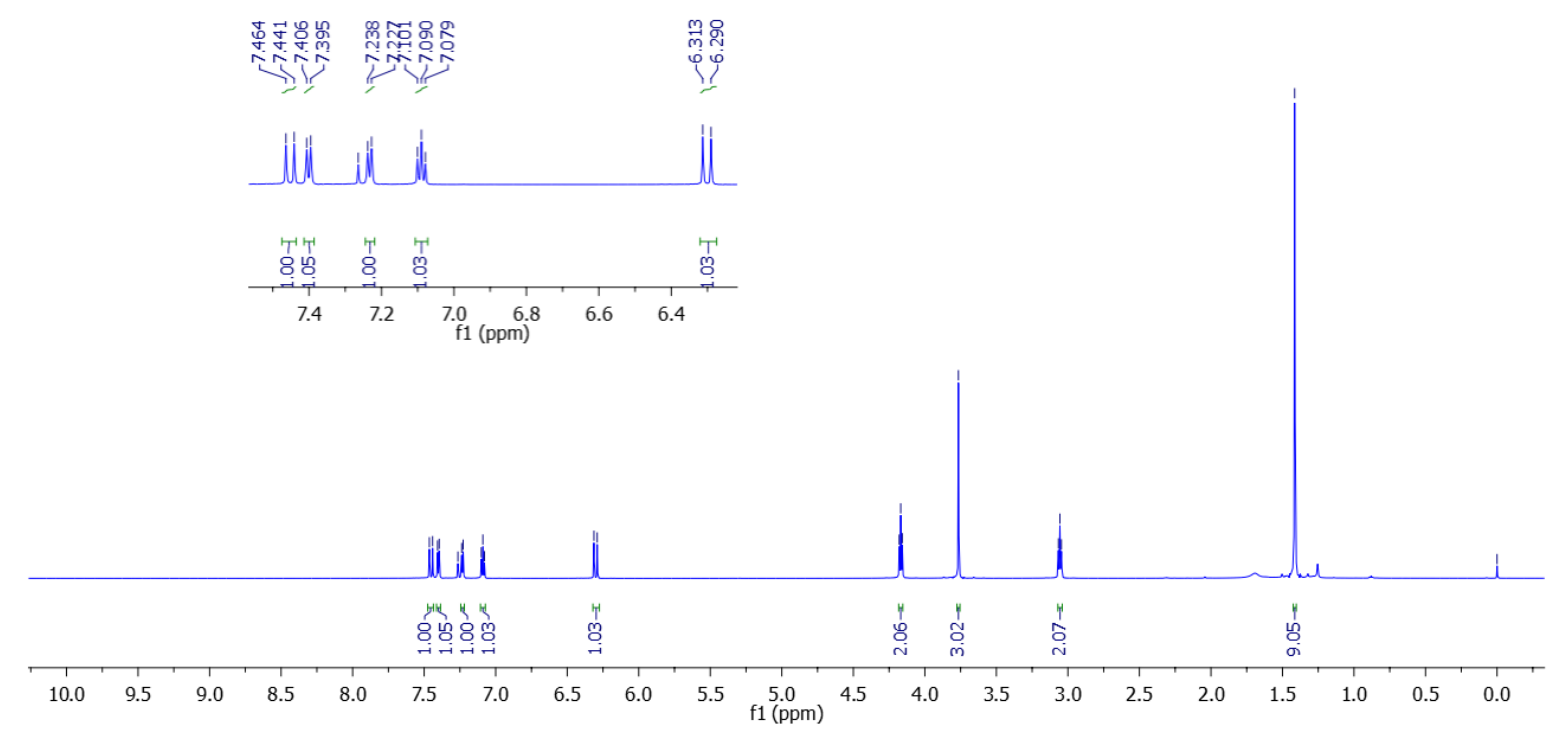

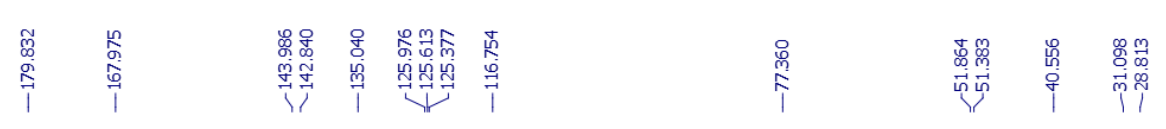

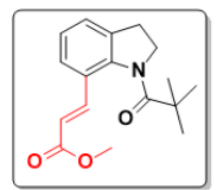

${ }^{13} \mathrm{C} \mathrm{NMR}\left(\mathrm{CDCl}_{3}, 175 \mathrm{MHz}\right)$
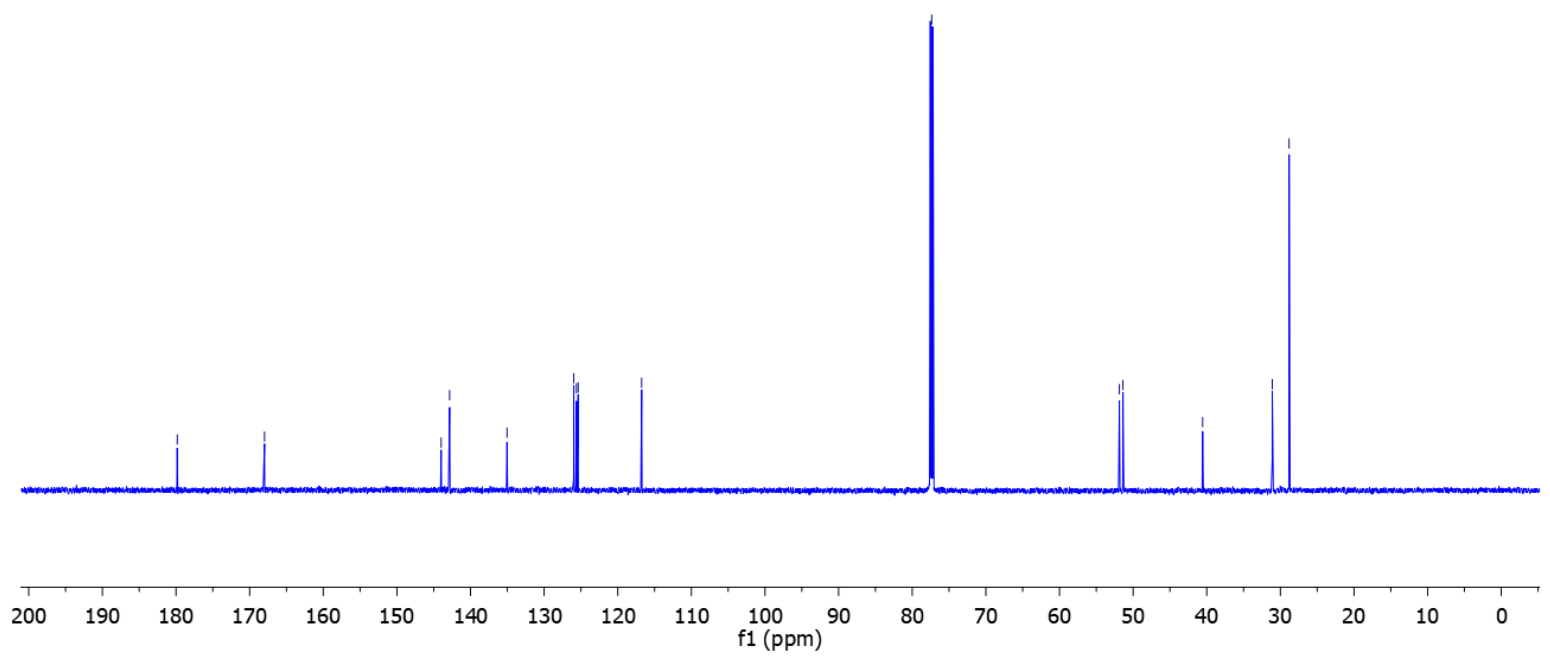
(E)-Methyl 3-(2-methyl-1-pivaloylindolin-7-yl)acrylate (4ba):
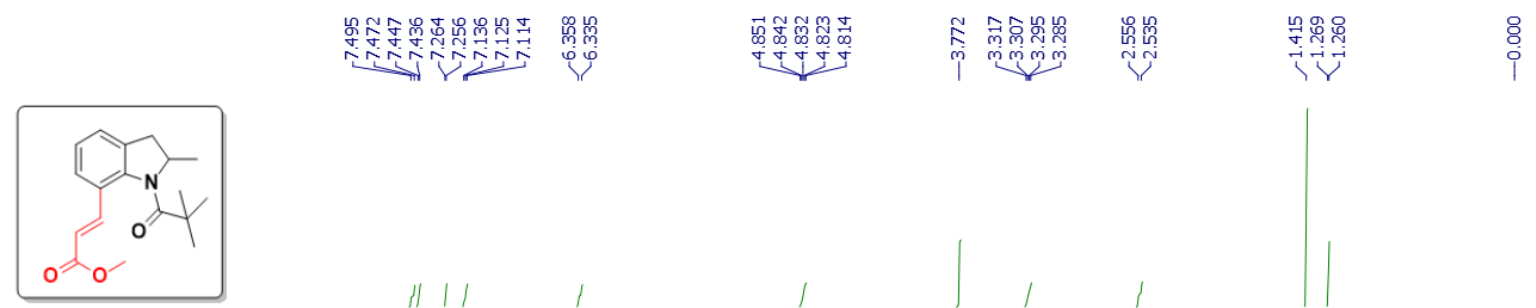

${ }^{1} \mathrm{H} \mathrm{NMR}\left(\mathrm{CDCl}_{3}, 700 \mathrm{MHz}\right)$
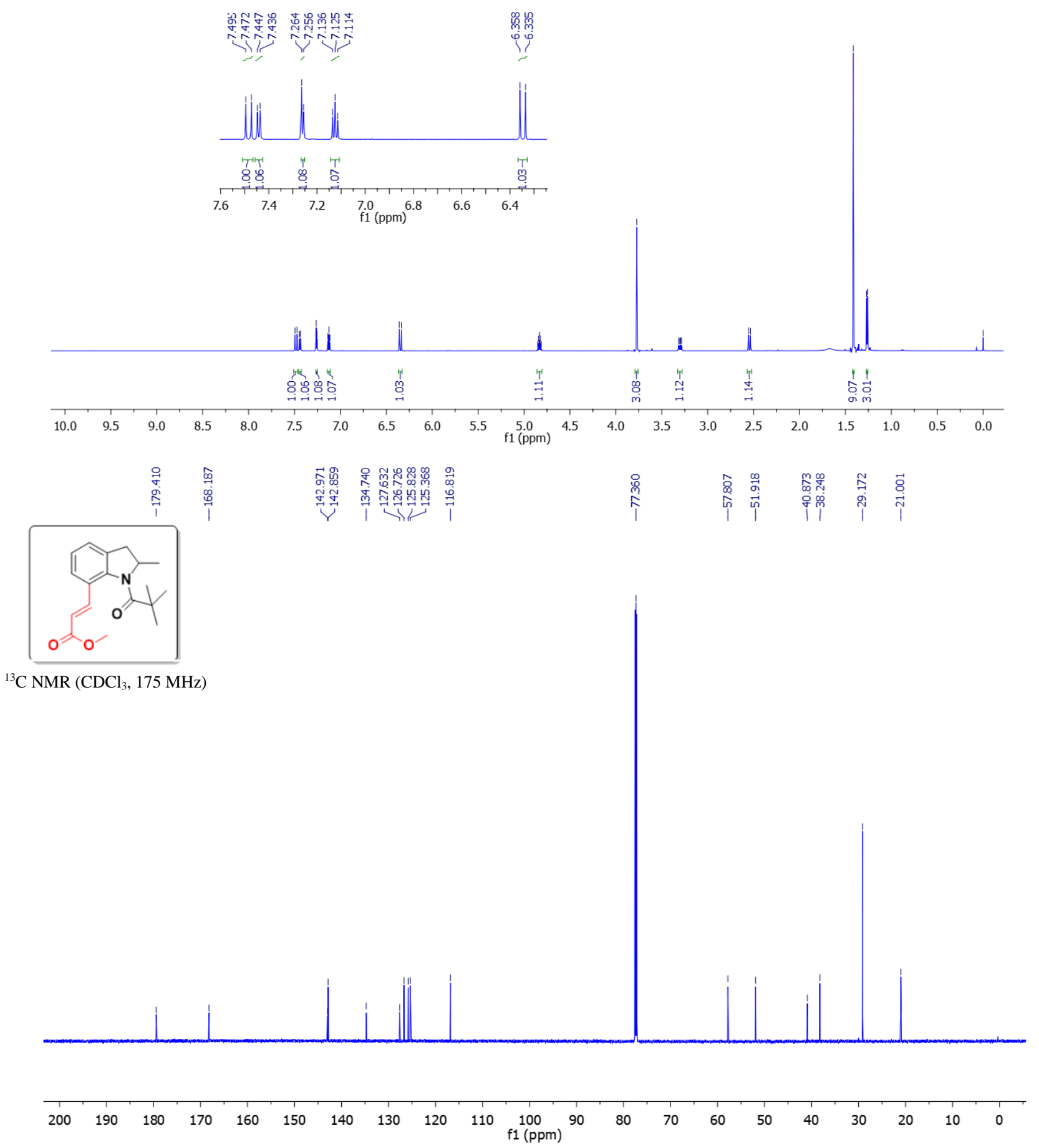
(E)-Methyl 3-(2,3-dimethyl-1-pivaloylindolin-7-yl)acrylate (4ca):
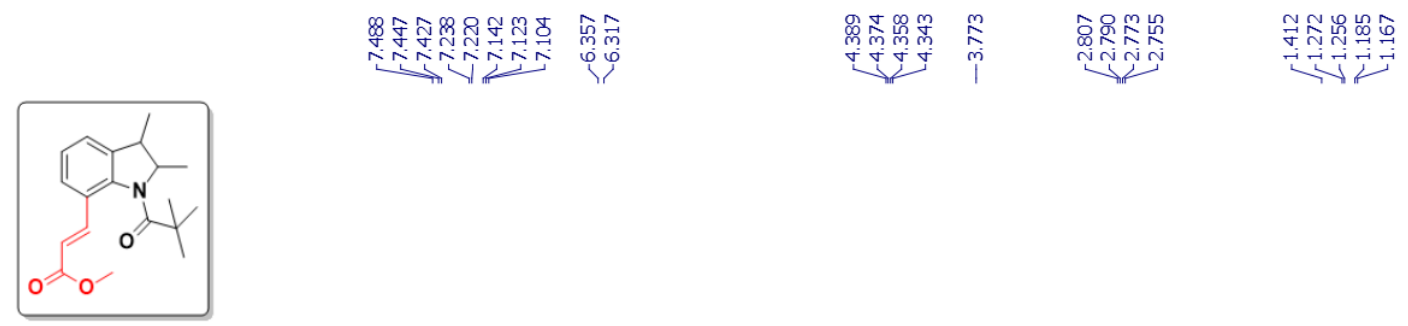

8

${ }^{1} \mathrm{H} \mathrm{NMR}\left(\mathrm{CDCl}_{3}, 400 \mathrm{MHz}\right)$
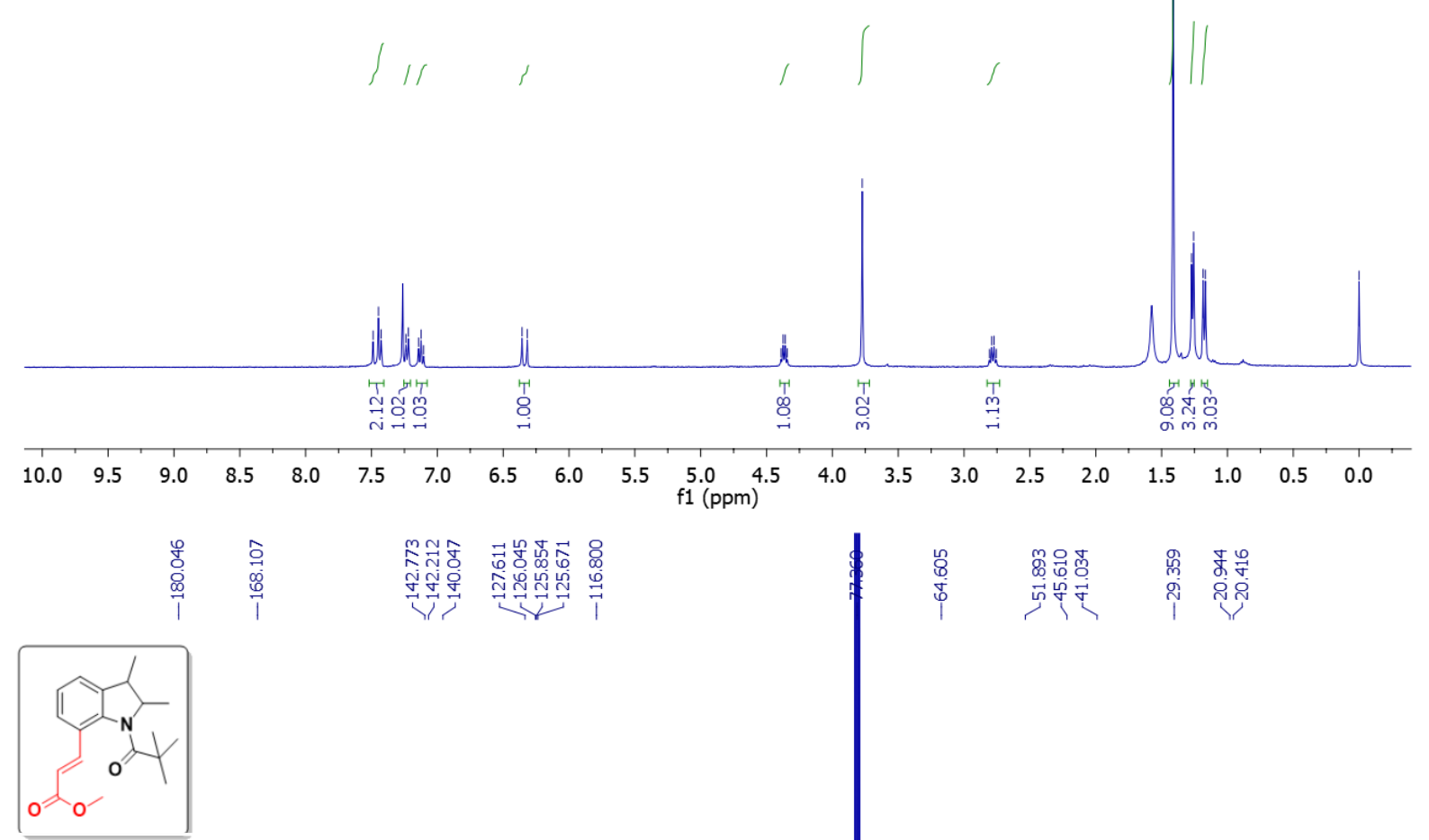

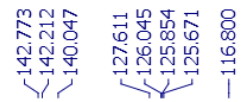

${ }^{13} \mathrm{C} \mathrm{NMR}\left(\mathrm{CDCl}_{3}, 100 \mathrm{MHz}\right)$

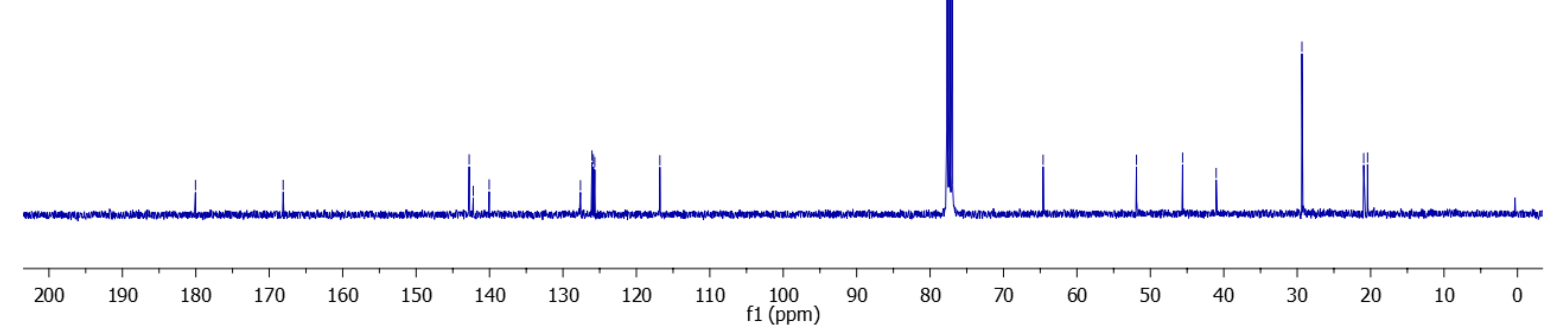


(E)-Methyl 3-(9-pivaloyl-2,3,4,4a,9,9a-hexahydro-1H-carbazol-8-yl)acrylate (4da):

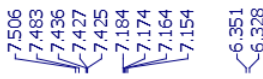

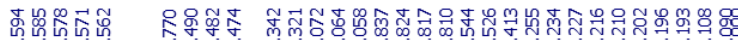

过过

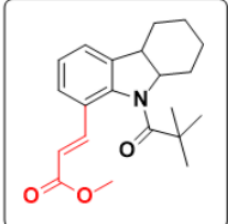

${ }^{1} \mathrm{H} \mathrm{NMR}\left(\mathrm{CDCl}_{3}, 700 \mathrm{MHz}\right)$
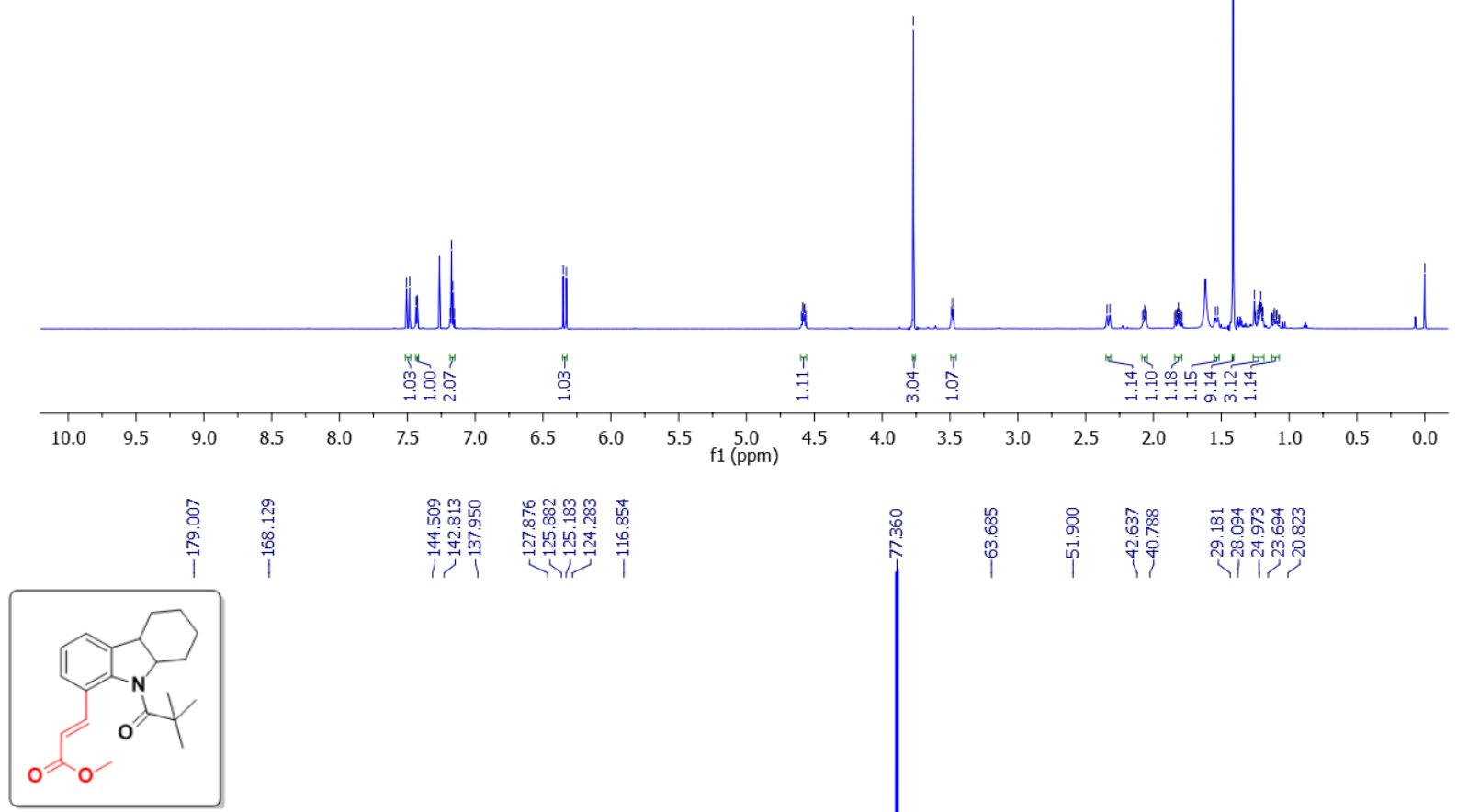

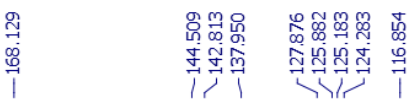

${ }^{13} \mathrm{C} \mathrm{NMR}\left(\mathrm{CDCl}_{3}, 175 \mathrm{MHz}\right)$
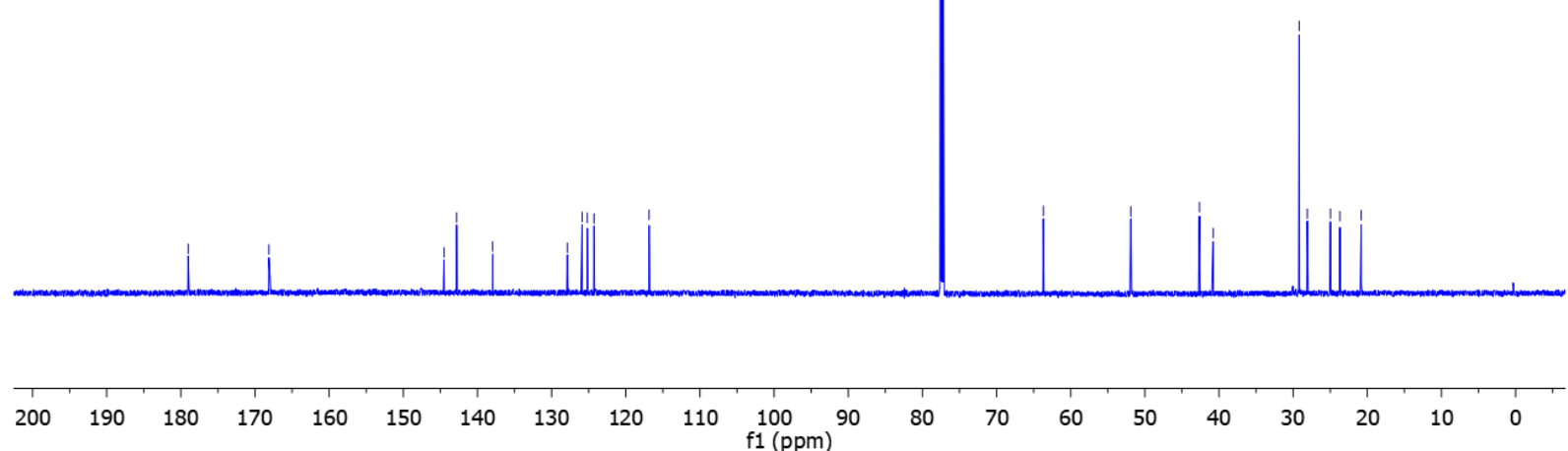
(E)-Methyl 3-(5-methoxy-1-pivaloylindolin-7-yl)acrylate (4ea):
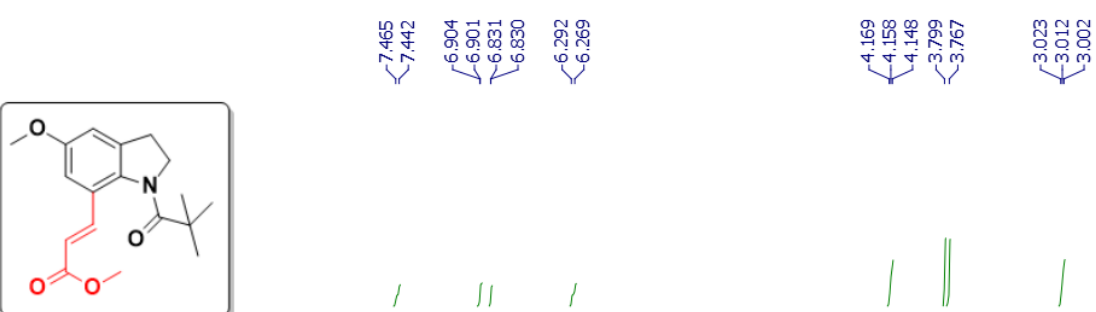

$\mathrm{H} \mathrm{NMR}\left(\mathrm{CDCl}_{3}, 700 \mathrm{MHz}\right)$

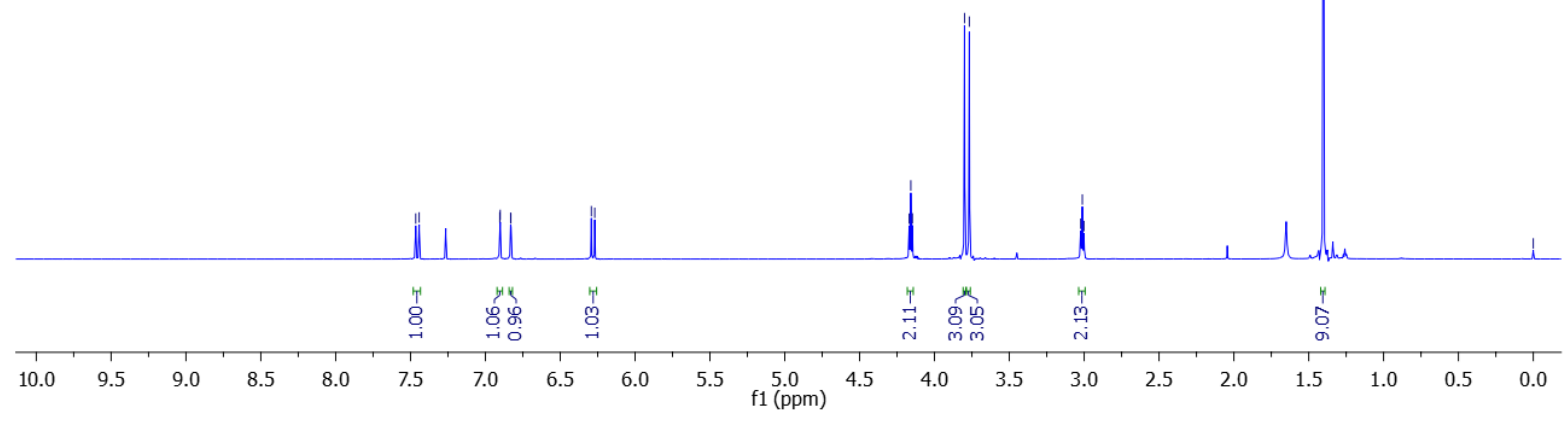

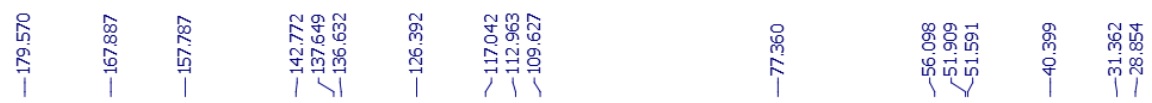

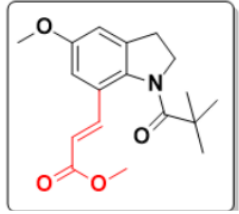

${ }^{13} \mathrm{C} \mathrm{NMR}\left(\mathrm{CDCl}_{3}, 175 \mathrm{MHz}\right)$
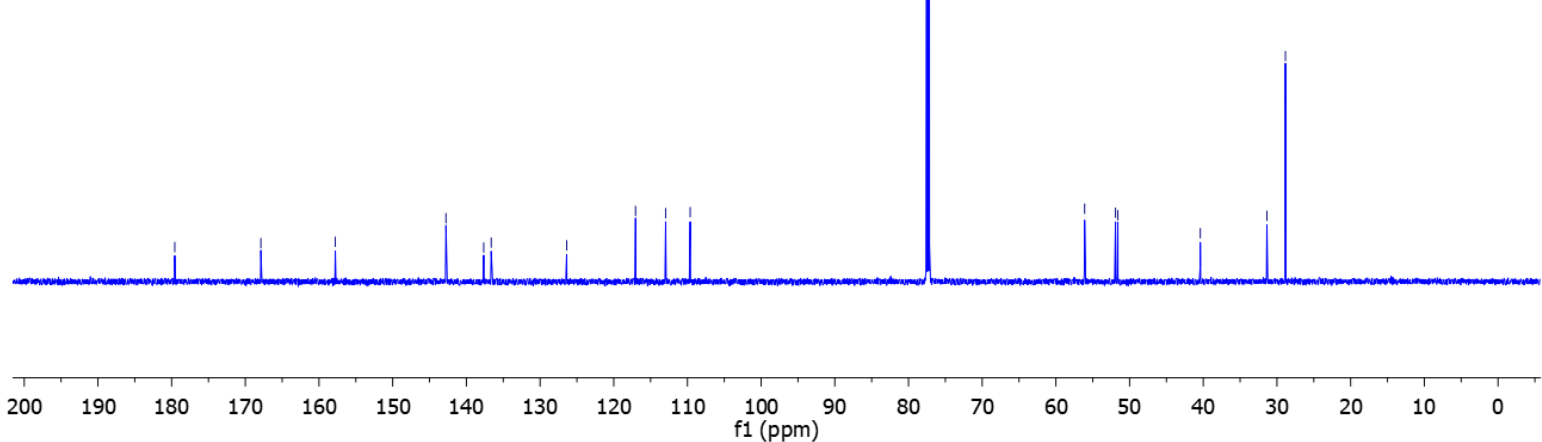
(E)-Methyl 3-(6-methoxy-1-pivaloylindolin-7-yl)acrylate (4fa):
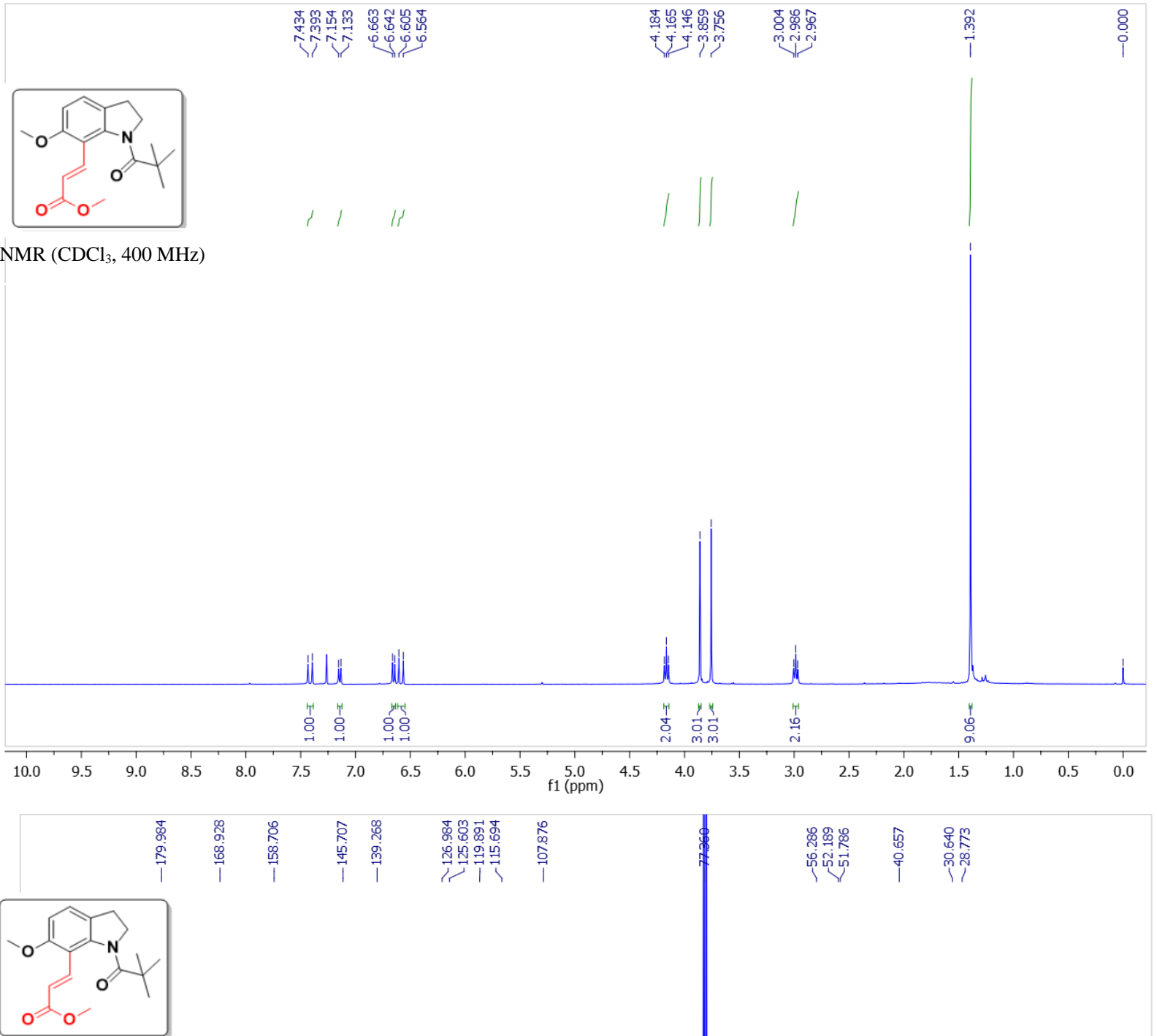

${ }^{13} \mathrm{C} \mathrm{NMR}\left(\mathrm{CDCl}_{3}, 100 \mathrm{MHz}\right)$

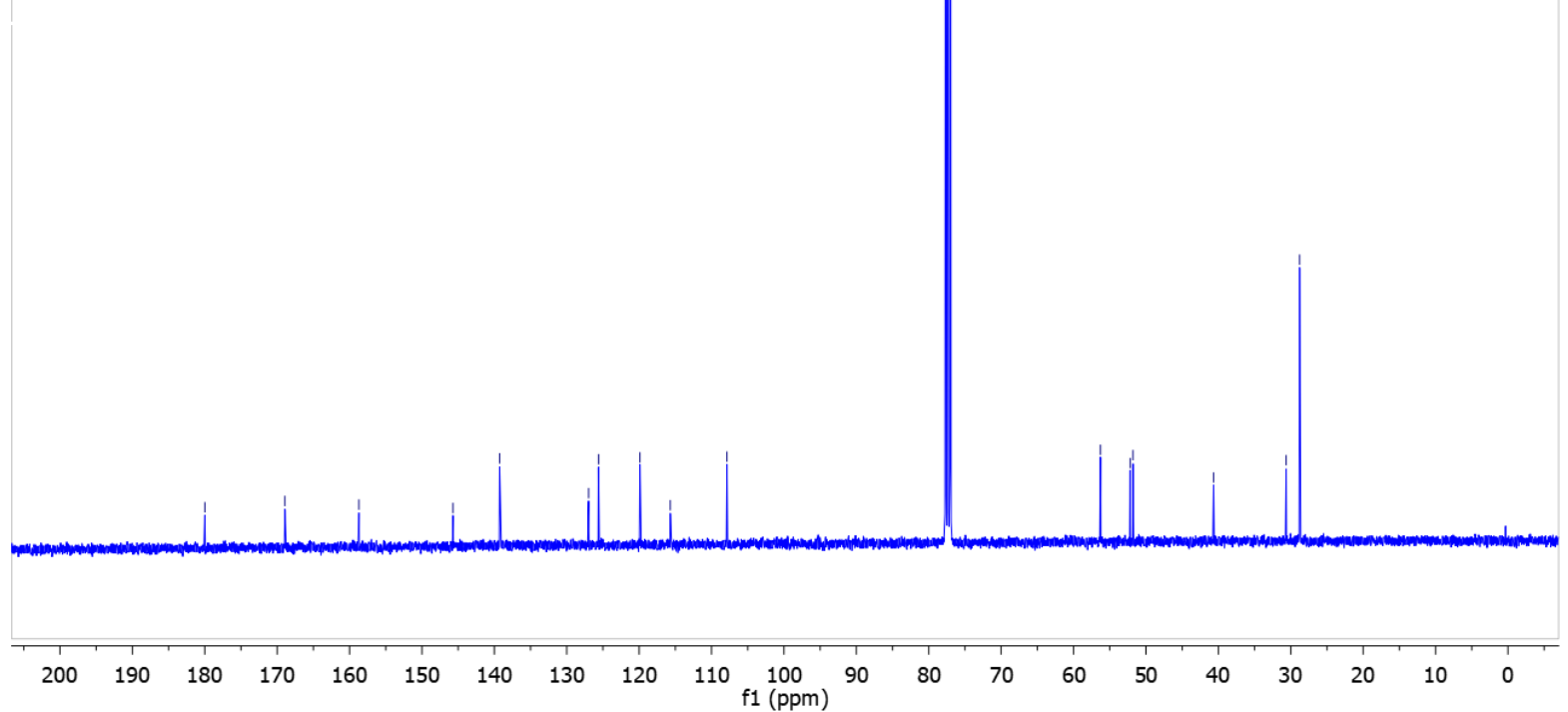


(E)-Methyl 3-(4-bromo-1-pivaloylindolin-7-yl)acrylate (4ga):
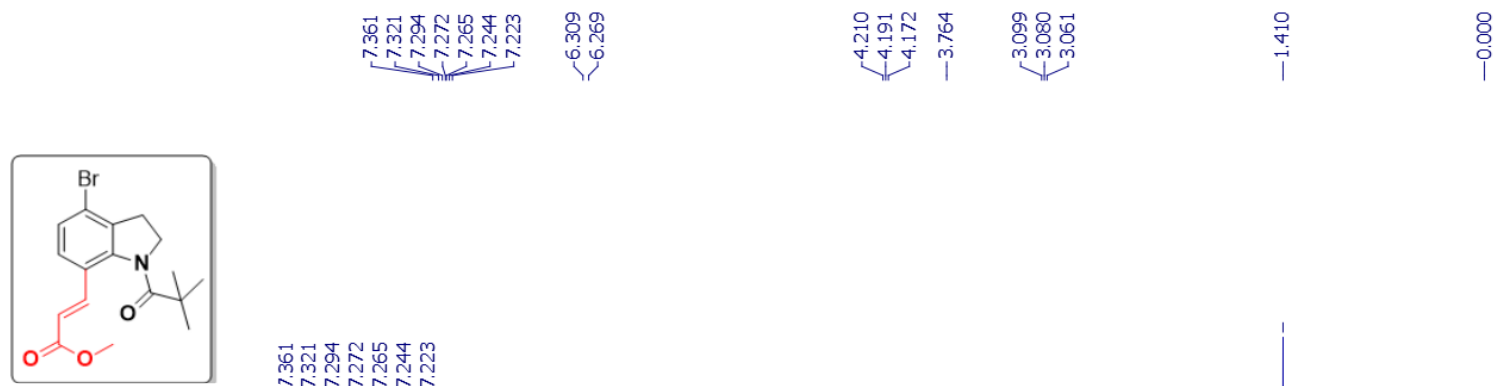

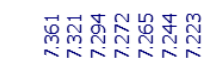
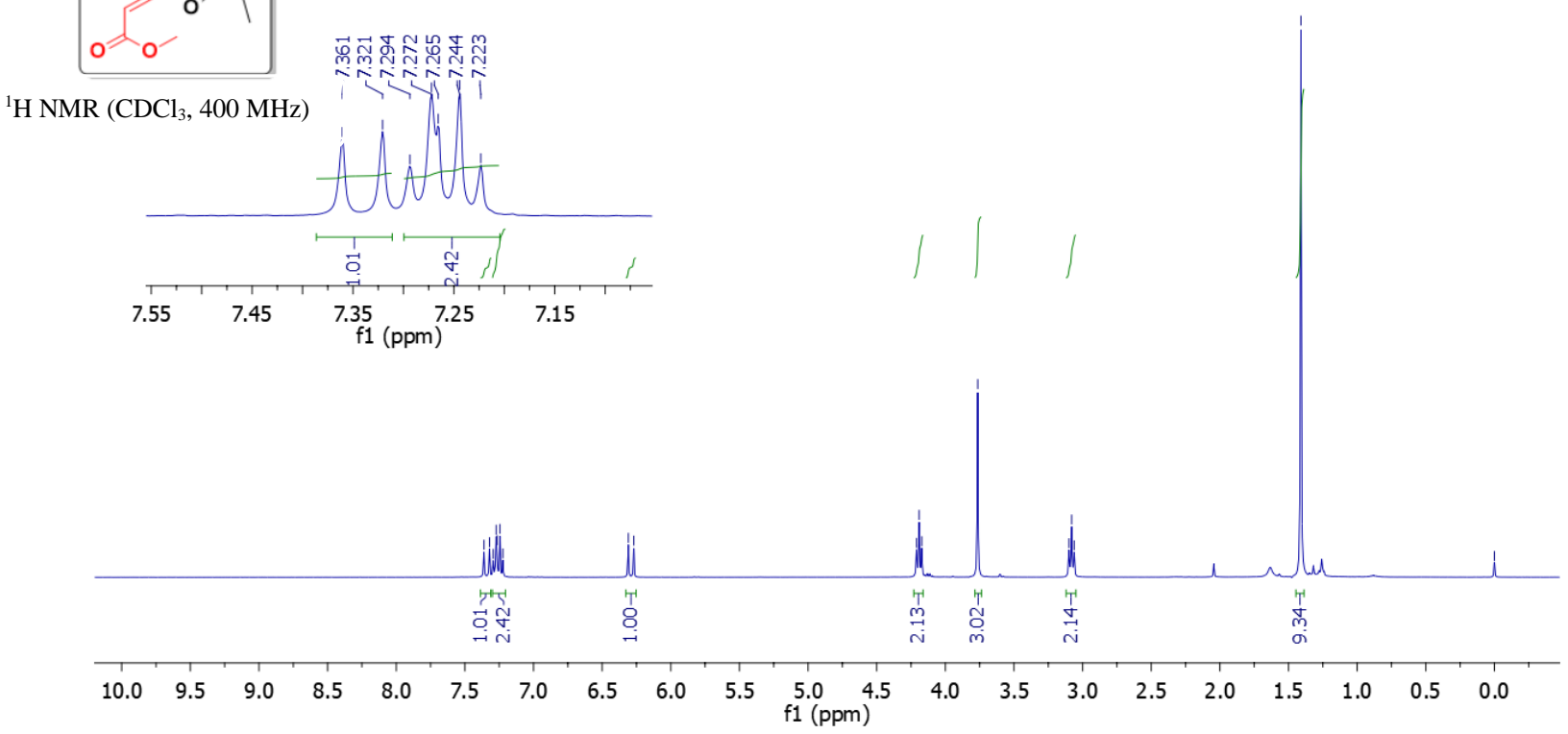

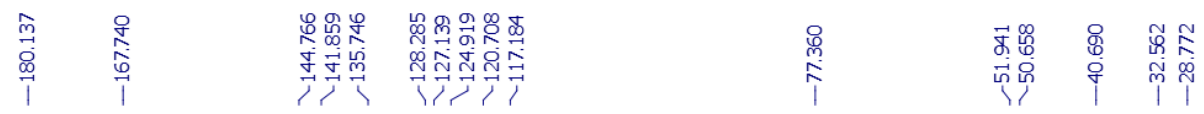

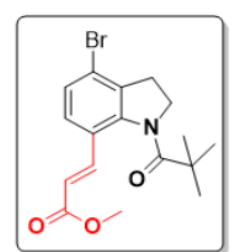

${ }^{13} \mathrm{C} \mathrm{NMR}\left(\mathrm{CDCl}_{3}, 100 \mathrm{MHz}\right)$

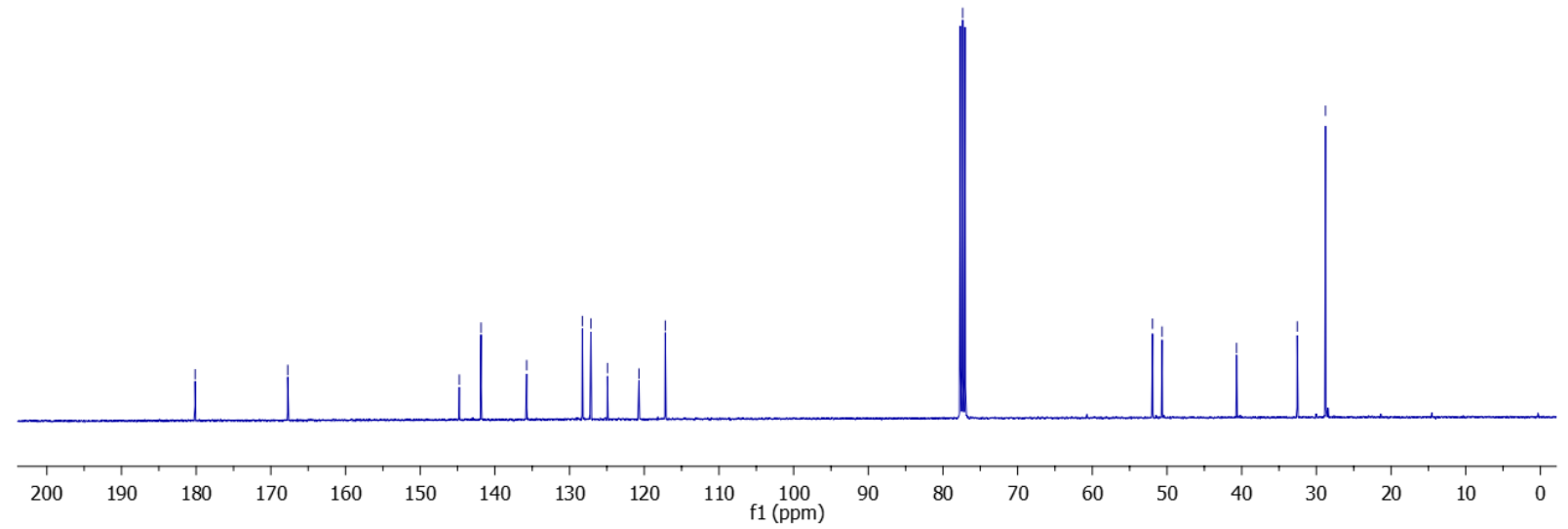


(E)-Methyl 3-(5-bromo-1-pivaloylindolin-7-yl)acrylate (4ha):

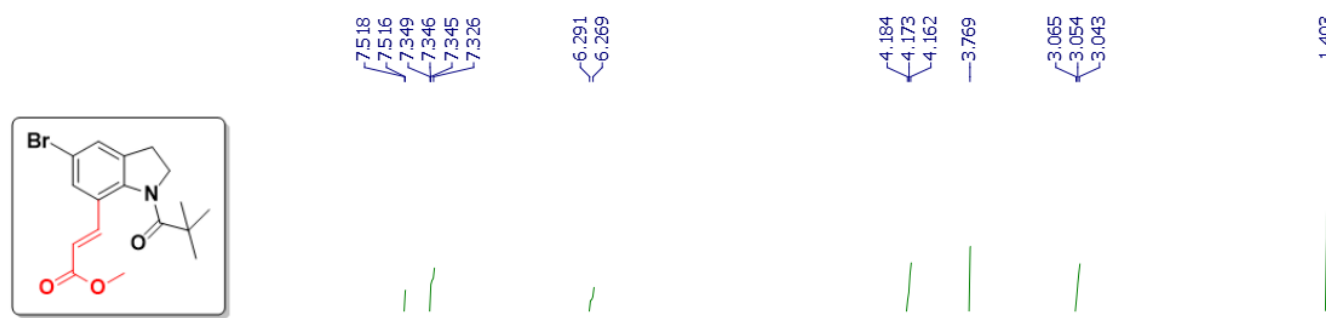

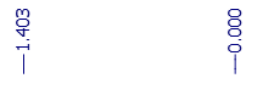

${ }^{\prime} \mathrm{H} \mathrm{NMR}\left(\mathrm{CDCl}_{3}, 700 \mathrm{MHz}\right)$
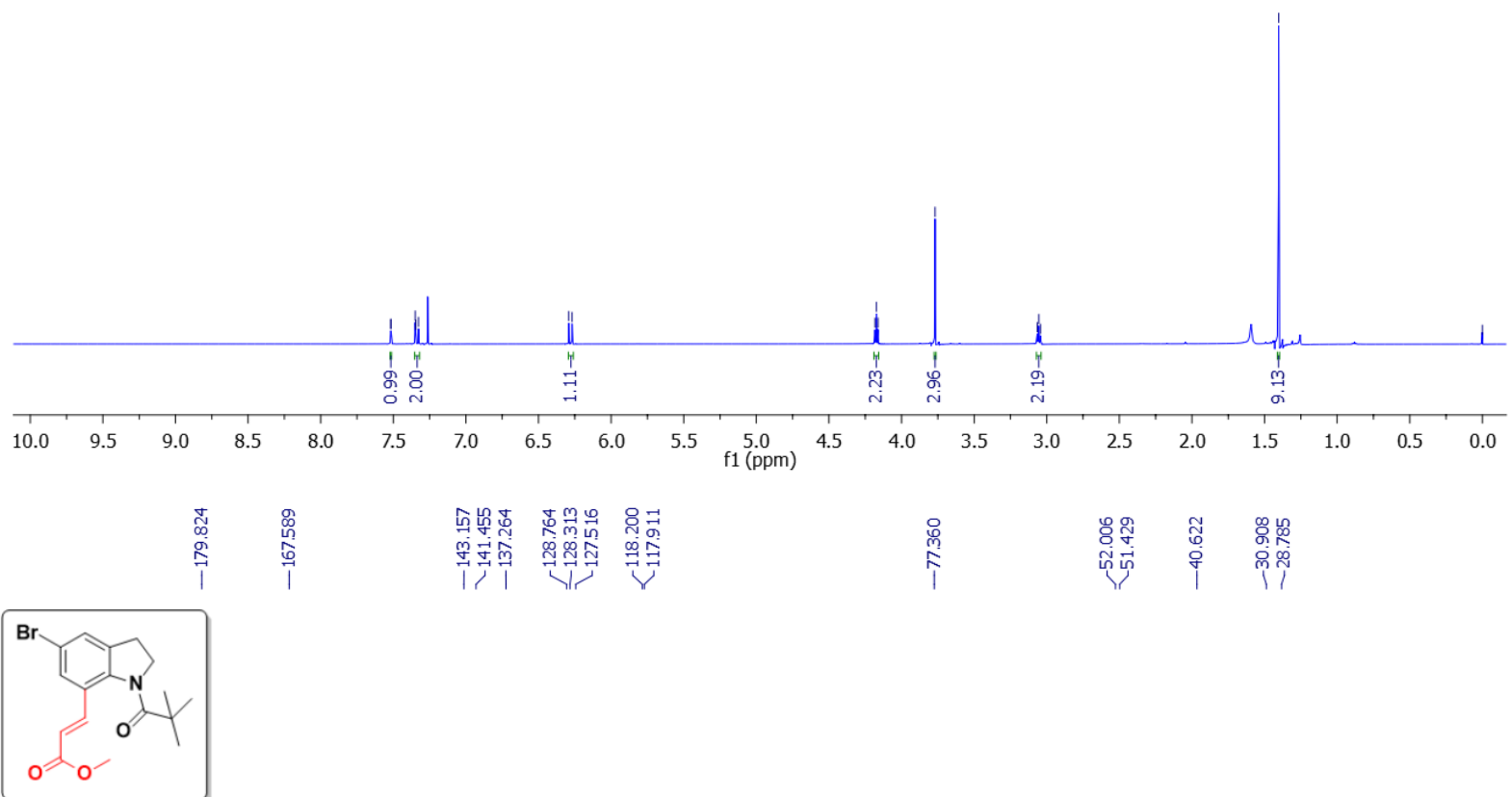

${ }^{13} \mathrm{C} \mathrm{NMR}\left(\mathrm{CDCl}_{3}, 175 \mathrm{MHz}\right)$

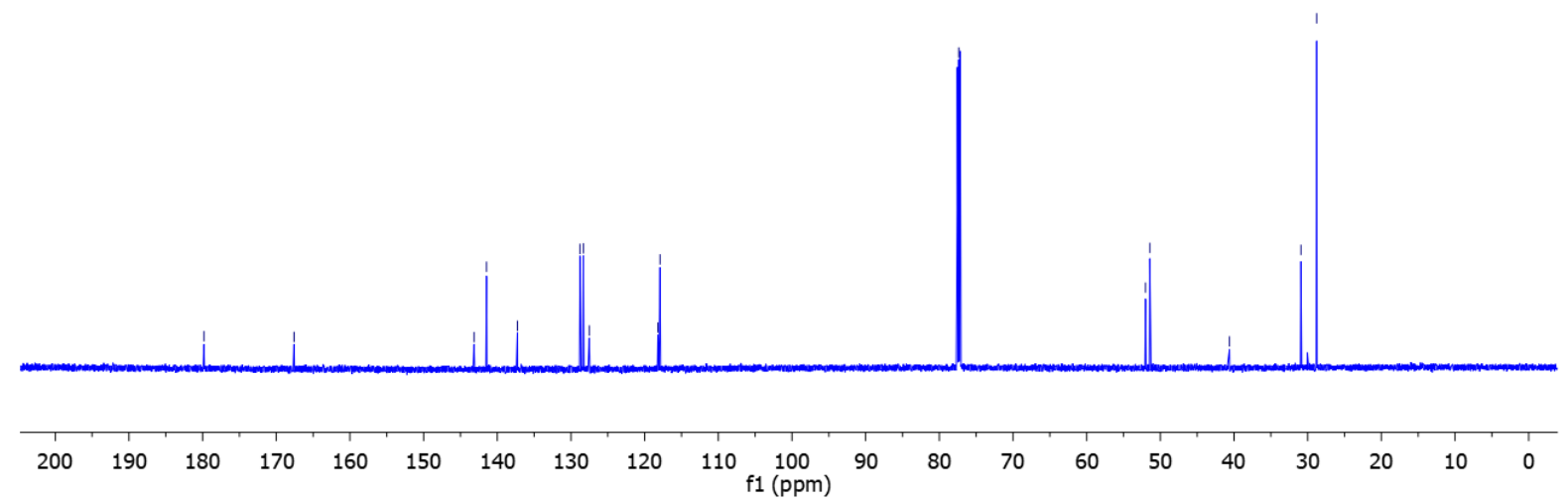


(E)-Methyl 3-(5-fluoro-1-pivaloylindolin-7-yl)acrylate (4ia):

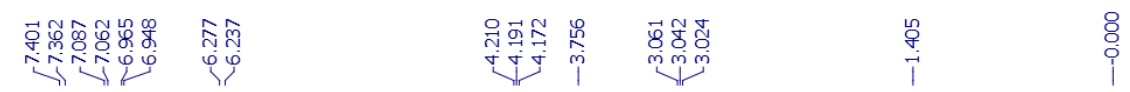

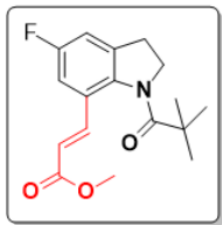

${ }^{1} \mathrm{H} \mathrm{NMR}\left(\mathrm{CDCl}_{3}, 400 \mathrm{MHz}\right)$

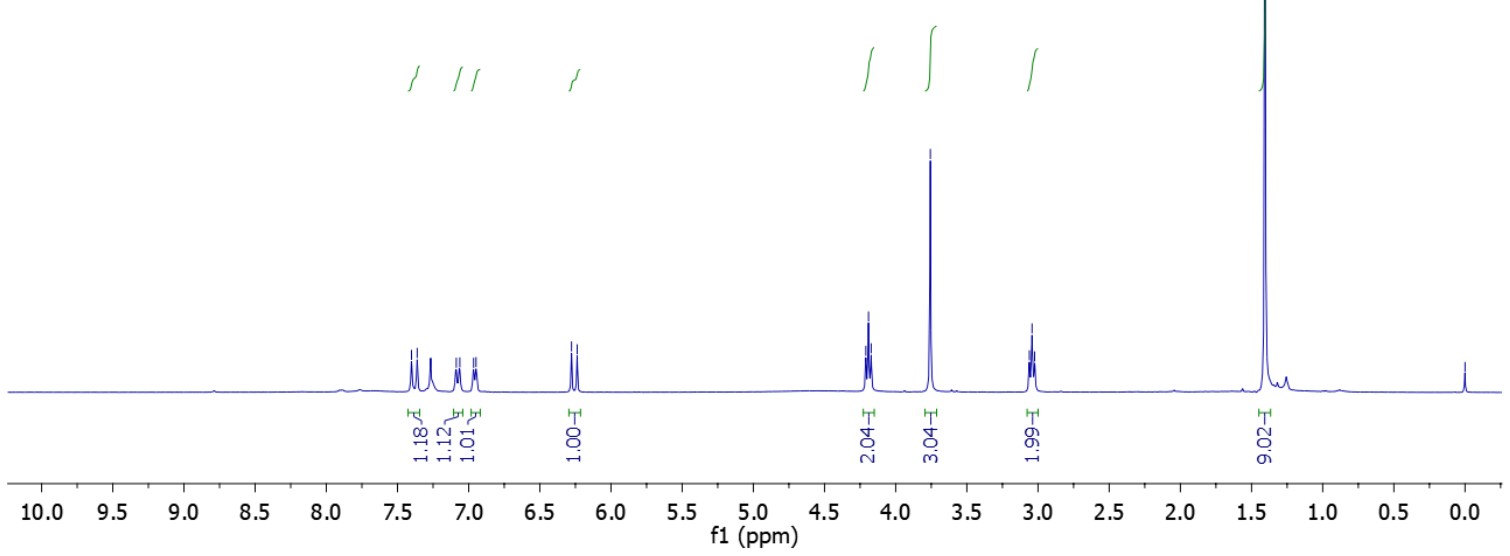

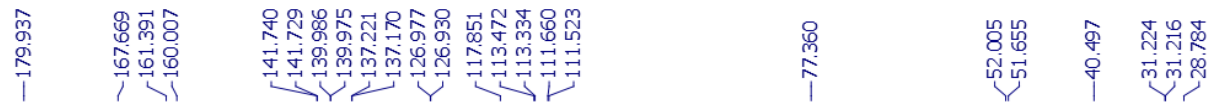

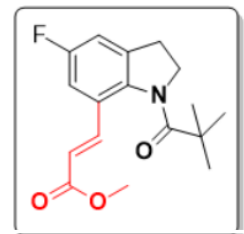

${ }^{13} \mathrm{C}$ NMR $\left(\mathrm{CDCl}_{3}, 175 \mathrm{MHz}\right)$

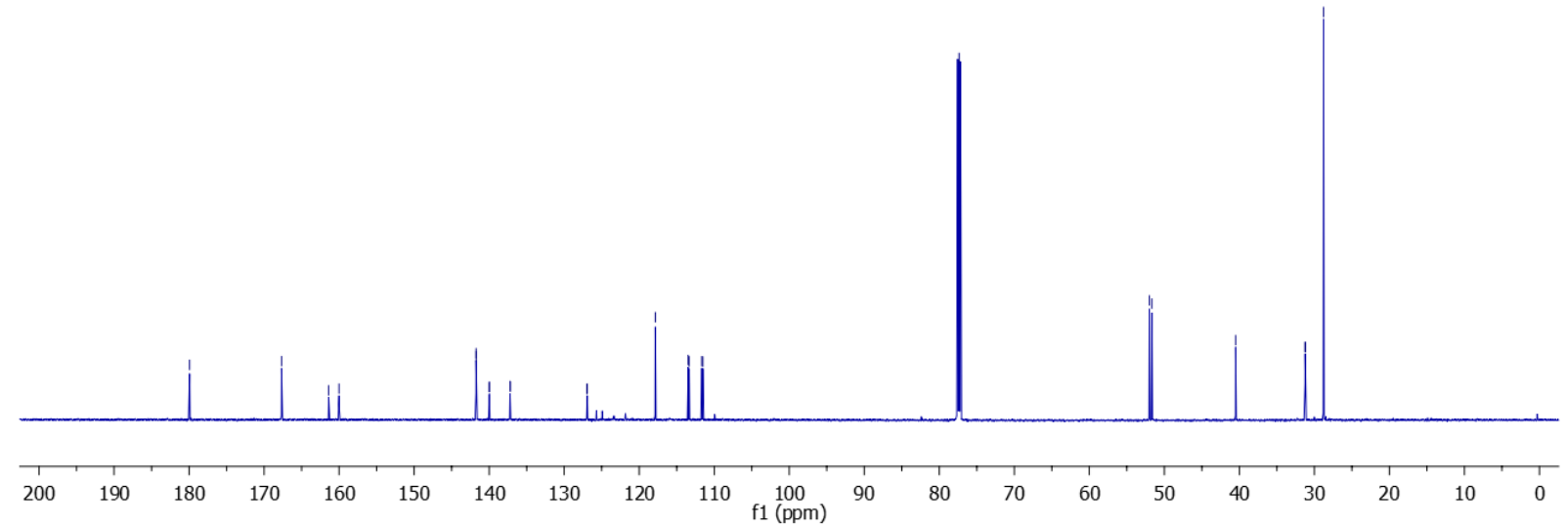


(E)-methyl 3-(5-chloro-1-pivaloylindolin-7-yl)acrylate (4iia):
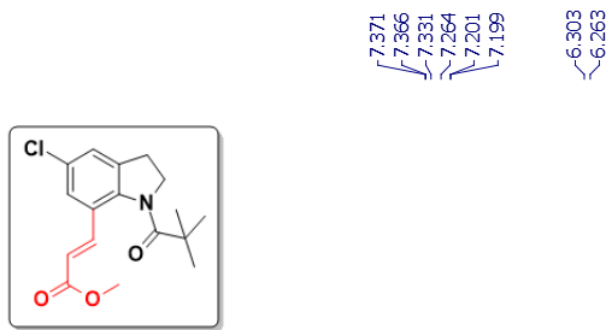

${ }^{1} \mathrm{H} \mathrm{NMR}\left(\mathrm{CDCl}_{3}, 400 \mathrm{MHz}\right)$

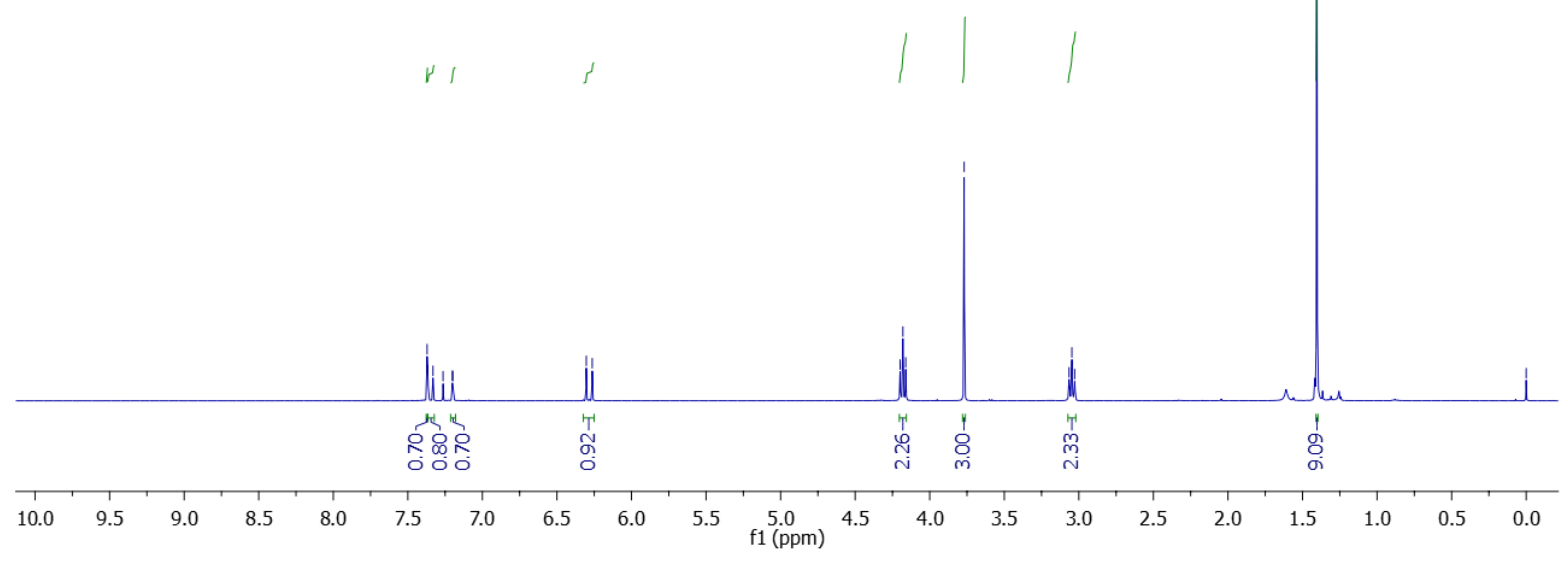

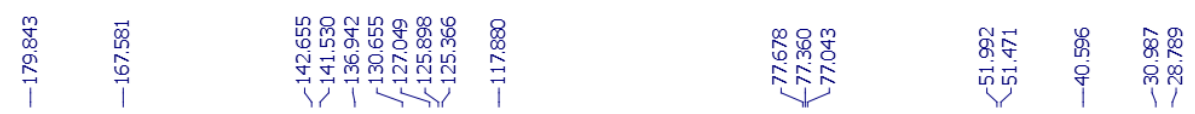

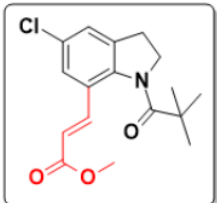

${ }^{13} \mathrm{C} \mathrm{NMR}\left(\mathrm{CDCl}_{3}, 100 \mathrm{MHz}\right)$
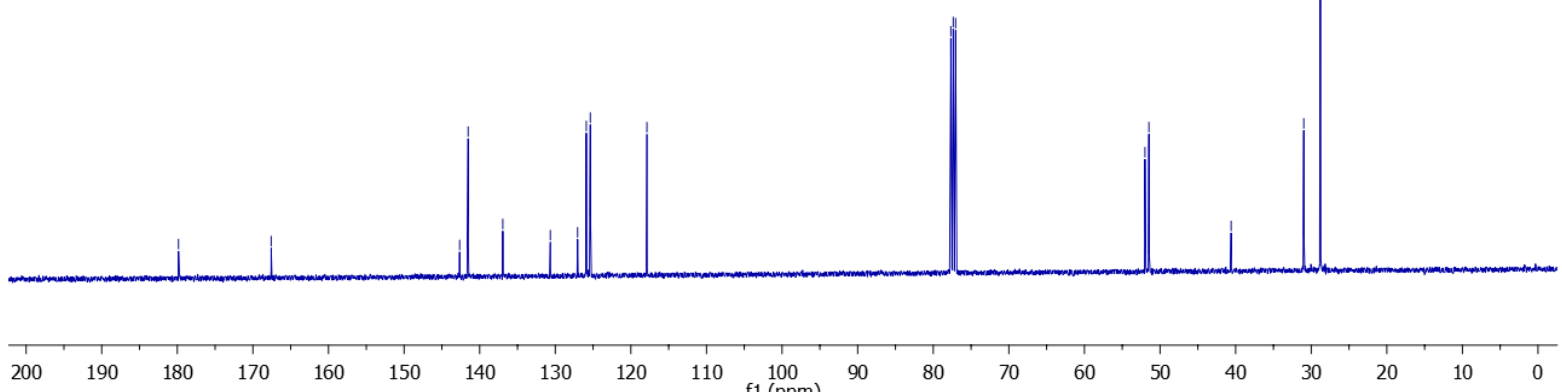
(E)-methyl 3-(5-iodo-1-pivaloylindolin-7-yl)acrylate (4iiia):
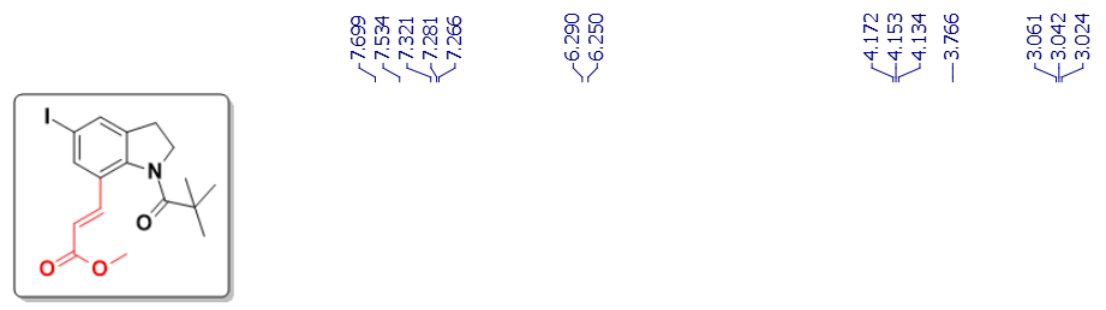

${ }^{1} \mathrm{H} \mathrm{NMR}\left(\mathrm{CDCl}_{3}, 400 \mathrm{MHz}\right)$
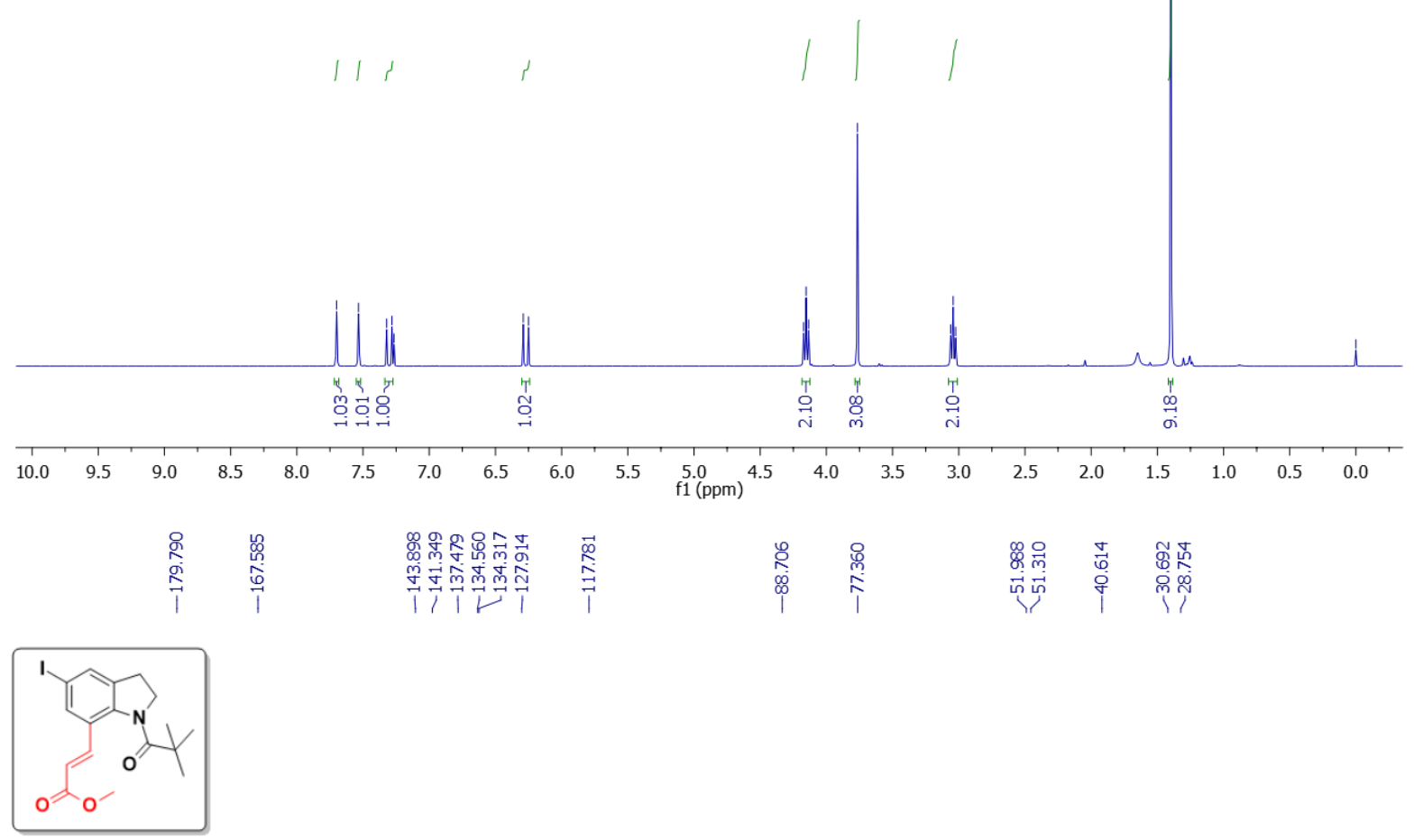

${ }^{13} \mathrm{C} \mathrm{NMR}\left(\mathrm{CDCl}_{3}, 100 \mathrm{MHz}\right)$

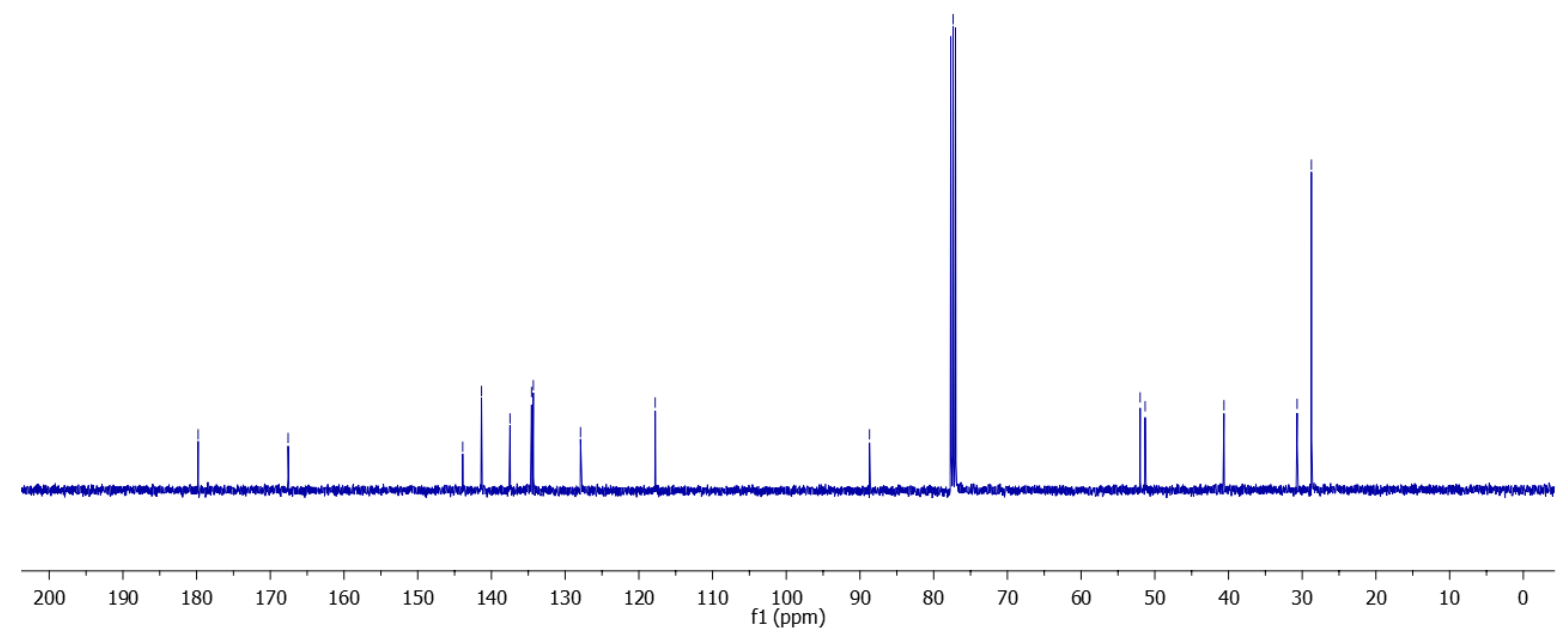


(E)-methyl 3-(5-nitro-1-pivaloylindolin-7-yl)acrylate (4ja):
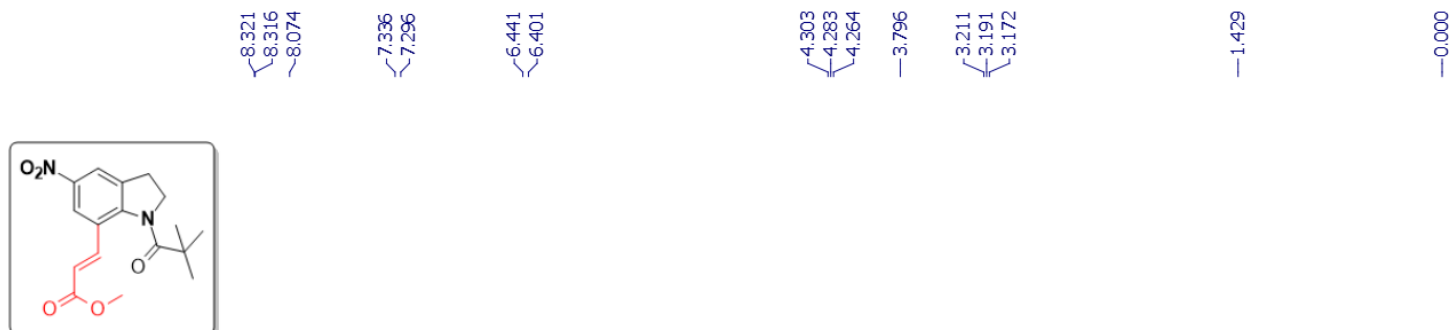

${ }^{1} \mathrm{H} \mathrm{NMR}\left(\mathrm{CDCl}_{3}, 400 \mathrm{MHz}\right)$

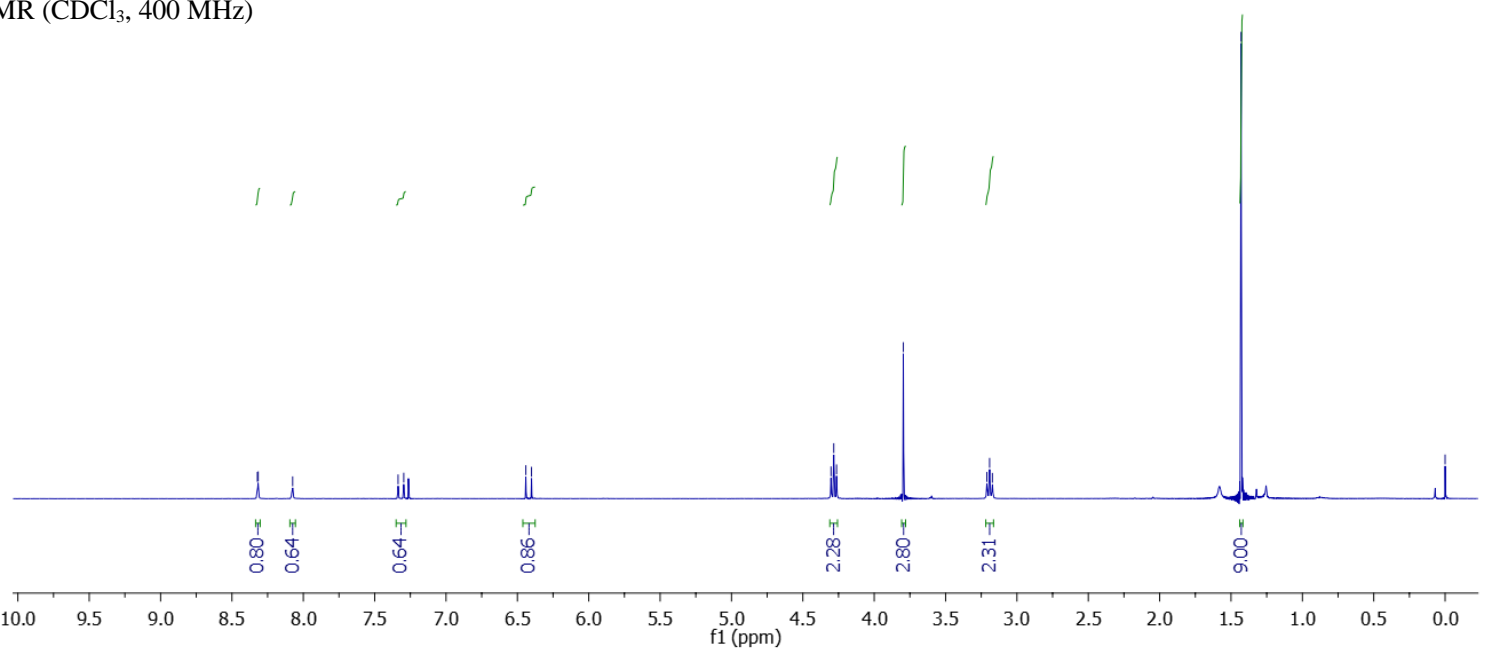

\begin{tabular}{|c|c|c|c|c|c|}
\hline 悉 & 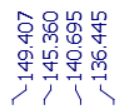 & 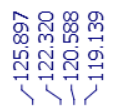 & $\stackrel{\substack{\infty \\
i}}{i}$ & 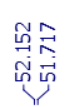 & \\
\hline
\end{tabular}

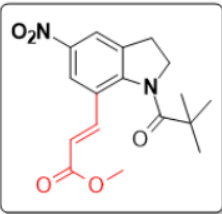

${ }^{13} \mathrm{C} \mathrm{NMR}\left(\mathrm{CDCl}_{3}, 100 \mathrm{MHz}\right)$
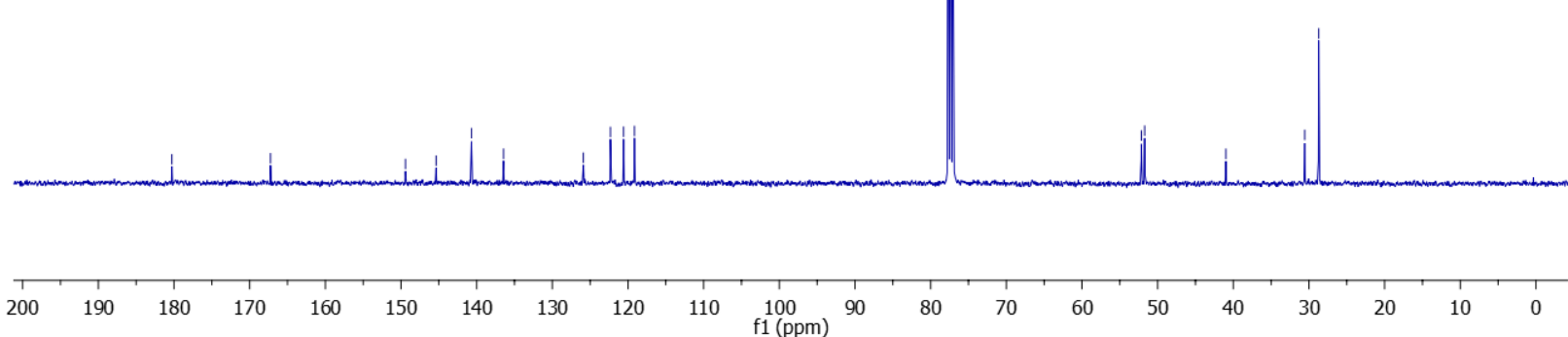
(E)-Methyl 3-(1-acetylindolin-7-yl)acrylate (4ma):

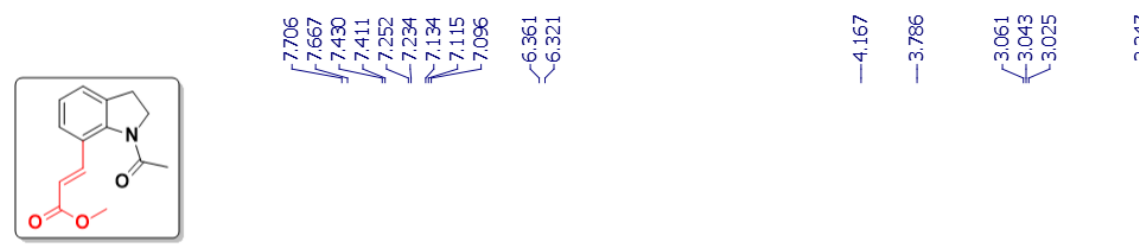

$\begin{array}{ll}\stackrel{f}{N} & 8 \\ i & O \\ i\end{array}$

${ }^{1} \mathrm{H} \mathrm{NMR}\left(\mathrm{CDCl}_{3}, 400 \mathrm{MHz}\right), 298 \mathrm{~K}$

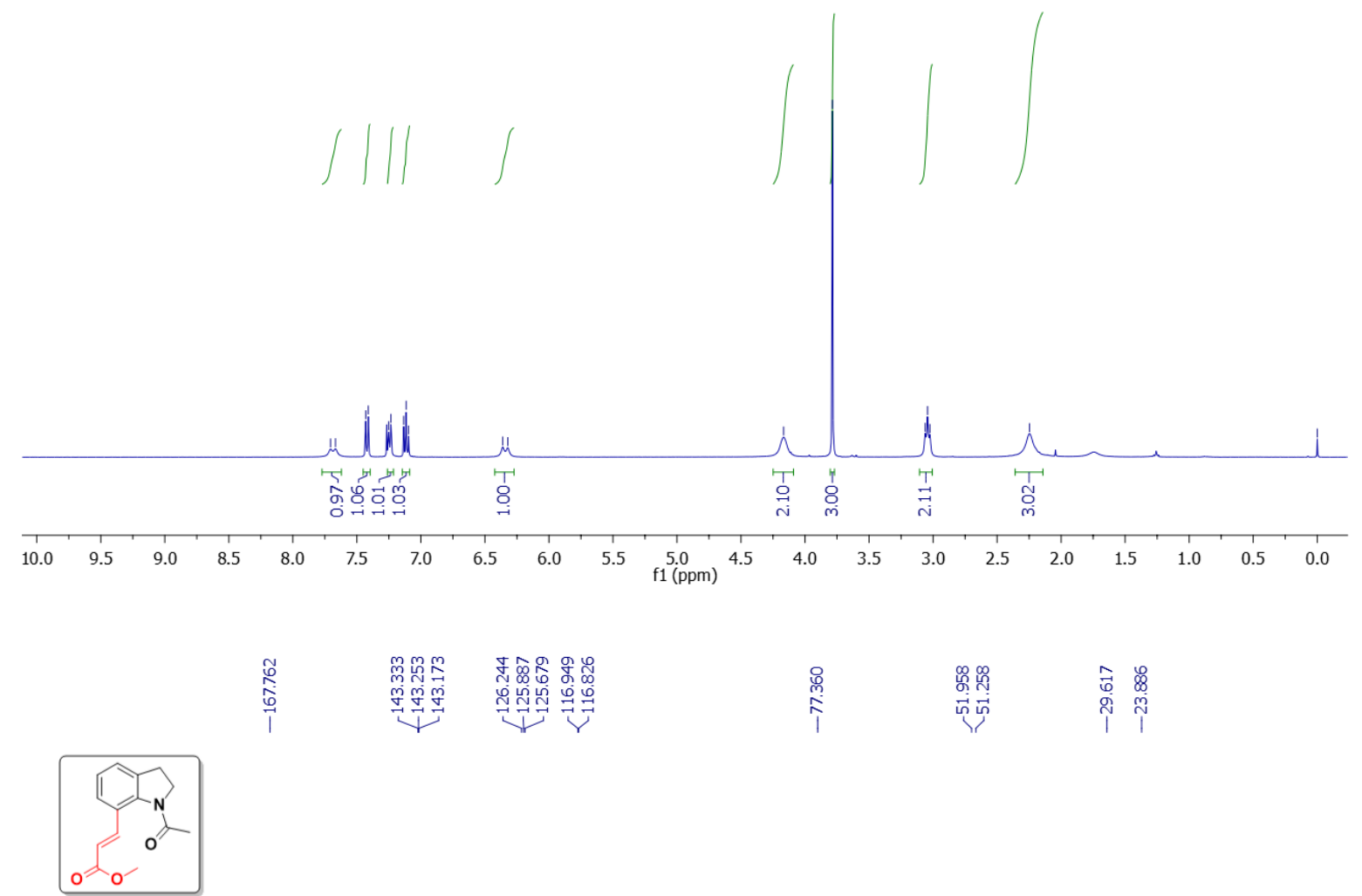

${ }^{13} \mathrm{C}$ NMR (CDCl, $\left.100 \mathrm{MHz}\right), 298 \mathrm{~K}$

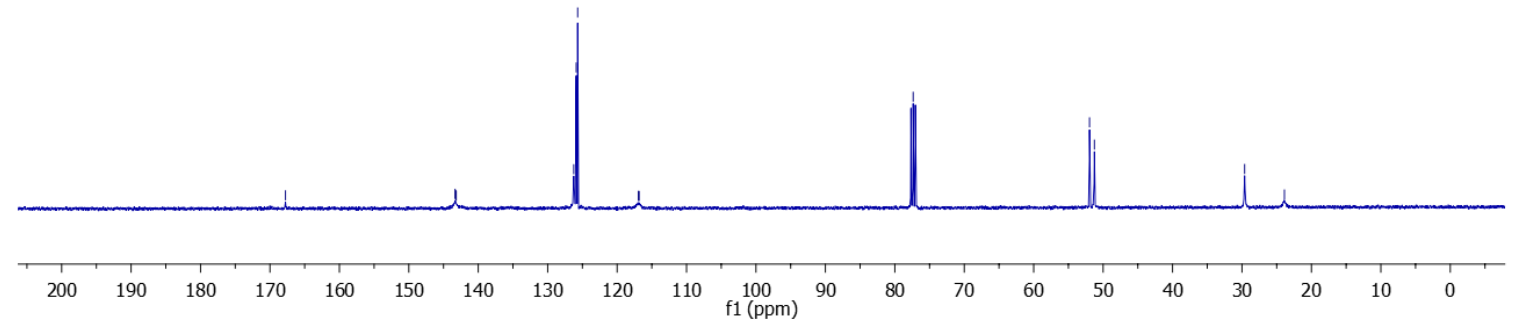


(E)-Methyl 3-(1-benzoylindolin-7-yl)acrylate (4na):
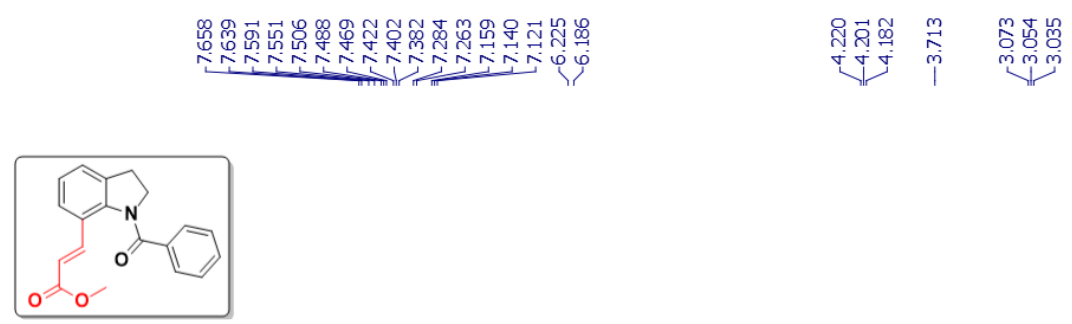

${ }^{1} \mathrm{H} \mathrm{NMR}\left(\mathrm{CDCl}_{3}, 400 \mathrm{MHz}\right)$

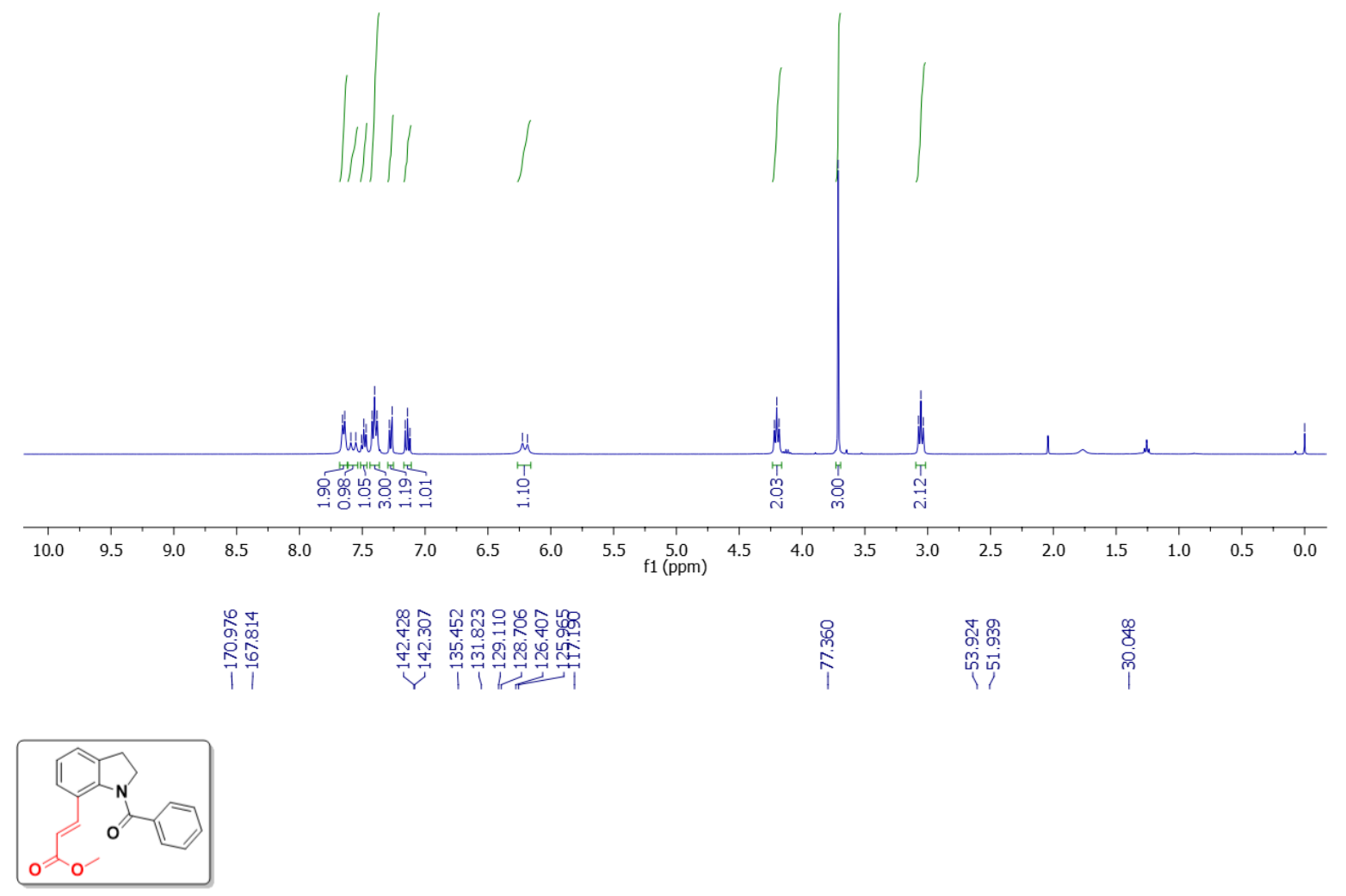

${ }^{13} \mathrm{C}$ NMR $\left(\mathrm{CDCl}_{3}, 100 \mathrm{MHz}\right)$

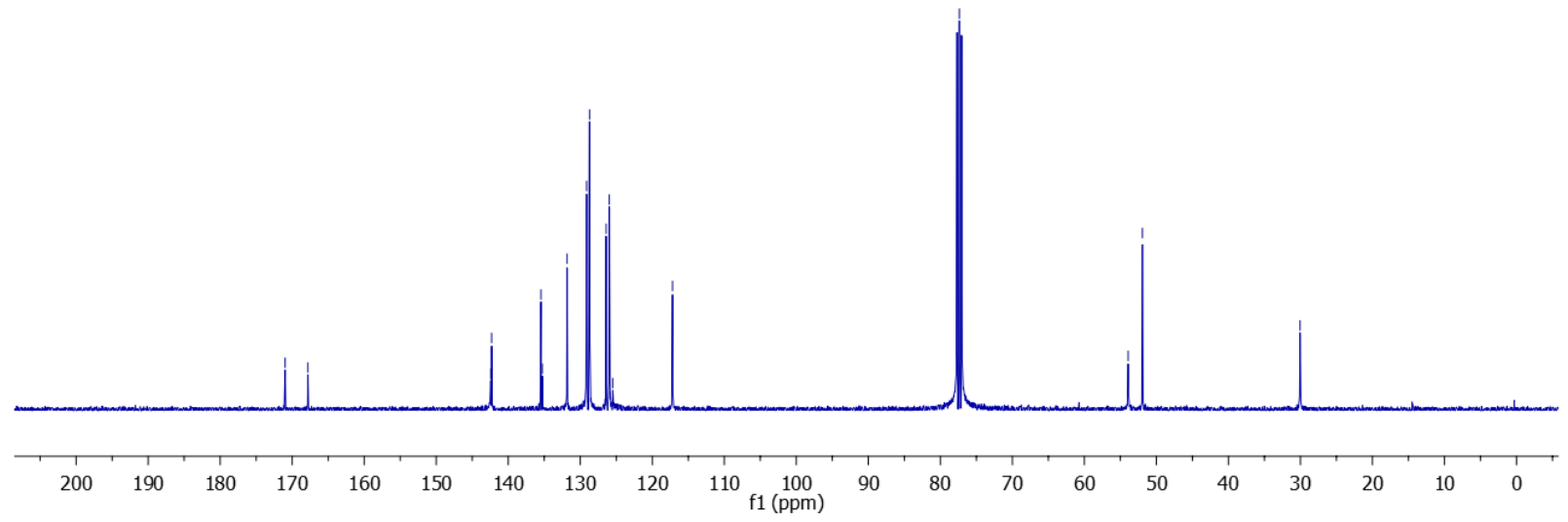


(E)-Ethyl 3-(1-pivaloylindolin-7-yl)acrylate (4ab):

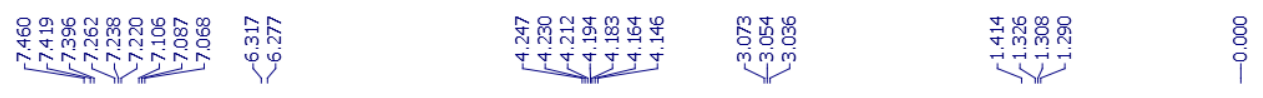
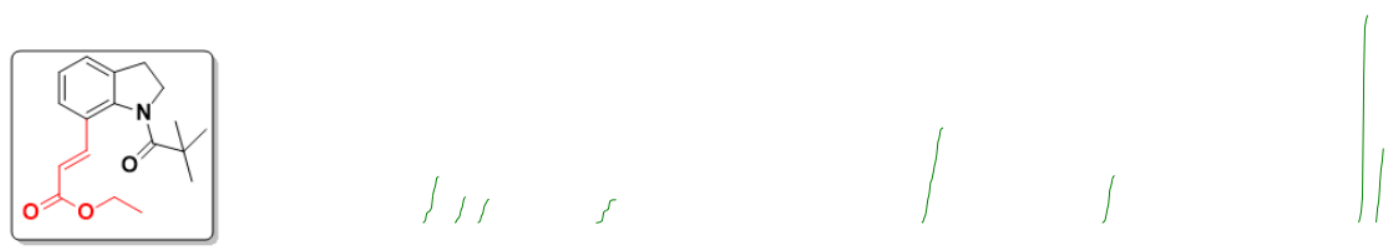

${ }^{1} \mathrm{H} \mathrm{NMR}\left(\mathrm{CDCl}_{3}, 400 \mathrm{MHz}\right)$
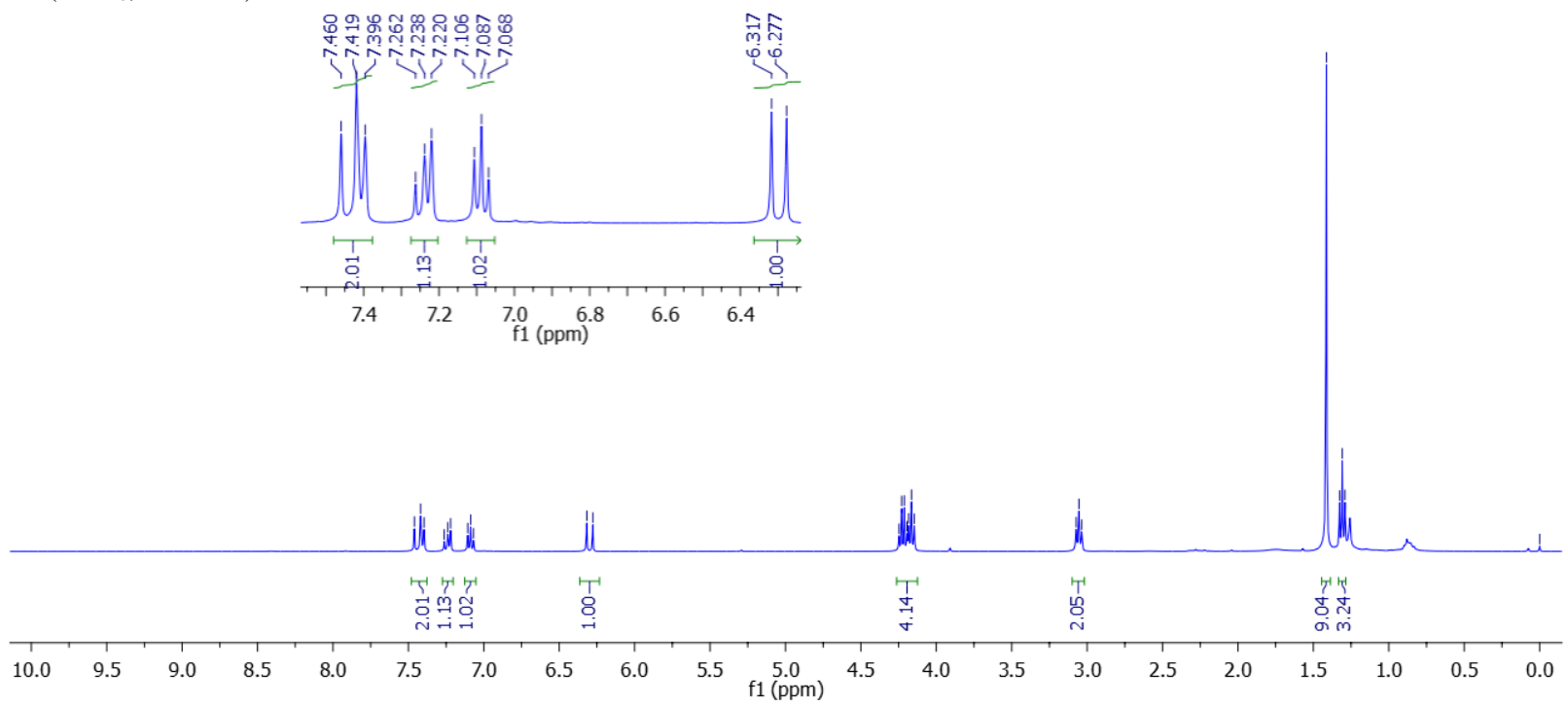

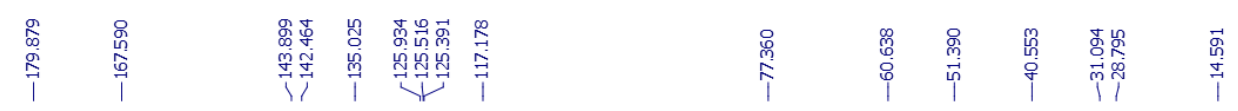

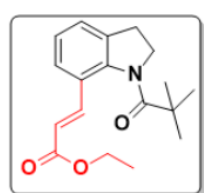

${ }^{13} \mathrm{C} \mathrm{NMR}\left(\mathrm{CDCl}_{3}, 100 \mathrm{MHz}\right)$

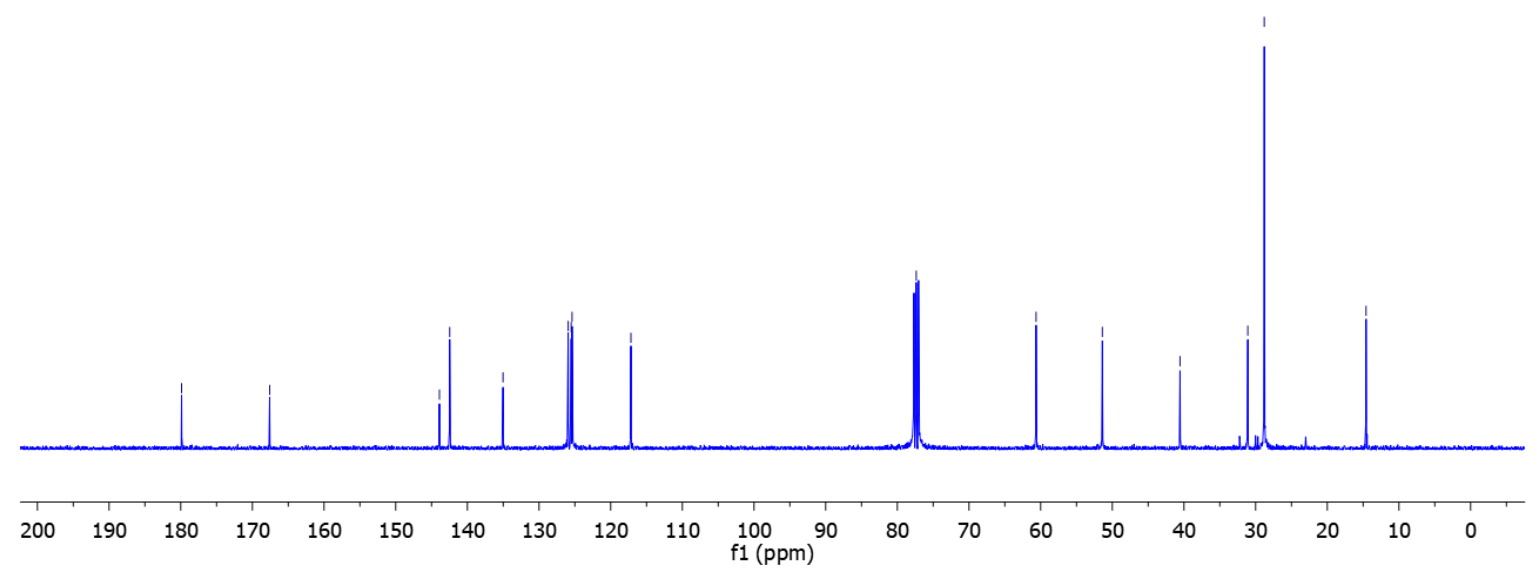


(E)-Butyl 3-(1-pivaloylindolin-7-yl)acrylate (4ac):

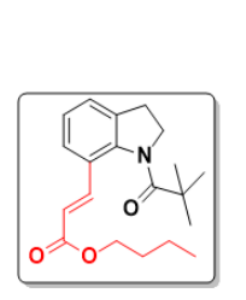

${ }^{1} \mathrm{H} \mathrm{NMR}\left(\mathrm{CDCl}_{3}, 400 \mathrm{MHz}\right)$
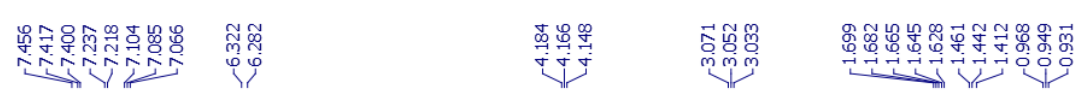

8
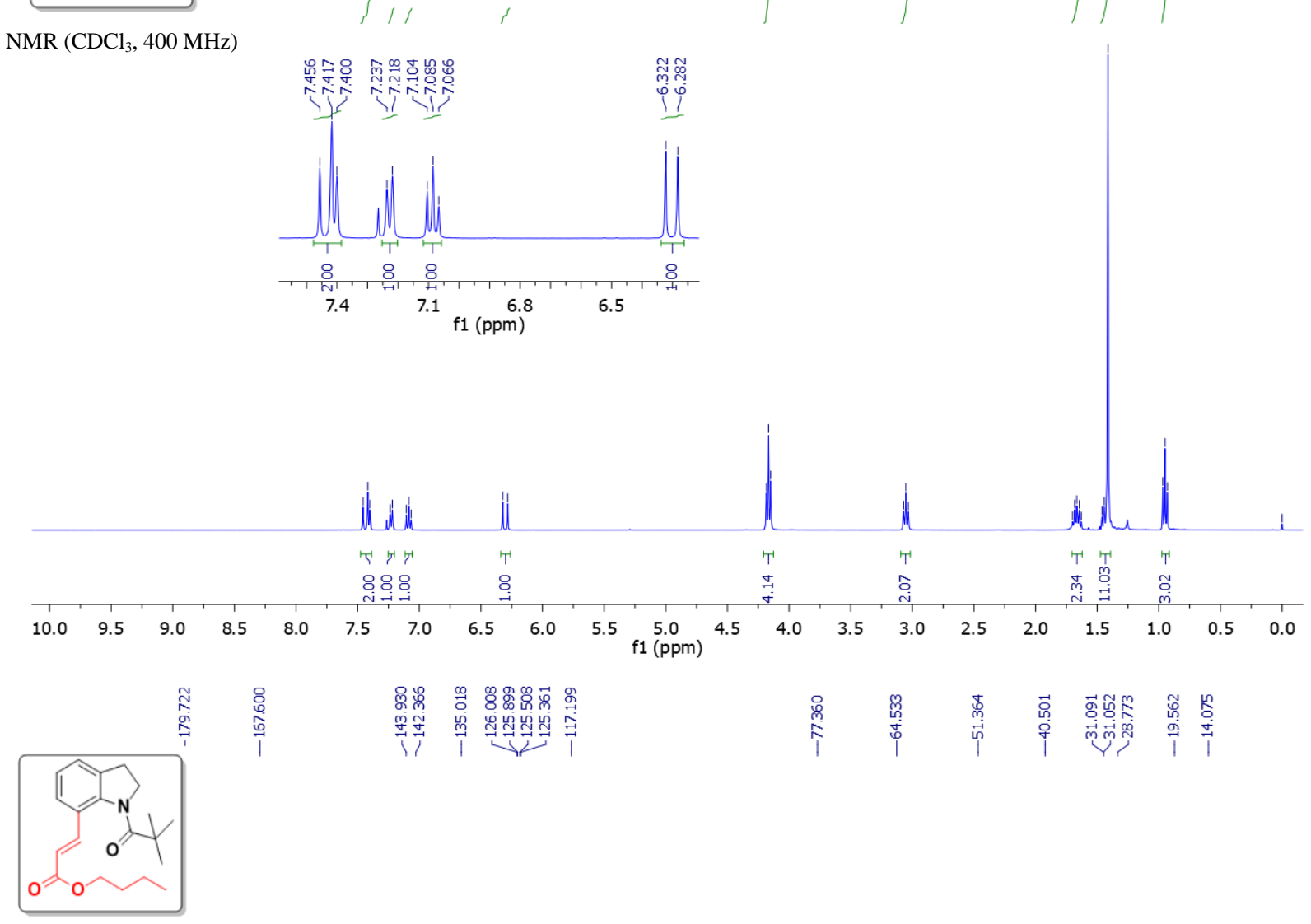

${ }^{13} \mathrm{C} \mathrm{NMR}\left(\mathrm{CDCl}_{3}, 100 \mathrm{MHz}\right)$

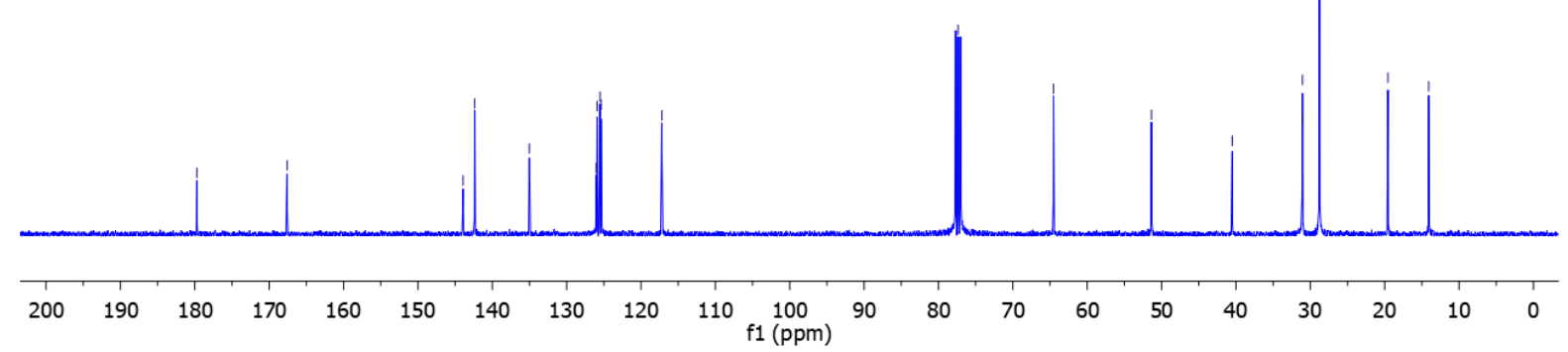


(E)-Tert-butyl 3-(1-pivaloylindolin-7-yl)acrylate (4ad):

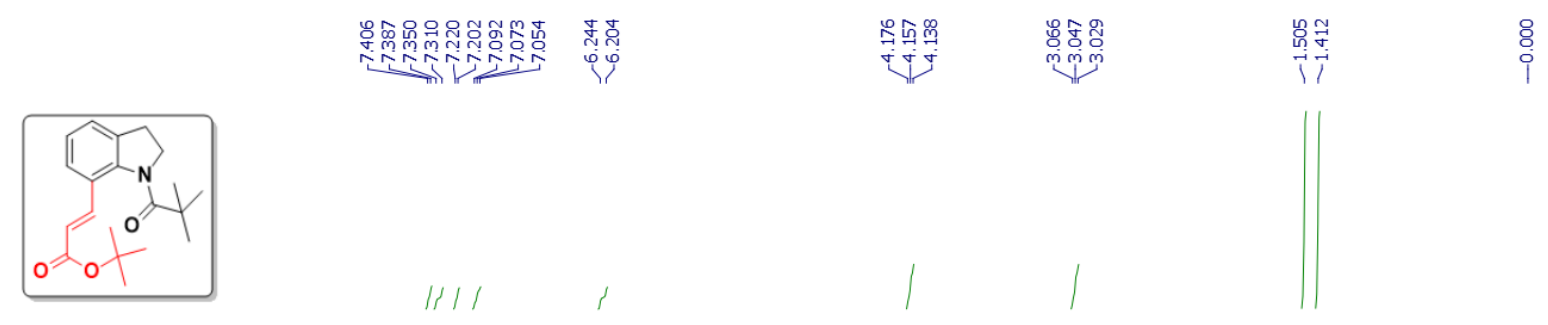

${ }^{1} \mathrm{H} \mathrm{NMR}\left(\mathrm{CDCl}_{3}, 400 \mathrm{MHz}\right)$

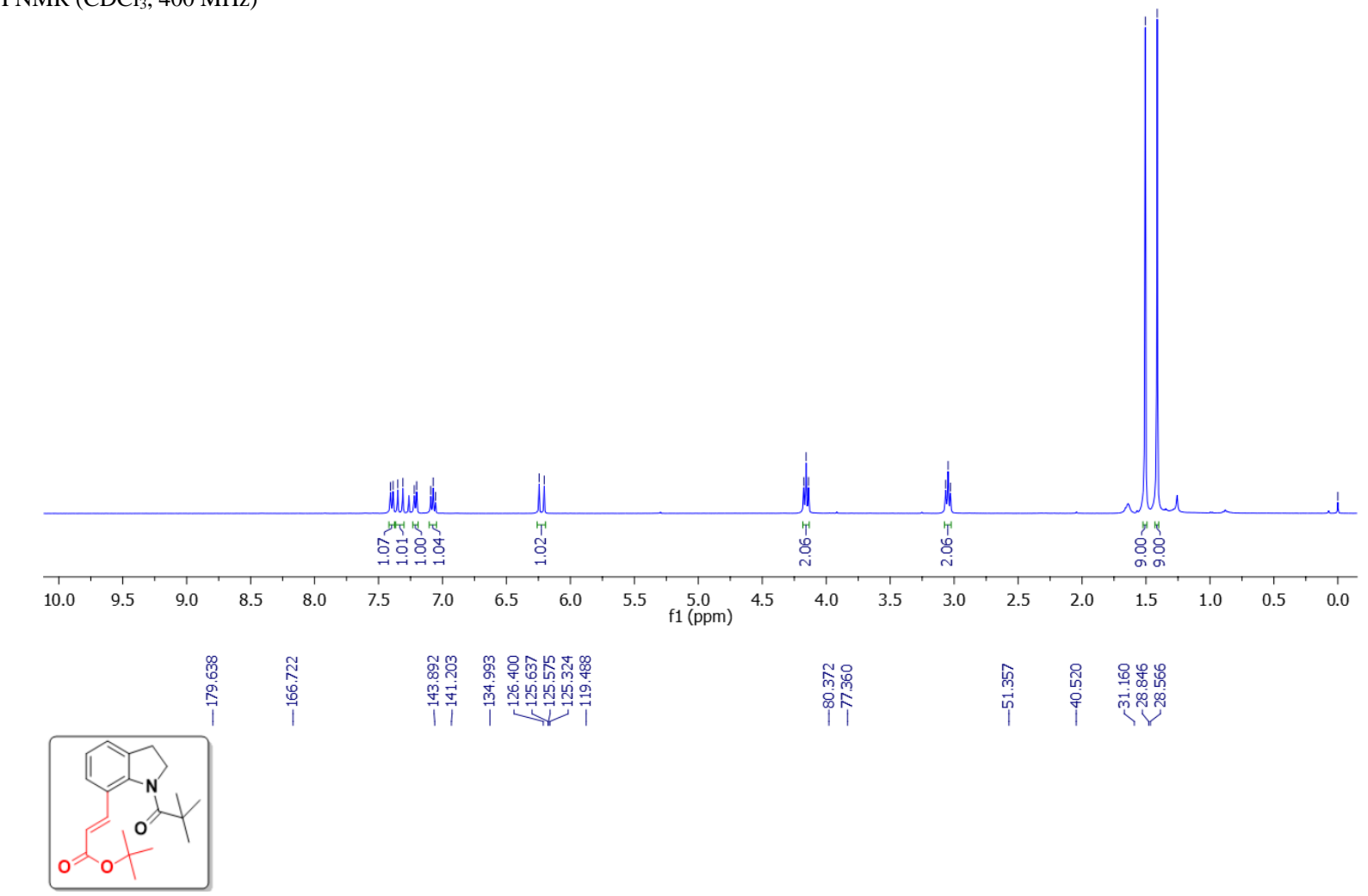

${ }^{13} \mathrm{C} \mathrm{NMR}\left(\mathrm{CDCl}_{3}, 100 \mathrm{MHz}\right)$

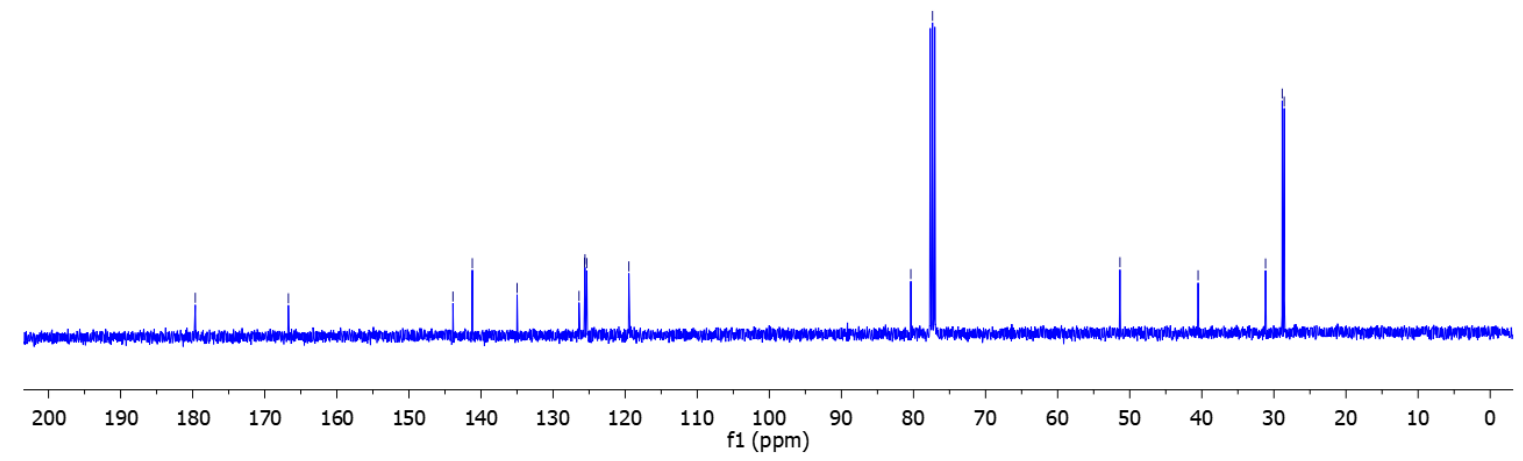


(E)-3-(1-Pivaloylindolin-7-yl)acrylic acid (4ae):
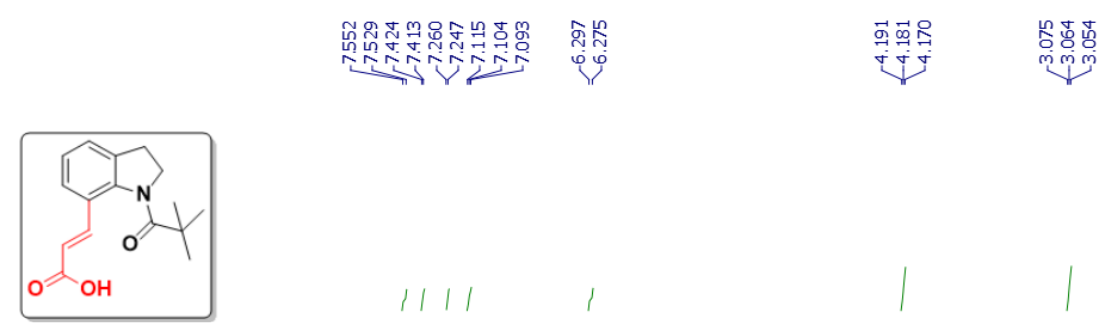

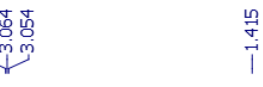

${ }^{1} \mathrm{H} \mathrm{NMR}\left(\mathrm{CDCl}_{3}, 700 \mathrm{MHz}\right)$
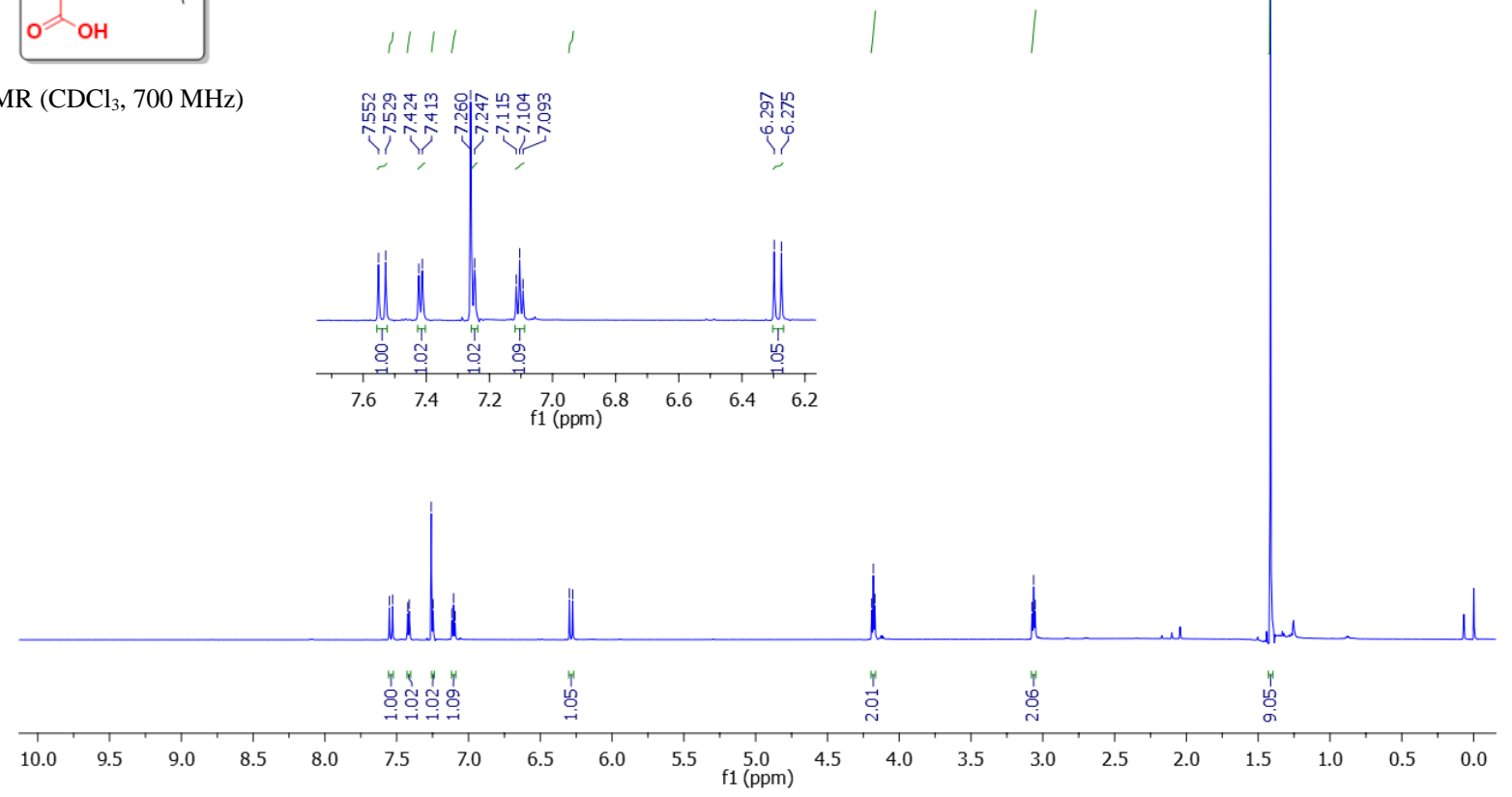

\begin{tabular}{|c|c|c|c|}
\hline 怘 & 量 & 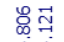 & ষ্ \\
\hline$\stackrel{g}{\stackrel{2}{\leftrightarrows}}$ & $\stackrel{-1}{5}$ & 尃尃 & 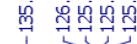 \\
\hline
\end{tabular}

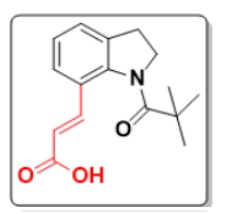

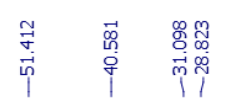

${ }^{13} \mathrm{C} \mathrm{NMR}\left(\mathrm{CDCl}_{3}, 175 \mathrm{MHz}\right)$

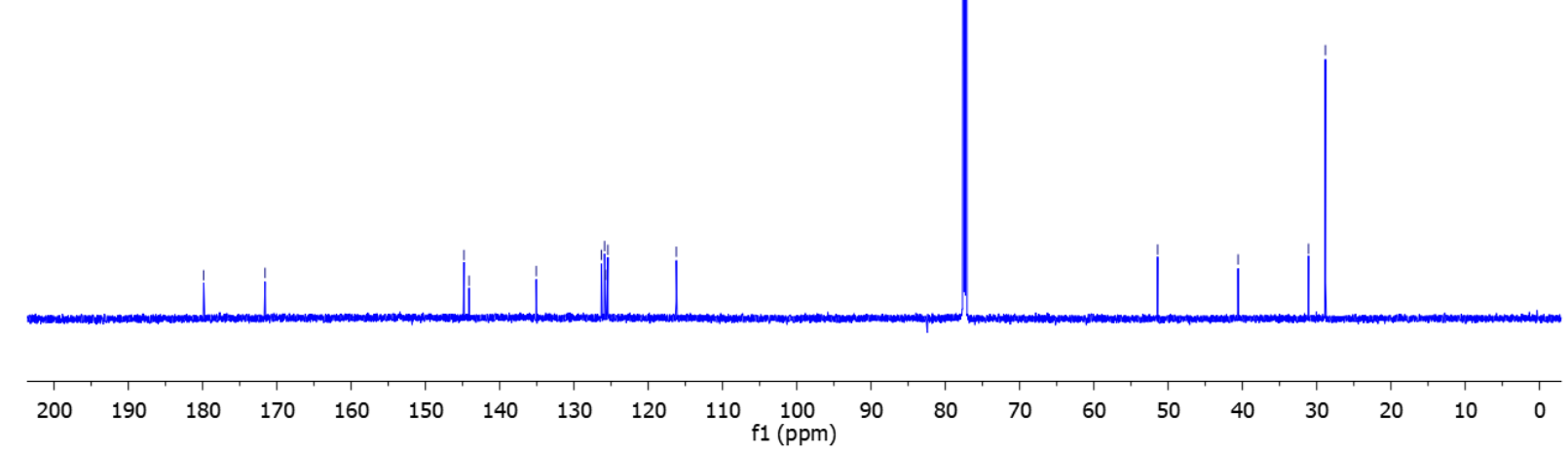


(E)-Phenyl 3-(1-pivaloylindolin-7-yl)acrylate (4af):

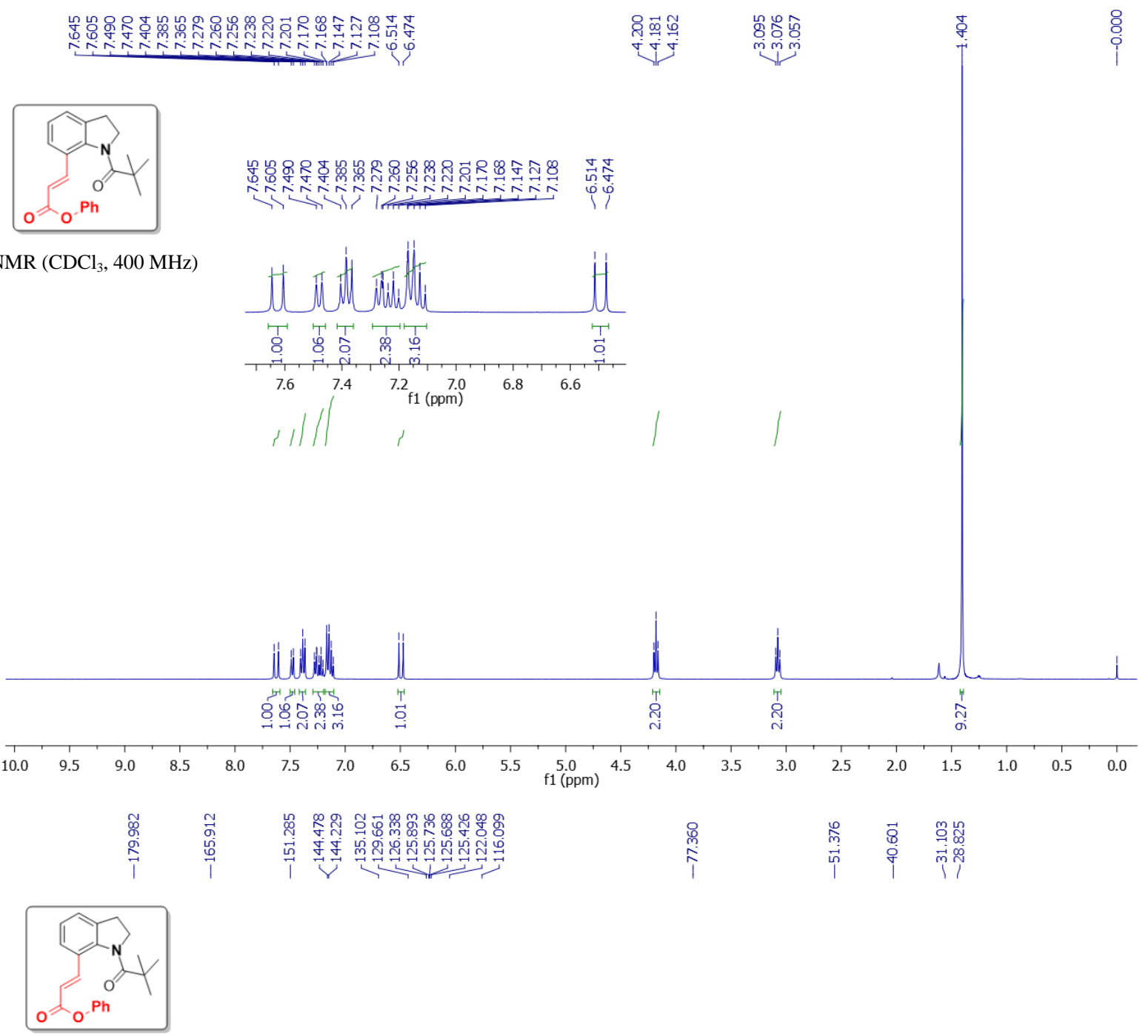

${ }^{13} \mathrm{C} \mathrm{NMR}\left(\mathrm{CDCl}_{3}, 100 \mathrm{MHz}\right)$

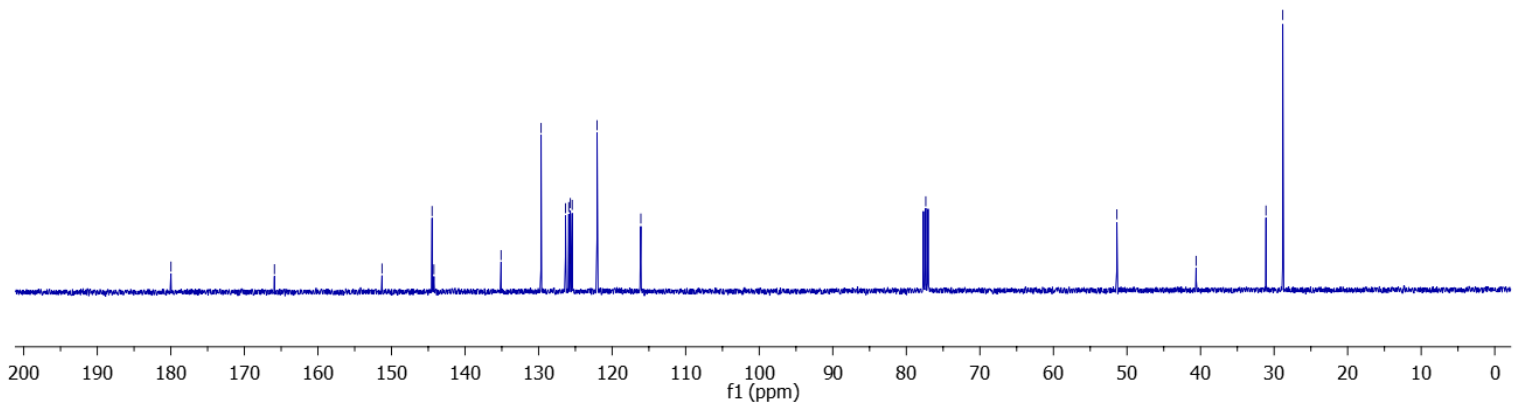


(E)-13-Methyl-17-oxo-7,8,9,11,12,13,14,15,16,17-decahydro-6H-cyclopenta[a]phenanthren-2-yl 3-(1-pivaloylindolin-7yl)acrylate (4al):

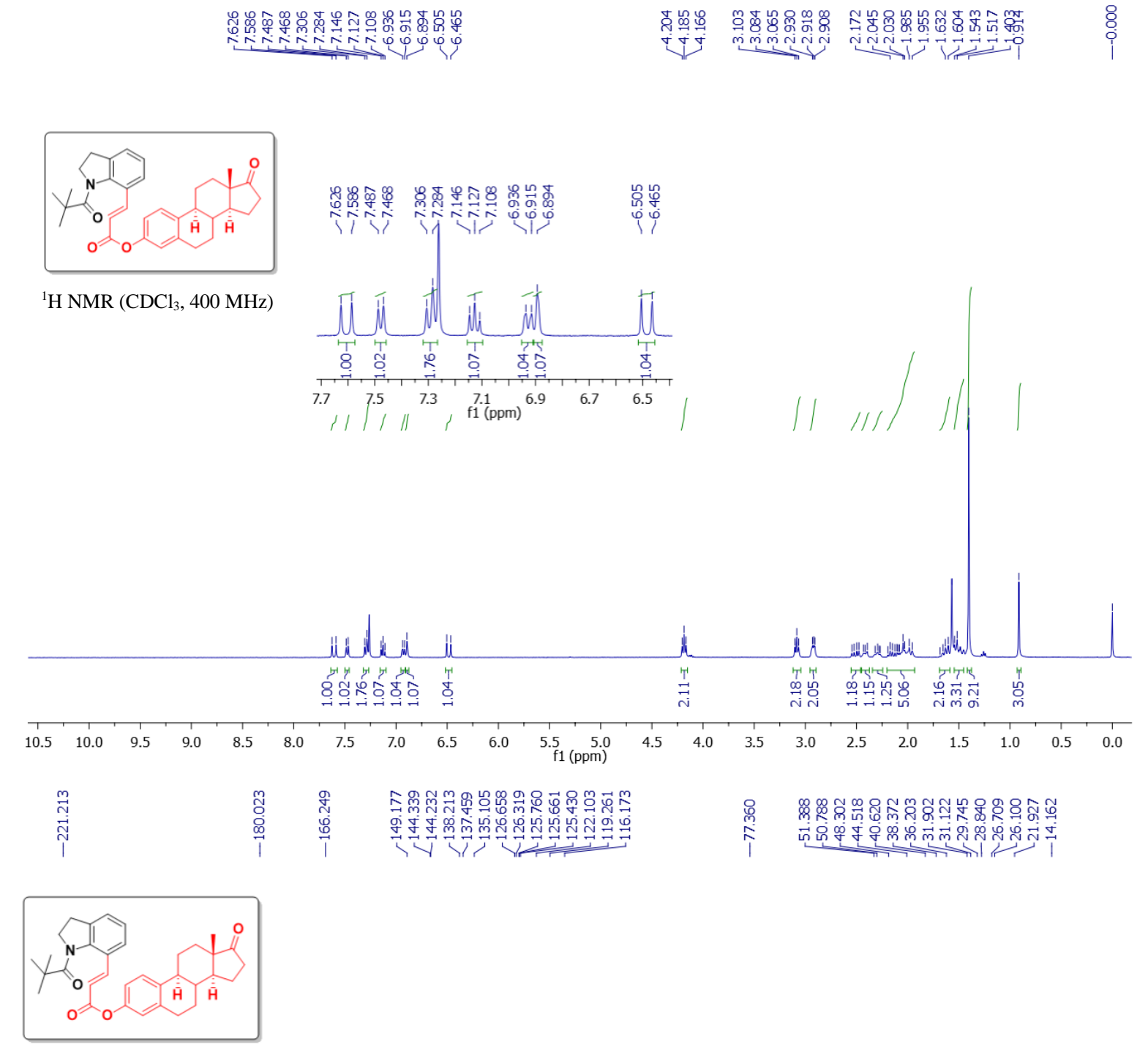

${ }^{13} \mathrm{C} \mathrm{NMR}\left(\mathrm{CDCl}_{3}, 100 \mathrm{MHz}\right)$

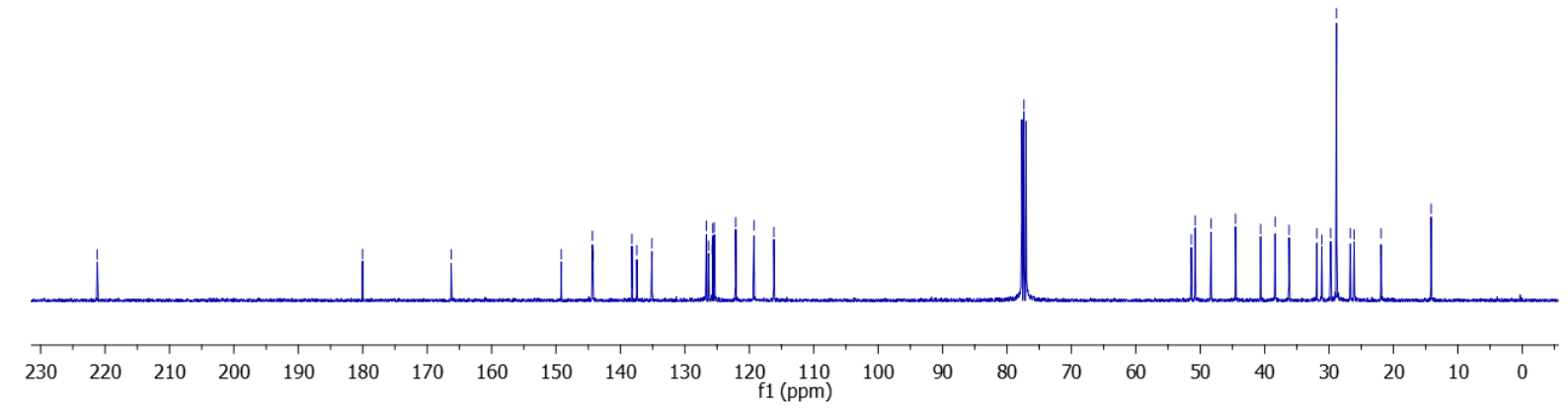


(E)-Methyl 3-(1-pivaloyl-1H-indol-7-yl)acrylate (4am):

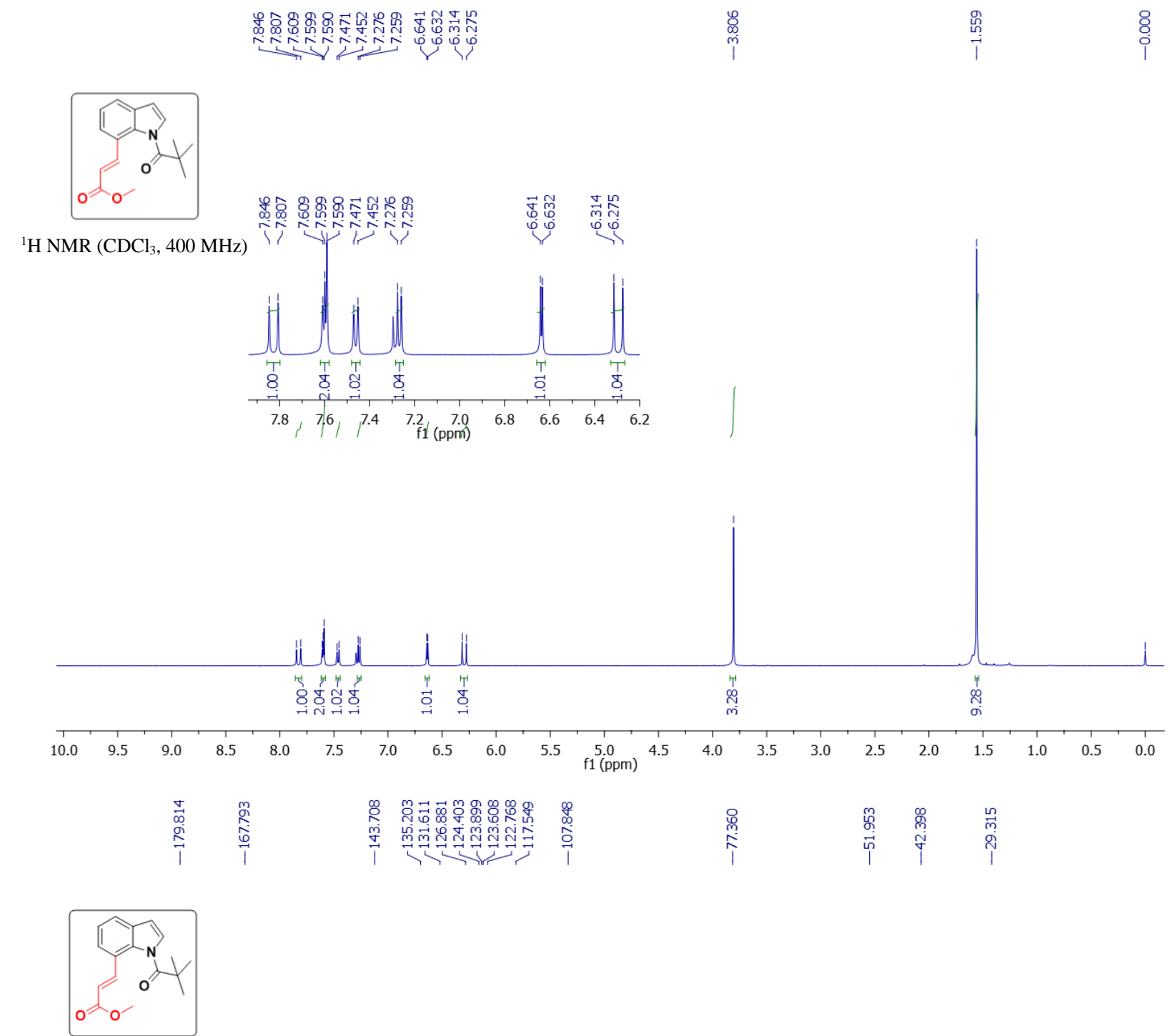

${ }^{13} \mathrm{C} \mathrm{NMR}\left(\mathrm{CDCl}_{3}, 100 \mathrm{MHz}\right)$
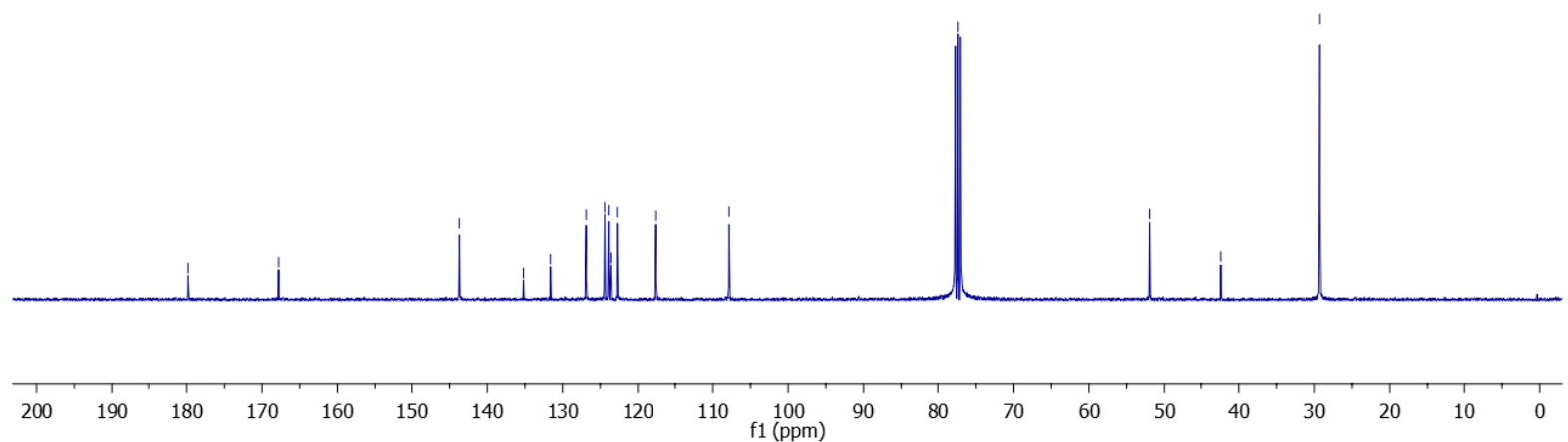
1H-Pyrrolo[3,2,1-ij]quinolin-4(2H)-one (4an):

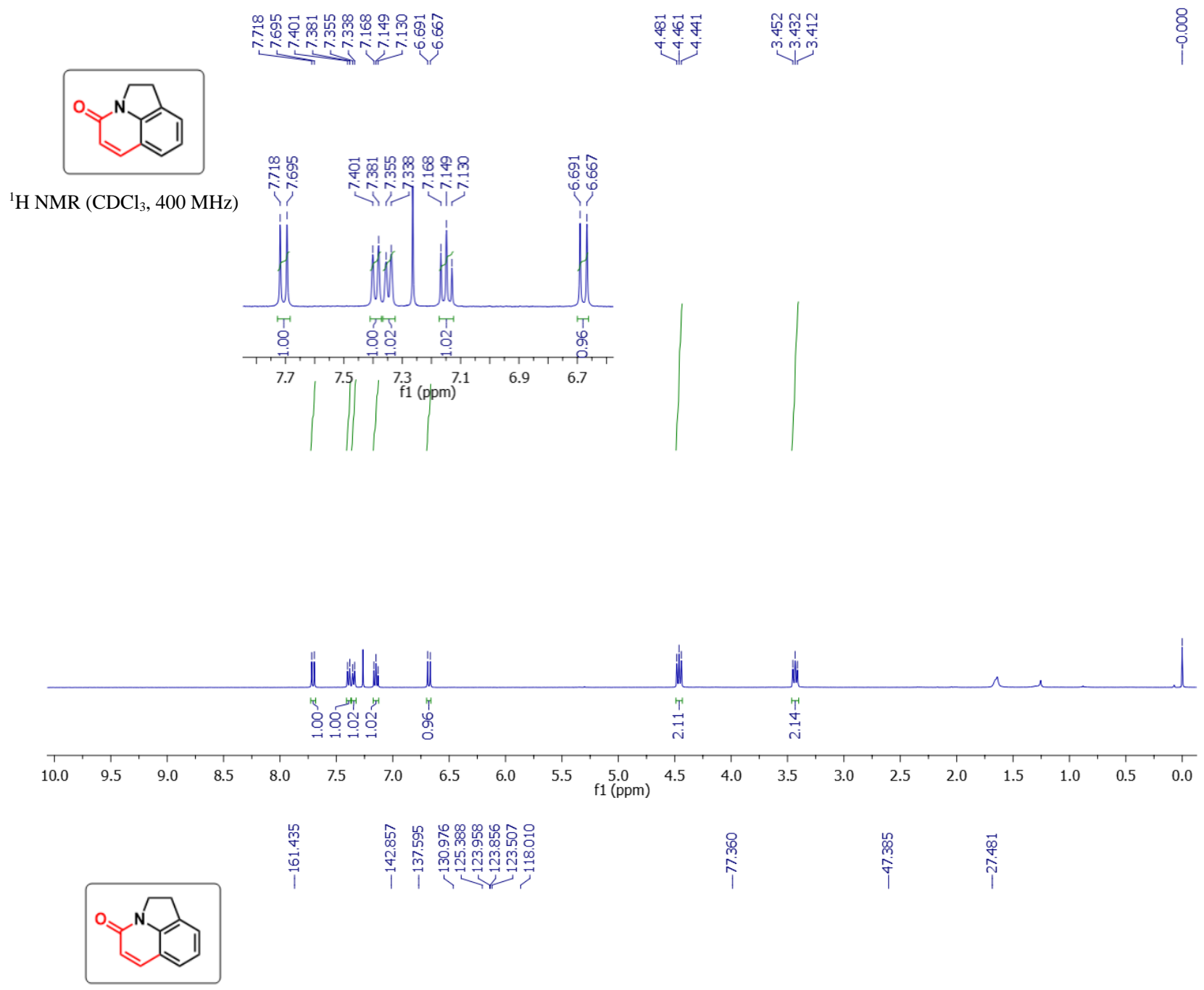

${ }^{13} \mathrm{C} \mathrm{NMR}\left(\mathrm{CDCl}_{3}, 100 \mathrm{MHz}\right)$

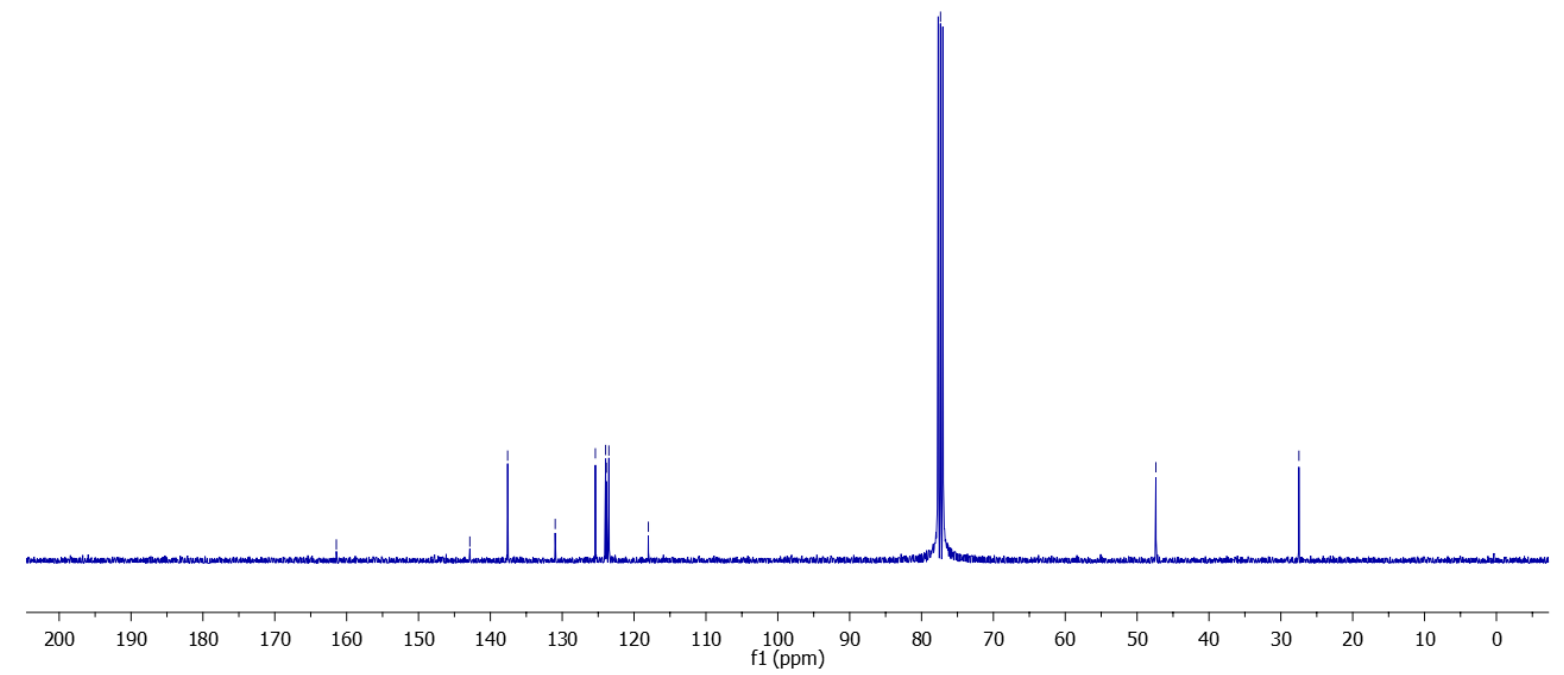




\section{X-ray crystallography data:}

(a) Crystal structure of 8-fluoro-5,6-dihydro-1H-pyrrolo[3,2,1-ij]quinolin-4(2H)-one (3ia): Crystals of the compounds 3ia were obtained after slow evaporation of methanol. The crystals data were collected with Bruker SMART D8 goniometer equipped with an APEX CCD detector and with an INCOATEC micro source (Mo-K $\alpha$ radiation, $\lambda=0.71073$ ). SAINT+3 and SADABS4 were used to integrate the intensities and correction of the absorption respectively. The structure was resolved by direct methods and refined on F2 with SHELXL-97.5.

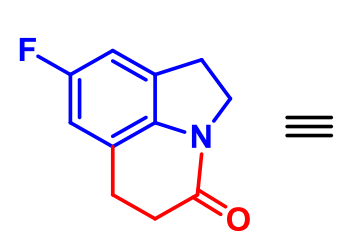

3ia, 57\%

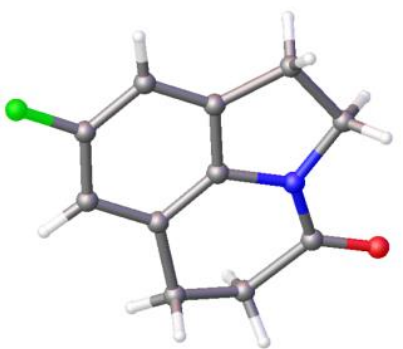

CCDC 1960668

Table S2. Crystal data and structure refinement for 3ia.

\begin{tabular}{|c|c|}
\hline Identification code & PCR-sba-19-08-19 Pyroquilon \\
\hline Empirical formula & $\mathrm{C}_{11} \mathrm{H}_{10} \mathrm{FNO}$ \\
\hline Formula weight & 191.20 \\
\hline Temperature/K & 293(2) \\
\hline Crystal system & orthorhombic \\
\hline Space group & $\mathrm{Pca2}_{1}$ \\
\hline $\mathrm{a} / \AA$ & $15.8646(10)$ \\
\hline $\mathrm{b} / \AA$ & $5.3549(3)$ \\
\hline $\mathrm{c} / \AA$ & $10.5519(6)$ \\
\hline$\alpha /^{\circ}$ & 90 \\
\hline$\beta /^{\circ}$ & 90 \\
\hline$\gamma^{\circ}$ & 90 \\
\hline Volume $/ \AA^{3}$ & $896.42(9)$ \\
\hline $\mathrm{Z}$ & 4 \\
\hline$\rho_{\text {calc }} \mathrm{g} / \mathrm{cm}^{3}$ & 1.417 \\
\hline$\mu / \mathrm{mm}^{-1}$ & 0.105 \\
\hline $\mathrm{F}(000)$ & 400.0 \\
\hline Crystal size $/ \mathrm{mm}^{3}$ & $0.35 \times 0.29 \times 0.24$ \\
\hline Radiation & $\operatorname{MoK} \alpha(\lambda=0.71073)$ \\
\hline $2 \Theta$ range for data collection $/{ }^{\circ}$ & 7.61 to 52.722 \\
\hline Index ranges & $-19 \leq \mathrm{h} \leq 19,-6 \leq \mathrm{k} \leq 6,-12 \leq 1 \leq 13$ \\
\hline Reflections collected & 14340 \\
\hline Independent reflections & $1755\left[\mathrm{R}_{\mathrm{int}}=0.0505, \mathrm{R}_{\text {sigma }}=0.0232\right]$ \\
\hline Data/restraints/parameters & $1755 / 1 / 127$ \\
\hline Goodness-of-fit on $\mathrm{F}^{2}$ & 1.044 \\
\hline
\end{tabular}




\begin{tabular}{|c|c|}
\hline Final R indexes $[\mathrm{I}>=2 \sigma(\mathrm{I})]$ & $\mathrm{R}_{1}=0.0632, \mathrm{wR}_{2}=0.1795$ \\
\hline Final R indexes [all data] & $\mathrm{R}_{1}=0.0736, \mathrm{wR}_{2}=0.1909$ \\
\hline Largest diff. peak/hole / e $\AA^{-3}$ & $0.51 /-0.22$ \\
\hline Flack parameter & $-0.1(6)$ \\
\hline
\end{tabular}

Datablock sba-19-08-19 - ellipsoid plot

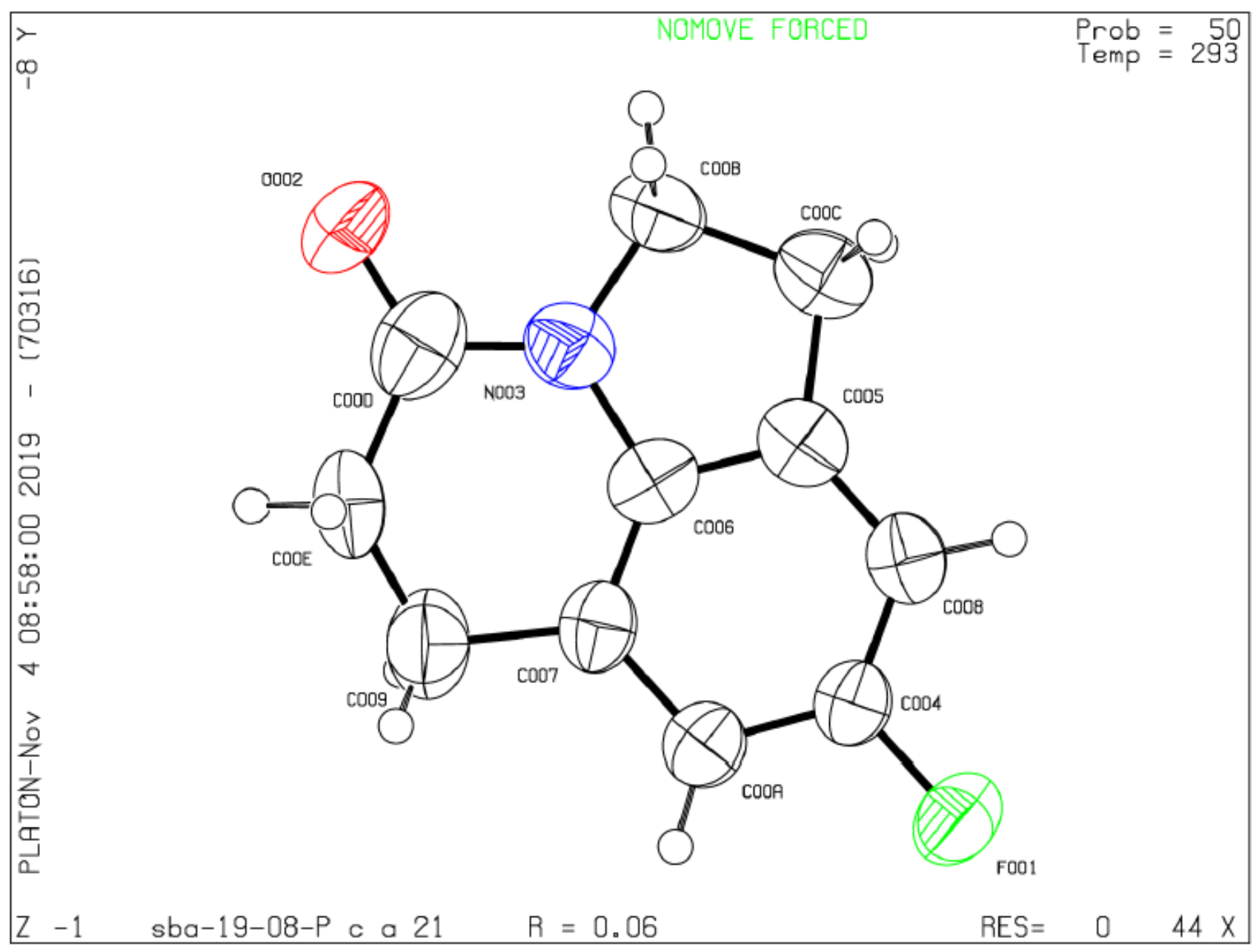




\section{checkCIF/PLATON report}

You have not supplied any structure factors. As a result the full set of tests cannot be run.

THIS REPORT IS FOR GUIDANCE ONLY. IF USED AS PART OF A REVIEW PROCEDURE FOR PUBLICATION, IT SHOULD NOT REPLACE THE EXPERTISE OF AN EXPERIENCED CRYSTALLOGRAPHIC REFEREE.

No syntax errors found. CIF dictionary Interpreting this report

\section{Datablock: sba-19-08-19}

\begin{tabular}{|c|c|c|c|}
\hline Bond precision: & $\mathrm{C}-\mathrm{C}=0.0078 \mathrm{~A}$ & Wave & $=0.71073$ \\
\hline Cell: & $a=15.8646(10)$ & $\mathrm{b}=5.3549(3)$ & $C=10.5519(6)$ \\
\hline & alpha $=90$ & bet $a=90$ & gamma $=90$ \\
\hline Temperature: & $293 \mathrm{~K}$ & & \\
\hline & Calculated & Repor & \\
\hline Volume & $896.42(9)$ & 896.4 & \\
\hline Space group & $P$ c a 21 & $\mathrm{P} \quad \mathrm{C}$ & \\
\hline Hall group & P $2 c-2 a c$ & P $2 \mathrm{C}$ & \\
\hline Moiety formula & C11 H10 F N O & $\mathrm{C} 11 \mathrm{H}$ & $\mathrm{F} \mathrm{NO}$ \\
\hline Sum formula & C11 H10 F N O & $\mathrm{C} 11 \mathrm{H}$ & $\mathrm{F} \mathrm{N} O$ \\
\hline $\mathrm{Mr}$ & 191.20 & 191.2 & \\
\hline $\mathrm{Dx}, \mathrm{g} \mathrm{cm-3}$ & 1.417 & $1.41^{\circ}$ & \\
\hline $\mathrm{z}$ & 4 & 4 & \\
\hline $\mathrm{Mu} \quad(\mathrm{mm}-1)$ & 0.105 & 0.105 & \\
\hline F000 & 400.0 & 400. & \\
\hline Fo00' & 400.22 & & \\
\hline$h, k, 1 \max$ & $19,6,13$ & 19,6 , & \\
\hline Nref & $1831[968]$ & 1743 & \\
\hline Tmin, Tmax & $0.964,0.975$ & 0.522 & 000 \\
\hline 'Tmin' & 0.964 & & \\
\hline
\end{tabular}

Correction method= \# Reported T Limits: Tmin=0.522 Tmax $=1.000$

AbsCorr $=$ MULTI-SCAN

Data completeness $=1.80 / 0.95 \quad$ Theta $(\max )=26.361$

$R($ reflections $)=0.0590(1460) \quad$ wR2 (reflections $)=0.1710(1743)$

$S=1.033 \quad$ Npar $=135$

The following ALBRTS were generated. Bach ALBRT has the format test-name_ALERT_alert-type_alert-level.

Click on the hyperlinks for more details of the test. 


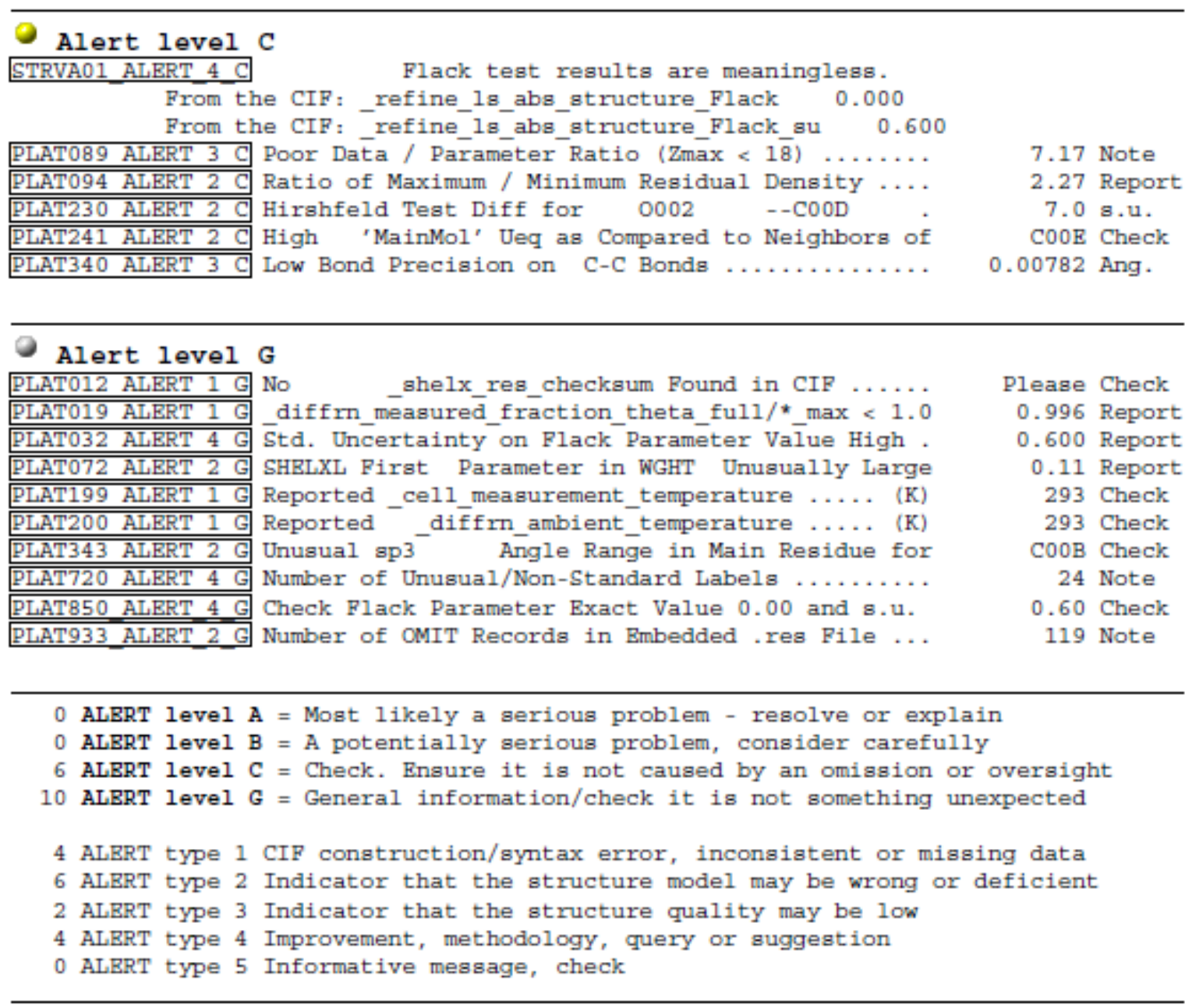

\section{Validation response form}

Please find below a validation response form (VRF) that can be filled in and pasted into your CIF.

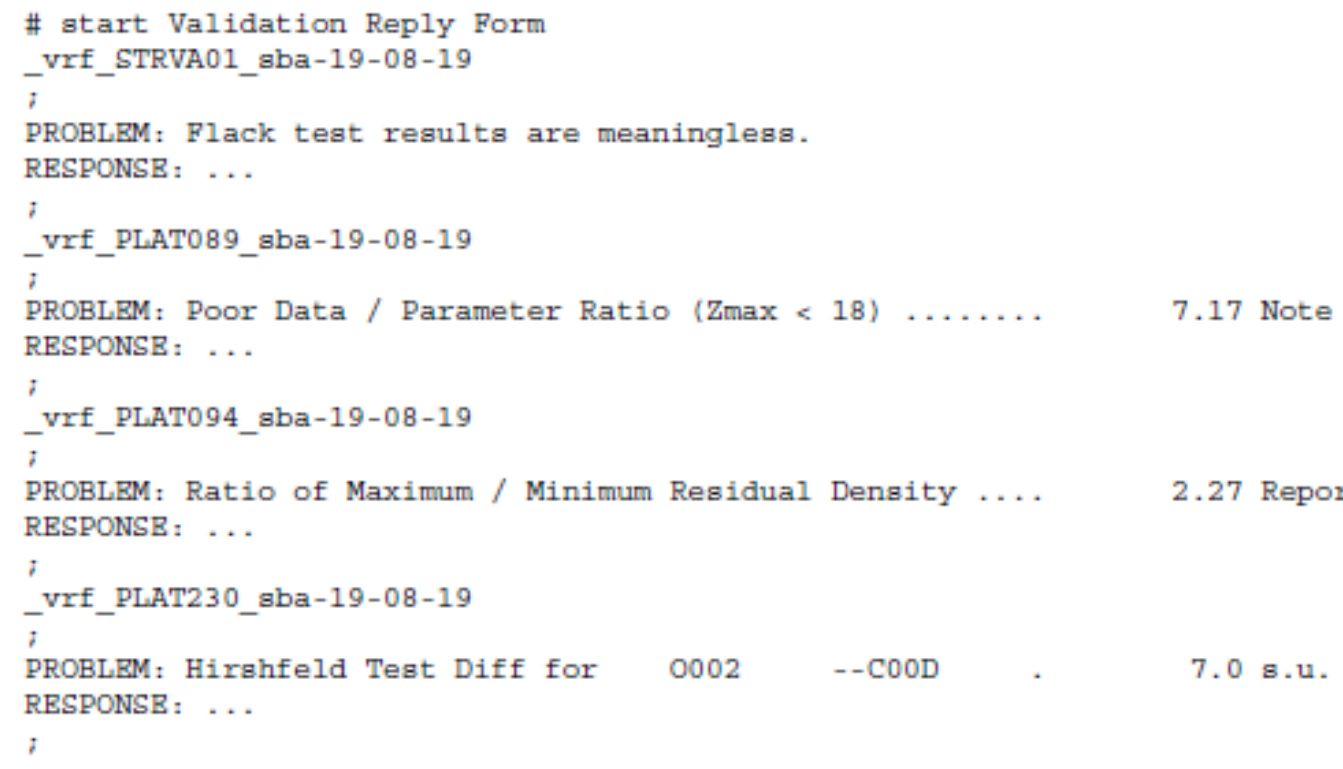




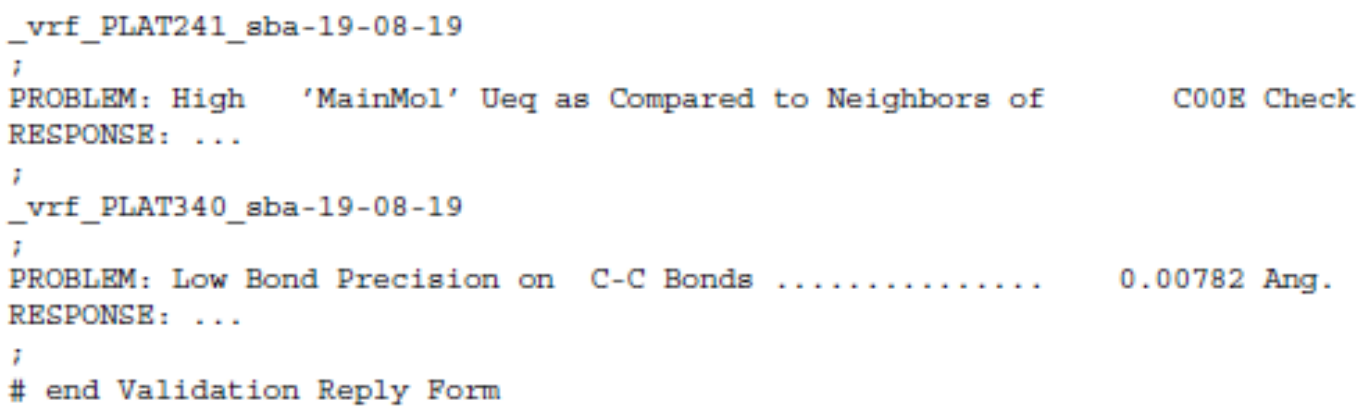

It is advisable to attempt to resolve as many as possible of the alerts in all categories. Often the minor alerts point to easily fixed oversights, errors and omissions in your CIF or refinement strategy, so attention to these fine details can be worthwhile. In order to resolve some of the more serious problems it may be necessary to carry out additional measurements or structure refinements. However, the purpose of your study may justify the reported deviations and the more serious of these should normally be commented upon in the discussion or experimental section of a paper or in the "special_details" fields of the CIF. checkCIF was carefully designed to identify outliers and unusual parameters, but every test has its limitations and alerts that are not important in a particular case may appear. Conversely, the absence of alerts does not guarantee there are no aspects of the results needing attention. It is up to the individual to critically assess their own results and, if necessary, seek expert advice.

\section{Publication of your $\mathrm{CIF}$ in IUCr journals}

A basic structural check has been run on your CIF. These basic checks will be run on all CIFs submitted for publication in IUCr journals (Acta Crystallographica, Journal of Applied Crystallography, Joumal of Synchrotron Radiation); however, if you intend to submit to Acta Crystallographica Section C or E or IUCrData, you should make sure that full publication checks are run on the final version of your CIF prior to submission.

\section{Publication of your CIF in other journals}

Please refer to the Notes for Authors of the relevant journal for any special instructions relating to CIF submission.

PLATON version of 07/08/2019; check.def file version of 30/07/2019 
(b) Crystal structure of (E)-methyl 3-(1-pivaloylindolin-7-yl)acrylate (4aa): Crystals of the compounds 4aa were obtained after slow evaporation of dichloromethane. The crystals data were collected with Bruker SMART D8 goniometer equipped with an APEX CCD detector and with an INCOATEC micro source $(\mathrm{Cu}-\mathrm{K} \alpha$ radiation, $\lambda=1.54184)$. SAINT+3 and SADABS4 were used to integrate the intensities and correction of the absorption respectively. The structure was resolved by direct methods and refined on F2 with SHELXL-97.5.

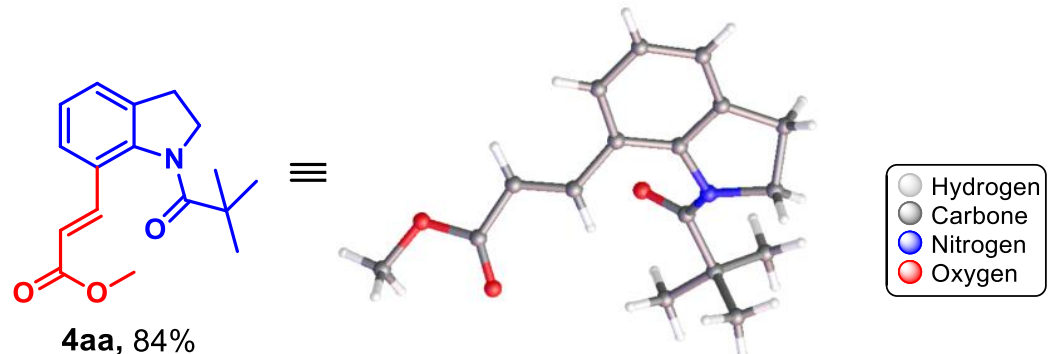

CCDC 1960669

Table S3.Crystal data and structure refinement for 4aa.

\begin{tabular}{|c|c|}
\hline Identification code & PCR-SBA-Heck-Alkenylation \\
\hline Empirical formula & $\mathrm{C}_{17} \mathrm{H}_{21} \mathrm{NO}_{3}$ \\
\hline Formula weight & 287.35 \\
\hline Temperature/K & 293(2) \\
\hline Crystal system & orthorhombic \\
\hline Space group & $P 2_{1} 2_{1} 2_{1}$ \\
\hline $\mathrm{a} / \AA$ & $16.6762(8)$ \\
\hline $\mathrm{b} / \AA$ & $15.5082(6)$ \\
\hline $\mathrm{c} / \AA$ & $6.18290(10)$ \\
\hline$\alpha /{ }^{\circ}$ & 90 \\
\hline$\beta /{ }^{\circ}$ & 90 \\
\hline$\gamma /{ }^{\circ}$ & 90 \\
\hline Volume $/ \AA^{3}$ & $1599.01(10)$ \\
\hline $\mathrm{Z}$ & 4 \\
\hline$\rho_{\text {calc }} \mathrm{g} / \mathrm{cm}^{3}$ & 1.194 \\
\hline$\mu / \mathrm{mm}^{-1}$ & 0.657 \\
\hline $\mathrm{F}(000)$ & 616.0 \\
\hline Crystal size $/ \mathrm{mm}^{3}$ & $0.28 \times 0.24 \times 0.17$ \\
\hline Radiation & $\mathrm{CuK} \alpha(\lambda=1.54184)$ \\
\hline $2 \Theta$ range for data collection $/^{\circ}$ & 7.784 to 149.008 \\
\hline Index ranges & $-20 \leq \mathrm{h} \leq 20,-19 \leq \mathrm{k} \leq 19,-6 \leq 1 \leq 7$ \\
\hline Reflections collected & 10754 \\
\hline Independent reflections & $3051\left[\mathrm{R}_{\mathrm{int}}=0.1212, \mathrm{R}_{\mathrm{sigma}}=0.0814\right]$ \\
\hline Data/restraints/parameters & $3051 / 0 / 194$ \\
\hline Goodness-of-fit on $\mathrm{F}^{2}$ & 1.020 \\
\hline Final $\mathrm{R}$ indexes $[\mathrm{I}>=2 \sigma(\mathrm{I})]$ & $\mathrm{R}_{1}=0.0795, \mathrm{wR}_{2}=0.1977$ \\
\hline Final $\mathrm{R}$ indexes [all data] & $\mathrm{R}_{1}=0.1039, \mathrm{wR}_{2}=0.2221$ \\
\hline Largest diff. peak/hole / e $\AA^{-3}$ & $0.22 /-0.32$ \\
\hline Flack parameter & $0.3(3)$ \\
\hline
\end{tabular}


Datablock pcr-sba-heck - ellipsoid plot

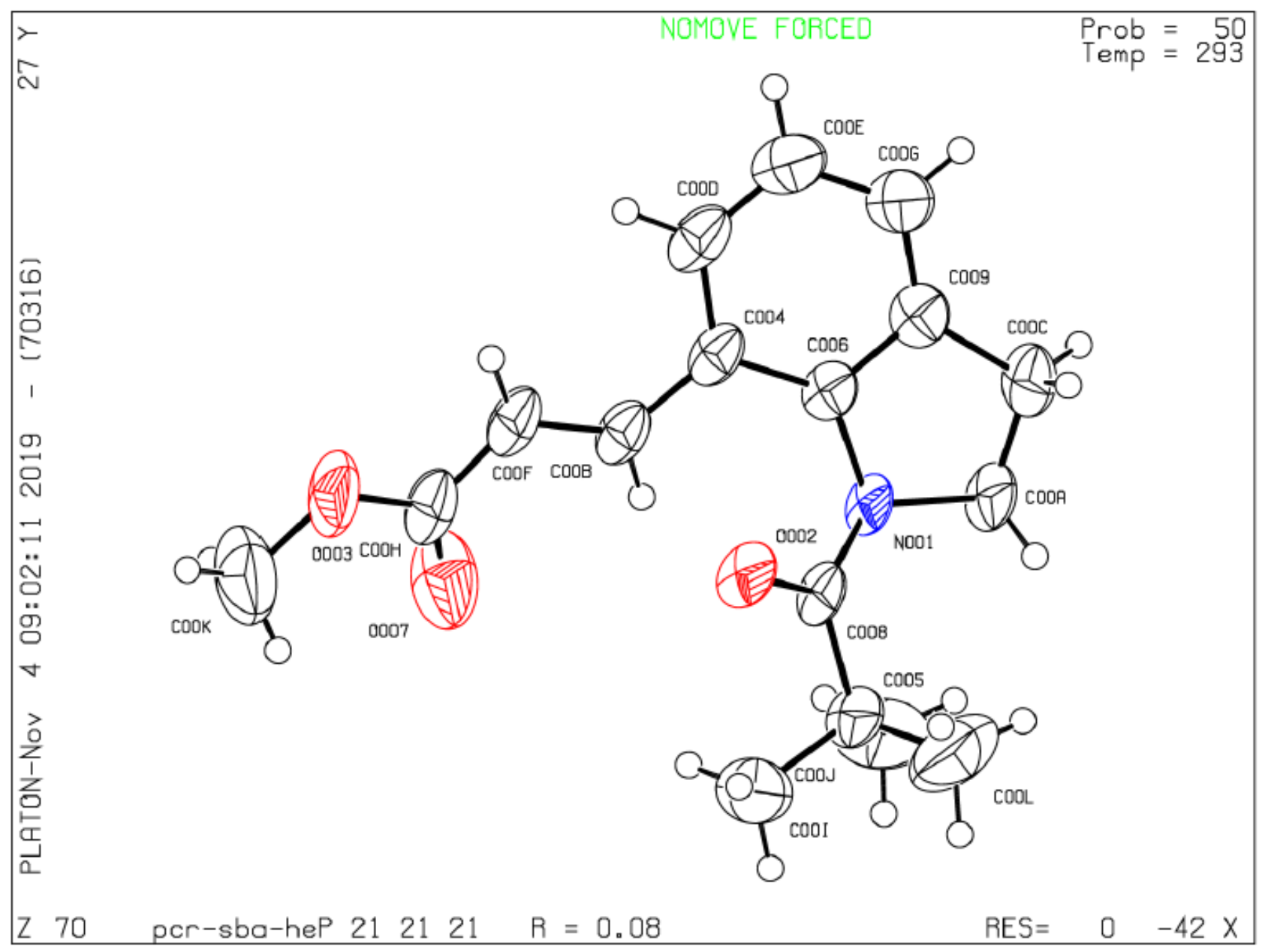




\section{checkCIF/PLATON report}

You have not supplied any structure factors. As a result the full set of tests cannot be run.

THIS REPORT IS FOR GUIDANCE ONLY. IF USED AS PART OF A REVIEW PROCEDURE FOR PUBLICATION, IT SHOULD NOT REPLACE THE EXPERTISE OF AN EXPERIENCED CRYSTALLOGRAPHIC REFEREE.

No syntax errors found. CIF dictionary Interpreting this report

\section{Datablock: pcr-sba-heck}

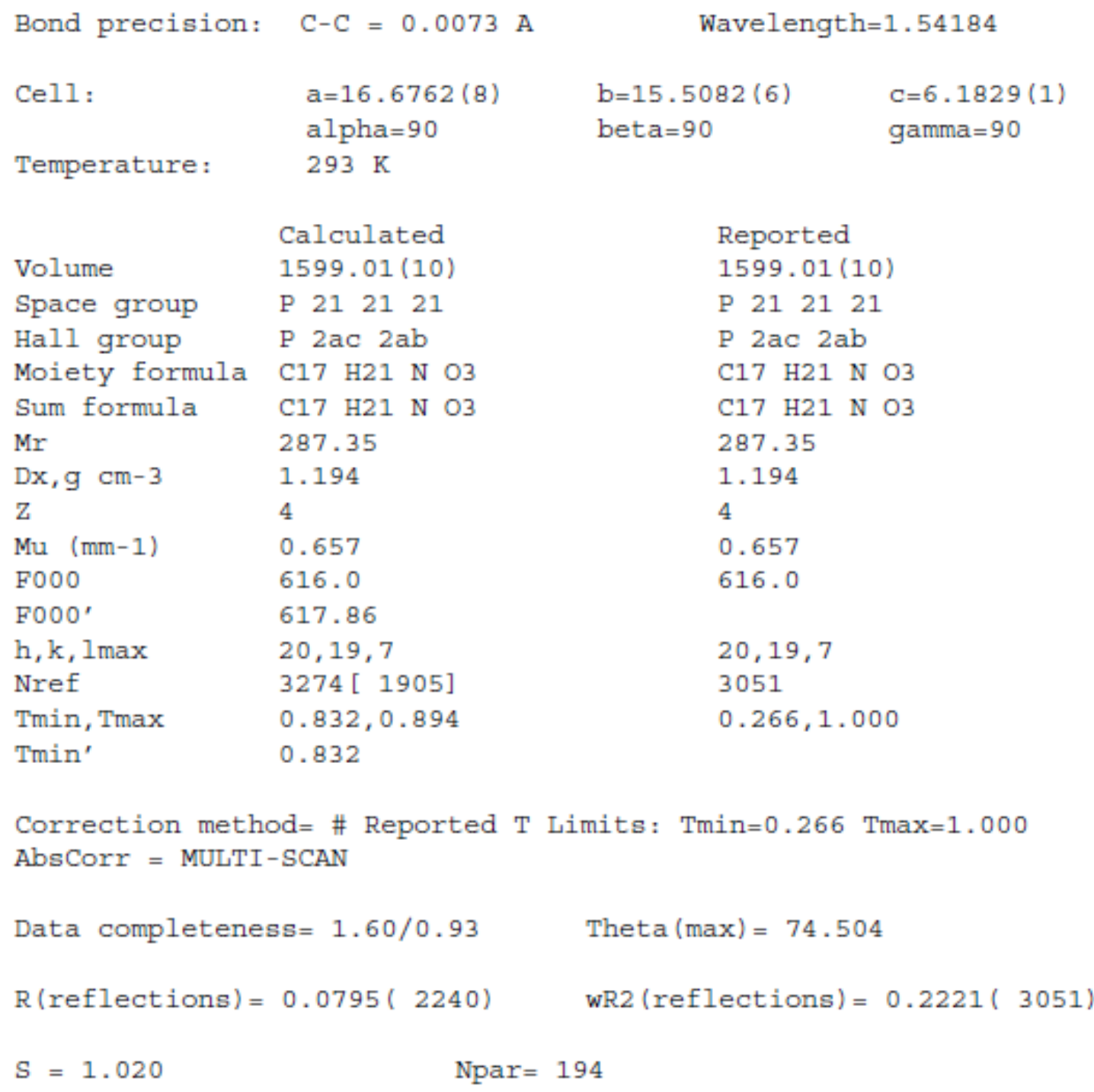

The following ALBRTS were generated. Bach ALBRT has the format test-name ALERT alert-type alert-level.

Click on the hyperlinks for more details of the test. 
Alert level $\mathrm{C}$

RINTA01 ALERT 3 C The value of Rint is greater than 0.12 Rint given 0.121

PLAT020 ALERT $3 \mathrm{C}$ The Value of Rint is Greater Than $0.12 \ldots \ldots$. PLAT029 ALRRT 3 C diffrn measured fraction theta full value Low. PLAT242 ALERT 2 C Low 'MainMo1' Ueq as Compared to Neighbors of PLAT242 ALERT 2 C Low 'MainMol' Ueq as Compared to Neighbors of PLAT250 ALERT 2 C Large U3/U1 Ratio for Average U(i,j) Tensor ....

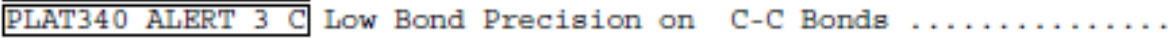
PLAT790 ALERT 4 C Centre of Gravity not Within Unit Cell: Read. \# $\mathrm{C} 17 \mathrm{H} 21 \mathrm{~N} \mathrm{O} 3$

\section{Alert level G}

PLAT012 ALERT $1 \mathrm{G}$ No_shelx_res_checksum Found in CIF ..... PLAT032 ALERT 4 G Std. Uncertainty on Plack Parameter Value High . PLAT072 ALERT 2 G SHBLXL First Parameter in WGHT Unusually Large PLAT199 ALERT $1 \mathrm{G}$ Reported_cell_measurement_temperature ...... (K) PLAT200 ALERT 1 G Reported - diffin_ambient_temperature ..... (K) PLAT720 ALERT 4 G Number of Unusual/Non-Standard Labels . . . . . . . . . PLAT933 ALERT 2 G Number of OMIT Records in Embedded . res File ...
0.121 Report

0.973 Why?

C005 Check

$\mathrm{COOH}$ Check

2.3 Note

0.00727 Ang.

1 Note

0 ALBRT level $\mathrm{A}=$ Most likely a serious problem - resolve or explain

0 ALBRT level B = A potentially serious problem, consider carefully

8 ALBRT level $\mathrm{C}=$ Check. Ensure it is not caused by an omission or oversight

7 ALBRT level $G$ = General information/check it is not something unexpected

3 ALRRT type 1 CIF construction/syntax error, inconsistent or missing data

5 ALRRT type 2 Indicator that the structure model may be wrong or deficient

4 ALRRT type 3 Indicator that the structure quality may be low

3 ALRRT type 4 Improvement, methodology, query or suggestion

0 ALRRT type 5 Informative message, check

\section{Validation response form}

Please find below a validation response form (VRF) that can be filled in and pasted into your CIF.

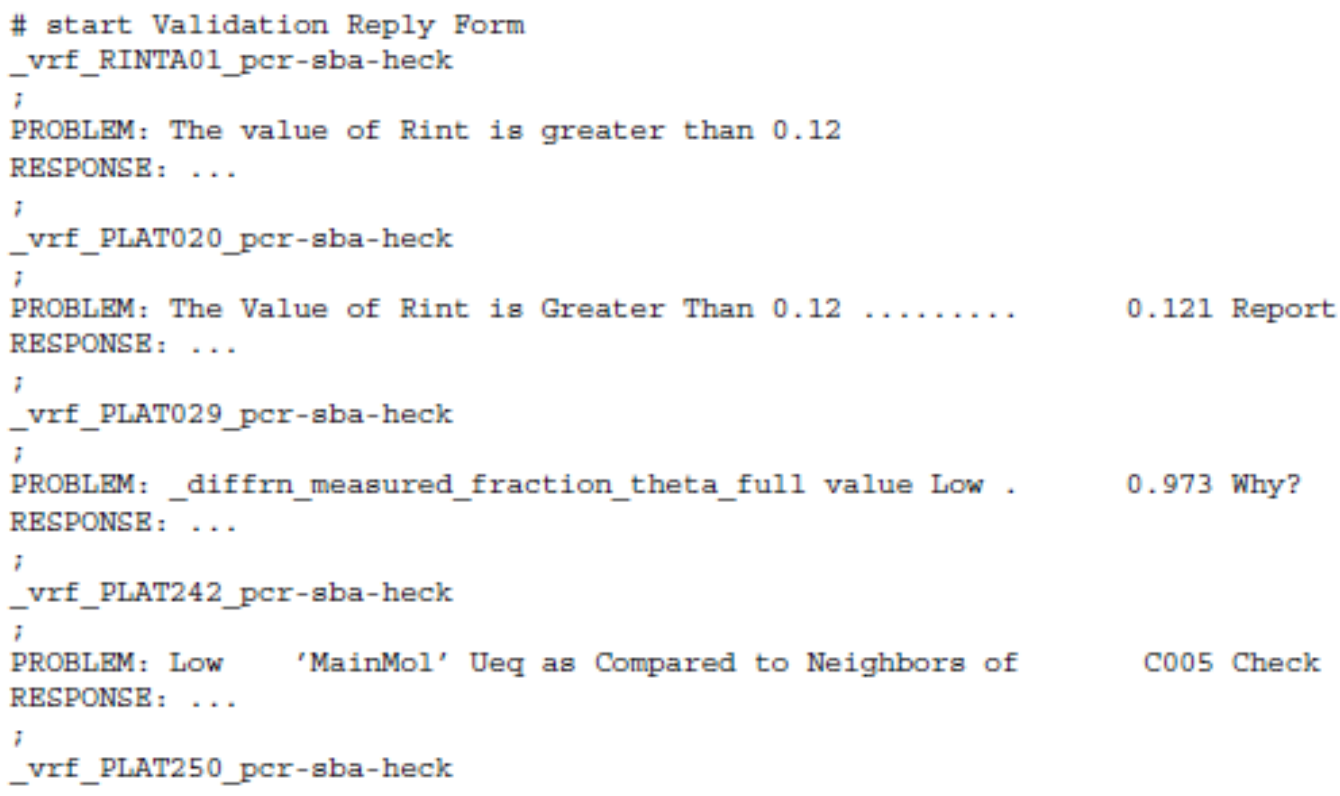




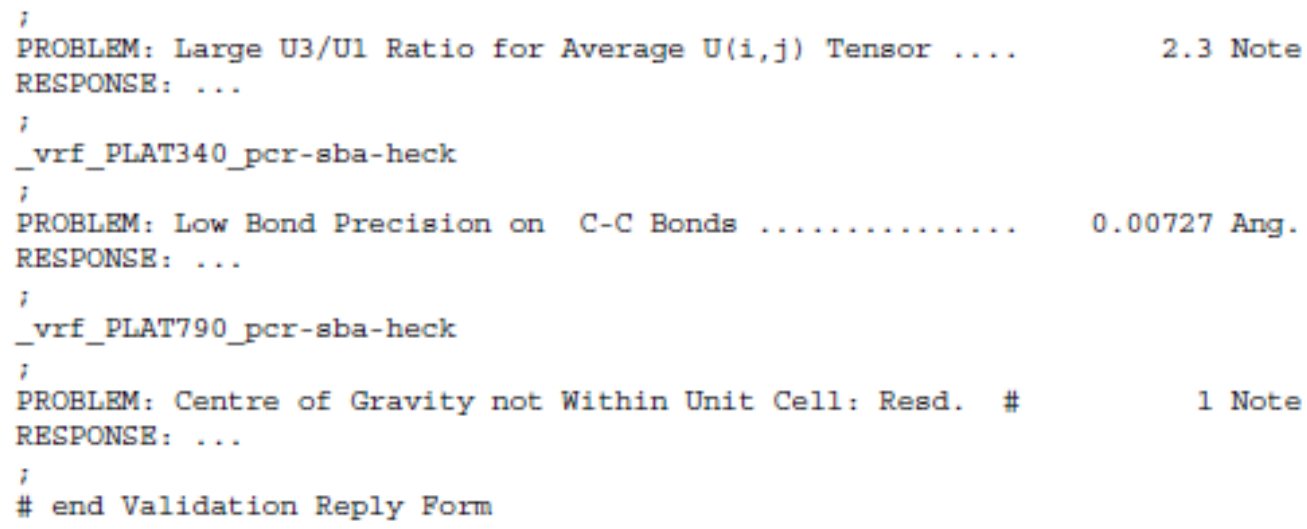

It is advisable to attempt to resolve as many as possible of the alerts in all categories. Often the minor alerts point to easily fixed oversights, errors and omissions in your CIF or refinement strategy, so attention to these fine details can be worthwhile. In order to resolve some of the more serious problems it may be necessary to carry out additional measurements or structure refinements. However, the purpose of your study may justify the reported deviations and the more serious of these should normally be commented upon in the discussion or experimental section of a paper or in the "special_details" fields of the CIF. checkCIF was carefully designed to identify outliers and unusual parameters, but every test has its limitations and alerts that are not important in a particular case may appear. Conversely, the absence of alerts does not guarantee there are no aspects of the results needing attention. It is up to the individual to critically assess their own results and, if necessary, seek expert advice.

\section{Publication of your CIF in IUCr journals}

A basic structural check has been run on your CIF. These basic checks will be run on all CIFs submitted for publication in IUCr journals (Acta Crystallographica, Journal of Applied Crystallography, Journal of Synchrotron Radiation); however, if you intend to submit to Acta Crystallographica Section $C$ or $E$ or IUCrData, you should make sure that full publication checks are run on the final version of your CIF prior to submission.

\section{Publication of your CIF in other journals}

Please refer to the Notes for Authors of the relevant journal for any special instructions relating to CIF submission.

PLATON version of 07/08/2019; check.def file version of 30/07/2019 